NBER WORKING PAPER SERIES

\title{
WIN SOME LOSE SOME? EVIDENCE FROM A RANDOMIZED MICROCREDIT PROGRAM PLACEMENT EXPERIMENT BY COMPARTAMOS BANCO
}

\author{
Manuela Angelucci \\ Dean Karlan \\ Jonathan Zinman \\ Working Paper 19119 \\ http://www.nber.org/papers/w19119 \\ NATIONAL BUREAU OF ECONOMIC RESEARCH \\ 1050 Massachusetts Avenue \\ Cambridge, MA 02138 \\ June 2013
}

Thanks to Tim Conley for collaboration and mapping expertise. Thanks to Innovations for Poverty Action staff, including Alissa Fishbane, Andrew Hillis, Elana Safran, Rachel Strohm, Braulio Torres, Asya Troychansky, Irene Velez, Sanjeev Swamy, Matthew White, Glynis Startz, and Anna York, for outstanding research and project management assistance. Thanks to Dale Adams, Abhijit Banerjee, Esther Duflo, Jake Kendall, Melanie Morten, David Roodman and participants in seminars at M.I.T./Harvard and NYU for comments. Thanks to Compartamos Banco, the Bill and Melinda Gates Foundation and the National Science Foundation for funding support to the project and researchers. All opinions are those of the researchers, and not the donors, Compartamos Banco, or the National Bureau of Economic Research. The research team has retained complete intellectual freedom from inception to conduct the surveys and estimate and interpret the results (contract available upon request).

NBER working papers are circulated for discussion and comment purposes. They have not been peerreviewed or been subject to the review by the NBER Board of Directors that accompanies official NBER publications.

(C) 2013 by Manuela Angelucci, Dean Karlan, and Jonathan Zinman. All rights reserved. Short sections of text, not to exceed two paragraphs, may be quoted without explicit permission provided that full credit, including $(\mathrm{C}$ notice, is given to the source. 
Win Some Lose Some? Evidence from a Randomized Microcredit Program Placement Experiment by Compartamos Banco

Manuela Angelucci, Dean Karlan, and Jonathan Zinman

NBER Working Paper No. 19119

June 2013

JEL No. D12,D22,G21,O17

\section{ABSTRACT}

Theory and evidence have raised concerns that microcredit does more harm than good, particularly when offered at high interest rates. We use a clustered randomized trial, and household surveys of eligible borrowers and their businesses, to estimate impacts from an expansion of group lending at $110 \%$ APR by the largest microlender in Mexico. Average effects on a rich set of outcomes measured 18-34 months post-expansion suggest some good and little harm. Other estimators identify heterogeneous treatment effects and effects on outcome distributions, but again yield little support for the hypothesis that microcredit causes harm.

Manuela Angelucci

Department of Economics

University of Michigan

Lorch Hall, 611 Tappan St.

Ann Arbor, MI 48109-1220

mangeluc@umich.edu

Dean Karlan

Department of Economics

Yale University

P.O. Box 208269

New Haven, CT 06520-8629

and NBER

dean.karlan@yale.edu
Jonathan Zinman

Department of Economics

Dartmouth College

314 Rockefeller Hall

Hanover, NH 03755

and NBER

jzinman@dartmouth.edu 


\section{Introduction}

The initial promise of microcredit, including such accolades as the 2006 Nobel Peace Prize, has given way to intense debate about if and when it is actually an effective development tool. A clear theoretical and empirical tension exists: innovations in lending markets, under the "microcredit movement", aim to expand access to credit by lowering transaction costs and mitigating information asymmetries. Yet theories and empirical evidence from behavioral economics raises concerns about overborrowing at available rates, and have drawn much media and political attention in India, Bolivia, the United States, Mexico, and elsewhere. Moreover, there may be negative spillovers from borrowers to non-borrowers, such as business stealing. Revealed preference may not be a sufficient starting point for welfare analysis: people may borrow based on present-biases that make debt seem attractive ex-ante, yet ultimately make them worse off in the sense that in a moment of informed ex-ante reflection they would not have borrowed as much. These biases may work through preferences (e.g., beta-delta discounting), expectations (e.g., over-optimism), and/or price perceptions (e.g., underestimating exponential growth and decline). ${ }^{2}$

Both sets of theories can have merit. For example, unbiased borrowers may use credit well, and benefit from expanded credit access, while others may borrow too much, and suffer from expanded access. Does such heterogeneity in impacts exist? Existing empirical evidence is limited, and mixed. Most of the evidence on the impacts of smalldollar credit thus far has been on mean outcomes, or on a limited examination of heterogeneous treatment effects. ${ }^{3}$ But expanded credit access could produce welfare losses for some borrowers even in the absence of mean negative impacts. If enough people are harmed — where "enough" depends on one's social welfare weights - null or even positive mean impacts can mask net negative welfare consequences.

Using a large-scale clustered randomized trial that substantially expanded access to group lending in north-central Sonora, Mexico, we provide evidence on impacts of expanded access to microcredit on outcome means and distributions measured from detailed household surveys. We do this for a broad set of outcomes, including credit access, perceived creditworthiness, use of funds, business outcomes, income, consumption, health, education, female decision-making power, social attitudes, and subjective measures of well-being and financial condition.

\footnotetext{
${ }^{2}$ See, e.g., DellaVigna (2009) for a discussion and review of such issues.

${ }^{3}$ Randomized-control evaluations of joint-liability microlending at lower interest rates by nonprofits (Banerjee et al. 2009; Crepon et al. 2011), or a for-profit bank (Attanasio et al. 2011), or individual liability loans (Karlan and Zinman 2010; Karlan and Zinman 2011; Augsburg et al. 2012) find somewhat positive but not transformational treatment effects. Further studies have found a wide range of impacts from business grants (de Mel, McKenzie, and Woodruff 2008; Berge, Bjorvatn, and Tungooden 2011; Fafchamps et al. 2011; Karlan, Knight, and Udry 2012), and from relatively large loans (Gine and Mansuri (2011)). See Karlan and Morduch (2009) for a broader literature review that includes non-experimental estimates of mean impacts.
} 
Strong impacts in either direction seem plausible in our setting. The market rate for microloans is about $100 \%$ APR, making concerns about overborrowing and negative impacts plausible. But existing evidence suggests that returns to capital in Mexico are about 200\% for microentrepreneurs (D. J. McKenzie and Woodruff 2006; D. McKenzie and Woodruff 2008), raising the possibility of transformative positive impacts.

Compartamos Banco (Compartamos) implemented the experiment. Compartamos is the largest microlender in Mexico, and targets working-age women who operate a business or are interested in starting one. ${ }^{4}$ In early 2009 we worked with Compartamos to randomize its rollout into an area it had not previously lent, North-Central Sonora State (near the Arizona border). Specifically, we randomized loan promotion-door-to-door for treatment, none for control-across 238 geographic "clusters" (neighborhoods in urban areas, towns or contiguous towns in rural areas). Compartamos also verified addresses to maximize compliance with the experimental protocol of lending only to those who live in treatment clusters. Treatment assignment strongly predicts the depth of Compartamos penetration: during the study period, according to analysis from merging our survey data with Compartamos administrative data, 18.9\% (1565) of those surveyed in the treatment areas had taken out Compartamos loans, whereas only 5.8\% (485) of those surveyed in the control areas had taken out Compartamos loans. We conducted 16,560 detailed business/household follow-up surveys during 2011 and 2012, up to three years, and an average of 26 months, since the beginning of the credit expansion.

Random assignment of treatment creates a control group that helps identify the causal impacts of access to credit by addressing the counterfactual "what would have happened had Compartamos not entered this market?" This addresses two selection biases: demandlevel decisions on whether to borrow, and supply-level decisions on where to lend. For example, under the canonical view of microcredit we would expect borrowers to be talented and spirited in ways that are difficult to control for using observational data. Such unobservables may be correlated with both self-selection into borrowing (borrowers with more potential have more to gain from borrowing) and good longer-run outcomes (e.g., more successful businesses). This pattern would bias estimates of the effects of microcredit upward; e.g., a positive correlation between longer-run outcomes and microcredit would be due, perhaps largely, to the effect of unobserved borrower characteristics rather than to the causal effect of credit itself. On the supply side, lenders may select on growth potential, and hence lend more in areas (and to borrowers) that are likely to improve over the evaluation horizon. Again, this means an observed positive correlation between outcomes and borrowing (or lending) would be driven by unobserved characteristics of the borrowers (communities, and/or lending strategies), not necessarily by the causal impacts of the credit itself. Understanding the causal impacts of borrowing and credit access informs theory, practice, and policy.

The randomized program placement design used here (see also, e.g., Crepon et al (2011), Banerjee et al (2009), and Attanasio et al (2011)) has advantages and disadvantages over individual-level randomization strategies (e.g., Karlan and Zinman (2010), Karlan and

4 See http://www.compartamos.com/wps/portal/Grupo/InvestorsRelations/FinancialInformation for annual and other reports from 2010 onward,. 
Zinman (2011) and Augsburg et al (2012)). Randomized program placement effectively measures treatment effects at the community level (more precisely: at the level of the unit of randomization), assuming no spillovers from treatment to control across community boundaries (we are not aware of any prior studies with evidence of such spillovers). Measuring treatment effects at the community level has the advantage of incorporating any within-community spillovers. These could in theory be positive (due, e.g., to complementarities across businesses) or negative (due, e.g., to zero-sum competition). Our estimated effects on the treatment group, relative to control, are net of any withintreatment group spillovers from borrowers to non-borrowers. Capturing spillovers with individual-level randomization is more difficult. But individual-level randomization can be done at lower cost because it typically delivers a larger take-up differential between treatment and control, thereby improving statistical power for a given sample size.

We start by estimating mean treatment effects (average intent-to-treat), and then take five approaches to examining distributional shifts and heterogeneous treatment effects. First we estimate effects on outcome variance and second we examine whether differences in variance are captured entirely by the variables we observe. Third, we estimate quantile treatment effects. Fourth, we estimate treatment effects on the likelihood that an outcome variable increased or decreased, for the sub-sets of outcomes and respondents for which we have panel data. Fifth, we examine whether treatment effects vary heterogeneously with baseline characteristics such as prior business ownership, education, location, and income, and (nonstandard) preferences.

The mean treatment effects suggest some good and little harm. Of the 34 more-ultimate outcomes for which we estimate treatment effects in the full sample, we find 8 treatment effects that are positive with at least $90 \%$ confidence, and only one statistically significant negative effect ( 0 when we adjust for multiple hypothesis testing). There is evidence of both increased business investment and improved consumption smoothing. Happiness, trust in others, and female intra-household decision power also increase.

We also find evidence of changes in dispersion. Of the 29 non-binary outcomes tested, we find statistically significant increases in eight, and statistically significant decreases in seven (both with and without adjustment for multiple hypothesis testing). Variance increases in the treatment group relative to control for total and Compartamos borrowing (both for the number of loans and the amount of loans), business revenues and expenses, and household expenditures on groceries and on school and medical expenses. Variance is lower for informal borrowing, nights the respondent did not go hungry, asset purchases, remittances received, fraction of children not working, lack of depression, and decisionmaking power.

We estimate quantile treatment effects and show that there are meaningful effects on the shape of outcome distributions, particularly in the form of positive treatment effects in the right tail: revenues, expenses, profits, groceries, and school and medical expenses each have this pattern. Treatment effects on happiness and on trust in people increase throughout their distributions. There is little evidence of negative impacts in the left tails 
of distributions, alleviating (but not directly addressing) concerns that expanded credit access might adversely impact people with the worst baseline outcomes.

Overall we do not find strong evidence that the credit expansion creates large numbers of "losers" as well as winners. None of the 17 outcomes for which we have panel data shows significant increases in the likelihood of worsening over time in treatment relative to control areas. In the sub-group analysis, there are hints that some sub-groups - in particular, those with lower incomes, and those without prior formal credit experience or with experience in an informal savings group - experience negative treatment effects on balance, but the evidence is statistically weak: only those three sub-groups, out of 20 subgroups, have more than three negative treatment effects out of the 34 we count as having fairly strong normative implications (and after adjusting for multiple hypothesis testing).

Our results come with several caveats. Cross-cluster spillovers could bias our estimates in an indeterminate direction. External validity to other settings is uncertain: theory and evidence do not yet provide much guidance on whether and how a given lending model will produce different impacts in different settings (with varying demographics, competition, etc.). Our results do not derive the optimal lending model: we cannot say whether a different lender type, product, etc. could have produced better (or worse) impacts. The time horizon for measuring impacts varies across individuals and clusters: the maximum window from first offer of loans to follow-up is three years, but given a fast but staggered start, the typical community can accurately be described as having about two years of exposure to lending before the follow-up surveys were completed.

\section{Background on the Lender, Loan Terms, and Study Setting}

\section{A. Compartamos and its Target Market}

The lender, Compartamos Banco, is the largest microlender in Mexico with 2.3 million borrowers. ${ }^{5}$ Compartamos was founded in 1990 as a nonprofit organization, converted to a commercial bank in 2006, went public in 2007, and has a market capitalization of US\$2.2 billion as of November $16^{\text {th }}, 2012$. As of $2012,71 \%$ of Compartamos clients borrow through Crédito Mujer, the group microloan product studied in this paper.

Crédito Mujer nominally targets women that have a business or self-employment activity or intend to start one. Empirically, $100 \%$ of borrowers are women but we estimate that only about $51 \%$ are "microentrepreneurs". ${ }^{6}$ Borrowers tend to lack the income and/or collateral required to qualify for loans from commercial banks and other "upmarket" lenders. Below we provide additional information on marketing, group formation, and screening.

\footnotetext{
5 According to Mix Market, http://www.mixmarket.org/mfi/country/Mexico, accessed August $22^{\text {nd }}, 2012$.

${ }^{6}$ We define microenterpreneurshp here as currently or ever having owned a business, and use our endline survey data, including retrospective questions, to measure it.
} 


\section{B. Loan Terms}

Crédito Mujer loan amounts during most of the study range from M\$1,500-M \$27,000 pesos (12 pesos, denoted $\mathrm{M} \$,=\$ 1 \mathrm{US}$ ), with amounts for first-time borrowers ranging from $\mathrm{M} \$ 1,500$ - $\mathrm{M} \$ 6,000$ pesos ( $\$ 125-\$ 500$ dollars) and larger amounts subsequently available to members of groups that have successfully repaid prior loans. ${ }^{7}$ The mean loan amount in our sample is M\$6,462 pesos, and the mean first loan is $\mathrm{M} \$ 3,946$ pesos. Loan repayments are due over 16 equal weekly installments, and are guaranteed by the group (i.e., joint liability). Aside from these personal guarantees there is no collateral. Loans cost about 110\% APR during our study period. For loans of this size, these rates are in the middle of the market (nonprofits charge similar, sometimes higher, sometimes lower, rates than Compartamos). ${ }^{8}$

\section{Targeting, Marketing, Group Formation, and Screening}

Crédito Mujer groups range in size from 10 to 50 members. When Compartamos enters a new market, as was the case in this study, loan officers typically target self-reported female entrepreneurs and promote the Credito Mujer product through diverse channels, including door-to-door promotion, distribution of fliers in public places, radio, promotional events, etc. In our study, Compartamos conducted only door-to-door promotion in randomly assigned treatment areas (see Section III). As loan officers gain more clients in new areas, they promote less frequently and rely more on existing group members to recruit other members.

When a group of about five women - half of the minimum required group size expresses interest, a loan officer visits the partial group at one of their homes or businesses to explain loan terms and process. These initial women are responsible for finding the rest of the group members. The loan officer returns for a second visit to explain loan terms in greater detail and complete loan applications for each individual. All potential members must be older than 18 years and also present a proof of address and valid identification to qualify for a loan. Business activities (or plans to start one) are not verified; rather, Compartamos relies on group members to screen out poor credit risks. In equilibrium, potential members who express an interest and attend the meetings are rarely screened out by their fellow members, since individuals who would not get approved are neither approached nor seek out membership in the group.

Compartamos reserves the right to reject any applicant put forth by the group but relies heavily on the group's endorsement. Compartamos does pull a credit report for each individual and automatically rejects anyone with a history of fraud. Beyond that, loan officers do not use the credit bureau information to reject clients, as the group has responsibility for deciding who is allowed to join.

\footnotetext{
7 Also, beginning in weeks 3 to 9 of the second loan cycle, clients in good standing can take out an additional, individual liability loan, in an amount up to $30 \%$ of their joint liability loan.

${ }^{8}$ See http://blogs.cgdev.org/open book/2011/02/compartamos-in-context.php for a more detailed elaboration of market interest rates in 2011 in Mexico.
} 
Applicants who pass Compartamos' screens are invited to a loan authorization meeting. Each applicant must be guaranteed by every other member of the group to get a loan. Loan amounts must also be agreed upon unanimously. Loan officers moderate the group's discussion, and sometimes provide information on credit history and assessments of individuals' creditworthiness. Proceeds from authorized loans are disbursed as checks to each client.

\section{Group Administration, Loan Repayment, and Collection Actions}

Each lending group decides where to meet, chooses the channel of repayment, creates a schedule of fines for late payments, and elects leadership for the group, including a treasurer, president, and secretary. In an attempt to promote group solidarity, Compartamos requires groups to choose a name for themselves, keep a plant to symbolize their strength, and take a group pledge at the beginning of each loan.

The treasurer collects payments from group members at each weekly meeting. The loan officer is present to facilitate and monitor but does not touch the money. If a group member does not make her weekly payment, the group president (and loan officer) will typically solicit and encourage "solidarity" pooling to cover the payment and keep the group in good standing. All payments are placed in a plastic bag that Compartamos provides, and the treasurer then deposits the group's payment at either a nearby bank branch or convenience store. ${ }^{9}$

Beyond the group liability, borrowers have several other incentives to repay. Members of groups with arrears are not eligible for another loan until the arrears are cured. Members of groups that remain in good standing qualify for larger subsequent loan amounts, and for interest rates as low as $2.9 \%$ monthly (compared to $3.89 \%$ on first loans). ${ }^{10}$ Compartamos also reports individual repayment history for each borrower to the Mexican Official Credit Bureau. Loans that are more than 90 days in arrears after the end of the loan term are sent to collection agencies.

Compartamos trains all of its employees in an integrated model of personal development, known as FISEP. Under FISEP, Compartamos employees are encouraged to strive for six values in their physical, intellectual, social-familiar, spiritual, and professional lives. Loan officers share this philosophy with Compartamos clients to promote their personal development and help build group solidarity. Each client also receives a magazine from Compartamos with financial advice, tips for personal development, and entertainment.

Late payments are common (Karlan and Zinman (2013) finds a 90-day group delinquency rate of $9.8 \%$ ) but the ultimate default rate is only about $1 \%$.

\footnotetext{
${ }^{9}$ Compartamos has partnerships with six banks (and their convenience stores) and two separate convenience stores. The banks include Banamex (Banamexi Aquí), Bancomer (Pitico), Banorte (Telecomm and Seven Eleven), HSBC, Scotiabank, and Santander. The two separate convenience stores are Oxxo and Chedraui.

${ }^{10}$ To determine the exact interest rate, Compartamos considers the number of group members, punctuality, willingness to pay, and group seniority.
} 


\section{E. Study Setting: North-Central Sonora, 2009-2012}

We worked with Compartamos to identify an area of Mexico that it planned to enter but had not yet done so. The bank selected the north-central part of the State of Sonora: Nogales, Caborca and Agua Prieta and surrounding towns. The study area borders Arizona to the north, and its largest city, Nogales (which is on the border), has about 200,000 people. The area contains urban, peri-urban, and rural settlements. The study began in 2009, and concluded in 2012.

To understand the market landscape, we examine data from our endline survey. Respondents in the control group report having the majority of their loans (66\% of all loan funds) from a bank or financial institution, including other microlenders. The average size of all loans is 8,351 pesos, or roughly $\$ 696$. The most prevalent lenders are all considered close competitors of Compartamos: Bancoppel (12.1\%, 5,001 pesos), Banco Azteca (9.3\%, 6,776 pesos) and Financiera Independencia (5.4\%, 4,918 pesos). Moneylenders $(0.7 \%, 4,468$ pesos) and pawnshops $(0.4 \%, 2,065$ pesos $)$ make up a small fraction of the market. Besides financial institutions, the other two prevalent sources are the government ( $8.4 \%$ of all loan funds, average size of 44,723 pesos) and trade credit $(11.7 \%, 5,331$ pesos).

\section{Research Design, Implementation, and Data}

\section{A. Design Overview}

Our analysis uses a randomized cluster encouragement design, with randomization at the neighborhood- (urban areas) or municipality- (rural areas) level, and two sample frames. One sample frame, containing 33 clusters in the outlying areas of Nogales, has baseline and follow-up surveys. The second sample frame contains the remaining 205 clusters and has just follow-up surveys. Both baseline and endline surveys were administered to potential borrowers - women 18 or older, who answered yes to any of three questions: (1) "Do you have an economic activity or a business? This can be, for example, the sale of a product like cosmetics, clothes, or food, either through a catalogue, from a physical location or from your home, or any activity for which you receive some kind of income"; (2) "If you had money to start an economic activity or a business, would you do so in the next year?"; (3) "If an institution were to offer you credit, would you consider taking it?"

The endline survey was administered approximately 2-3 years after Compartamos' entry, to 16,560 respondents. This constitutes our "Full Endline Sample". The baseline survey was administered to 2,912 respondents in an area in which Compartamos had not yet expanded about one year following its initial expansion activities. Combining the baseline and endline produces the "Panel Sample" of 1,823 respondents. Figure 1 depicts the timeline of surveying and treatment.

\section{B. Experimental Design and Implementation}

The research team divided the study area into 250 geographic clusters, with each cluster being a unit of randomization (see below for explanation of the reduction from 250 to 238 clusters). In most urban areas, cluster boundaries are based on formal and informal 
neighborhood boundaries. Rural areas are more easily defined as an entire community. We then further grouped the 168 urban clusters (each of these 168 were located within the municipal boundaries of Nogales, Caborca, or Agua Prieta) into "superclusters" of four adjacent clusters each. ${ }^{11}$ Then we randomized so that 125 clusters were assigned to receive direct promotion and access of Crédito Mujer (treatment group), while the other 125 clusters would not receive any promotion or access until study data collection was completed (control group). This randomization was stratified on superclusters for urban areas, and on branch offices in rural areas (one of three offices had primary responsibility for each cluster). ${ }^{12}$

Violence prevented both Compartamos and IPA surveyors from entering some neighborhoods to promote loans and conduct surveys, respectively. We set up a decision rule that was agnostic to treatment status, and strictly determined by the survey team with respect to where they felt they could safely conduct surveys. 12 clusters were dropped (five treatment and seven control). These are omitted from all analyses, and the final sample frame consists of 238 geographic clusters (120 treatment and 118 control).

Table 1 verifies that our survey respondents are observably similar across treatment and control clusters. Columns 1-3 present summary statistics for the full sample using data from the endline survey on variables unlikely to have changed due to treatment, such as age and adult educational attainment. Columns 4-6 present summary statistics for the baseline of the panel sample, for a larger set of variables (including income and preference measures). Columns 2 and 5 present tests of orthogonality between each variable and treatment status. We also report p-values from an F-test that all coefficients for the individual characteristics are zero in an OLS regression predicting treatment assignment presented in Columns 3 and 6. Both tests pass: the p-values are 0.337 and 0.222 .

Appendix Table 1 shows that, in the panel, attrition does not vary by treatment (Columns 1-3). While attrition is not random, as the probability of being in the endline is positively correlated with age, being married, and prior business ownership, and negatively correlated with income and formal account ownership (Column 2), it does not systematically differ in control and treatment areas, as the p-value of the F-test of joint significance of the coefficients of the baseline variables interacted by treatment is 0.145 (Column 3).

Compartamos began operating in the 120 treatment clusters in April 2009, and follow-up surveys concluded during March 2012 (see below). For this three-year study period, Compartamos put in place an address verification step to require individuals to live in treatment areas in order to get loans, and only actively promoted its lending in treatment clusters. This led to an $18.9 \%$ take-up rate among those with completed endline surveys

${ }^{11}$ In future work with Tim Conley, we plan to use these superclusters to estimate spillovers from treatment to control, by examining whether treatment versus control differences are smaller in high-intensity than low-intensity.

${ }^{12}$ In urban areas branches are completely nested in superclusters; i.e., any one supercluster is only served by one branch. 
in the treatment clusters, and a 5.8\% take-up rate in the control clusters. All analysis will be intent-to-treat, on those surveyed, not just on those who borrowed in the treatment clusters.

\section{Partial Baseline and Full Endline Survey}

After an initial failed attempt at a baseline survey in $2008,{ }^{13}$ we later capitalized on a delay in loan promotion rollout to 33 contiguous rural clusters (16 treatment and 17 control), on the outskirts of Nogales, to do a baseline survey during the first half of 2010. For sampling, we established a targeted number of respondents per cluster based on its estimated population of females above the ages of 18 (from Census data) who would have a high propensity to borrow from Compartamos if available: those who either had their own business, would want to start their own business in the following year, or would consider taking out a loan in the near future. Then we randomly sampled up to the target number in each cluster, for a total of 6,786 baseline surveys. Compartamos then entered these treatment clusters beginning in June 2010 (i.e., about a year after they entered the other treatment clusters). Respondents were informed that the survey was a comprehensive socioeconomic research survey being conducted by a nonprofit, nongovernmental organization (Innovations for Poverty Action) in collaboration with the University of Arizona (the home institution of one of the co-authors at the time of the survey). Neither the survey team nor the respondents were informed of the relationship between the researchers and Compartamos.

The survey firm then conducted an endline survey between November 2011 and March 2012. This timing produced an average exposure to Compartamos loan availability of 15 months in the clusters with baseline surveys. In those clusters, we tracked 2,912 respondents for endline follow up. In the clusters without baseline surveys, we followed the same sampling rules used in the baseline, and the average exposure to Compartamos loan availability was 28 months. In all, we have 16,560 completed endline surveys. We also have 1,823 respondents with both baseline and endline surveys.

Our main sample is the full sample of endline respondents. Their characteristics are described in Table 1, Columns 1-2. Relative to the female Mexican population aged 1860 , our sample has a similar age distribution (median 37 ), is more rural (27\% vs. 22\%) and married (75\% vs. $63 \%$ ), and has more occupants per household (4.6 vs. 3.9). ${ }^{14}$

\section{Who Borrows?}

Before estimating treatment effects of access to Compartamos credit, we provide some analysis of who borrows from Compartamos during our study period. Understanding the

\footnotetext{
${ }^{13}$ We were unable to track baseline participants successfully, and in the process of tracking and auditing discovered too many irregularities by the survey firm to give us confidence in the data. It was not cost-effective to determine which observations were reliable, relative to spending further money on an expanded follow-up survey and new baseline survey in areas still untouched by Compartamos. Thus we decided to not use the first baseline for any analysis.

${ }^{14}$ Source; Instituto Nacional de Estadìstica y Geografìa. "Demografìa y Poblaciòn." 2010. Accessed 22 March 2013 from http://www3.inegi.org.mx/.
} 
characteristics of borrowers is interesting descriptively, and also informs the interpretation of treatment effects. We measure borrowing using Compartamos administrative data, merged with borrower characteristics measured by our surveys. Table 2, Panel A uses the entire endline sample from treatment clusters. The mean of the dependent variable (i.e., take-up in the treatment clusters) is $18.9 \%$ during the study period. The mean number of loans per borrower among treatment group members is 3.7 (standard deviation of 3.05); 70\% of borrowers in the treatment group borrowed more than once (Appendix Figure 2). The endline provides a large sample from treatment areas, 8,262 observations, but contains only a few variables that are plausibly unaffected by treatment, i.e. unaffected by treatment. Of these variables, we observe that women who had prior businesses are more likely to borrow (by $9.6 \%$ percentage points), while those with tertiary education are less likely to borrow than those with primary or secondary education only, and younger respondents (18-30) are less likely to borrow than middle-aged respondents (31-50). However, with these few variables we cannot predict much of the variation in the dependent variable: the adjusted R-squared is only $4.4 \%$.

We now turn to the panel sample, which is much smaller-682 observations in treatment areas-but allows us to consider a much broader set of baseline predictors of take-up. Take-up is lower in the panel, $11.9 \%$, presumably at least in part due to the fact that the time elapsed between Compartamos' entry and our endline is about 13 months less for the panel sample than for the full endline sample (recall from Section III.C that Compartamos entered the areas covered by our panel later). Table 2 Column $2 \mathrm{a}$ presents results from a regression of take-up (again defined as borrowing from Compartamos during our study period) on household demographics, income, consumption, assets, business characteristics, direct or indirect knowledge of and experience with formal credit institutions, and perceived likelihood of being eligible for formal loans. This rich set of regressors explains only a very small share of the variation in the dependent variable: the adjusted-R-squared is $2.3 \% .{ }^{15}$ Therefore we do not attempt to predict take-up in the control group based on observable information.

\section{Identification and Estimation Strategies}

\section{A. Average Intent-to-Treat Effects}

We use survey data on outcomes to estimate the average effect of credit access, or the Average Intent to Treat (AIT) effect, with OLS equations of the form:

(1) $Y_{\text {ics }}=\alpha+\beta T_{\mathrm{c}}+X_{\mathrm{s}}+\gamma Z_{\text {ics }}+\mathrm{e}_{\mathrm{ics}}$

15 The bottom panel of Table 2 groups the regressors thematically and reports the partial adjusted $\mathrm{R}$-squared and the p-value from an F-test for joint significance for each group. These results indicate that the strongest predictors of take-up are "credit expectations": responses to questions about the likelihood of applying and being approved for a formal loan. If we omit these variables from the set of take-up predictors, the adjusted R-squared drops to $-1.4 \%$, that is, the other variables basically explain none of the variation in take-up. Consistent with this finding, besides credit-related variables, the only other statistically significant predictor of take-up is education (tertiary education increases take-up likelihood). 
The variable $Y$ is an outcome, or summary index of outcomes, following Kling et al (2007) and Karlan and Zinman (2010), for person $i$ in cluster $c$ and supercluster $s$. We code Y's so that higher values are more desirable (in a normative sense). Standard errors are clustered at the geographic cluster $c$ level, as that is the unit of randomization. The Data Appendix details the survey questions, or combinations thereof (for summary indices), that we use to measure each outcome. $T$ is a binary variable that is 1 if respondent $i$ lives ("lives" defined as where she sleeps) in a treatment cluster $c$, and is 0 otherwise; $X$ is a vector of randomization strata (supercluster fixed effects, where the superclusters are nested in the bank branches), and $Z$ is baseline value of the outcome measure, when available. ${ }^{16}$

The parameter $\beta$ identifies the AIT effect under random assignment and absent spillover effects from treatment to control clusters (We are not aware of any prior studies with evidence of such spillovers). $\beta$ is a useful policy parameter, because it estimates the effect of providing access to Credito Mujer.

The AIT is a lower bound of the Average Treatment on the Treated (ATT) effect under the assumption that any within-cluster spillover effect on "non-compliers" (non-borrowers) is lower than any within-cluster spillover effect on "compliers" (people induced to borrow by the treatment). In the absence of within-cluster spillovers, one can estimate the ATT effect on $Y$ by scaling up the estimated AIT effect on $Y$ by the reciprocal of the differential compliance rate in treatment and control areas. In our setting this would lead to ATT point estimates that are about eight times larger than the AITs.

\section{B. Heterogeneous Treatment Effects}

Looking only at mean impacts may miss important heterogeneity in treatment effects, as discussed at the outset. So we examine heterogeneity using several methods, none of which require additional identification assumptions.

\section{B.1. Distributions}

We start by testing whether the outcome variances are equal across treatment and control groups using a form of Levene's test for clustered data (Iachine et al. 2010). Rejecting the null hypothesis of equality of variances indicates that treatment effects are heterogeneous. When we do reject equality of variances, we also test whether the observed heterogeneity of treatment effects is explained by observed characteristics. To establish this, we test for equality of variances of the residuals obtained from regressing an outcome on the treatment dummy, a set of predetermined variables measured at baseline (either socioeconomic variables only, or those plus proxies for risk and time preferences), and their interaction with the treatment dummy. This exercise can help us understand the determinants of heterogeneity and predict which groups of people benefit or lose from treatment.

Quantile Treatment Effects (QTEs) provide further insight into how access to Compartamos credit changes the shape of outcome distributions; e.g., whether most of

${ }^{16}$ Adding controls for survey date does not change the results. 
the changes in outcomes between the treatment and control groups are in the tails, in the middle, or throughout the distribution. QTEs also provide some information on the "winners and losers" question: if a QTE is negative (positive) for a given outcome in the tails, the treatment worsens (improves) that outcome for at least one household. But one cannot infer more from QTEs about how many people gain or lose without further assumptions. ${ }^{17}$ We estimate standard errors using the block-bootstrap with 1000 repetitions.

B.2. Winners and Losers? Average Intent to Treat Effects on Changes (Panel Only)

Next, we examine a theoretical and policy question of critical interest: are there substantial numbers of people who are made worse off (as measured by one or more outcomes) by increased access to credit? We answer this question by using the panel data to estimate the average treatment effect on the likelihood that an outcome increases, or decreases, from baseline to follow up. We create two dummies for whether a person's outcome increased or decreased from baseline to endline. We separately estimate the treatment effects on the probability of improving (relative to not improving), and of worsening (relative to not worsening) by logit. Recall, however, that have panel data on only about $11 \%$ of our sample and for a subset of outcomes.

\section{B.3. Who Wins and Who Loses? Heterogeneous AITs}

Another method for addressing the winners and losers question is to estimate AITs for sub-groups of households. Note that there may substantial impact heterogeneity also within subgroups.. We do this with a modified version of equation (1):

(2) $Y_{i c}=a+\beta^{1} T_{c} * S_{i}^{1}+\beta^{2} T_{c} * S_{i}^{0}+S_{i}^{1}+X_{s}+\gamma Z_{i c s}+e_{i c s}$

Where $\beta^{1}$ and $\beta^{2}$ are the coefficients of interest, and $S_{\mathrm{i}}$ is a single baseline characteristic separated into two sub-groups; e.g., prior business owner $\left(S_{\mathrm{i}}{ }^{1}\right)$ or not $\left(S_{\mathrm{i}}{ }^{0}\right)$. As with the main AIT estimates, standard errors are clustered at the geographic cluster $c$ level, as that is the unit of randomization. We estimate (2) rather than putting several $S_{\mathrm{i}}$ into the same equation because we are particularly interested in whether there are potentially identifiable sub-groups that experience adverse treatment effects, and who hence might merit further scrutiny by microlenders or policymakers going forward (e.g., screened out,

17 The QTEs are conceptually different than the effect of the treatment at different quantiles. That is, QTEs do not necessarily tell us by how much specific households gain or lose from living in treatment clusters. For example: say we find that business profits increase at the $25^{\text {th }}$ percentile in treatment relative to control. This could be because the treatment shifts the distribution rightward around the $25^{\text {th }}$ percentile, with some business owners doing better and no one doing worse. But it also could be the result of some people doing better around the $25^{\text {th }}$ percentile while others do worse (by a bit less in absolute value); this would produce the observed increase at the $25^{\text {th }}$ percentile while also reshuffling ranks. More formally, rank invariance is required for QTEs to identify the effect of the treatment for the household at the qth quantile of the outcome distribution. Under rank invariance, the QTEs identify the treatment effects at a particular quantile. However, rank invariance seems implausible in our setting; e.g., effects on borrowers are likely larger (in absolute value) than effects on non-borrowers. 
or subjected to different underwriting) ${ }^{18}$. We examine $S_{\mathrm{i}}$ that have been deemed interesting by theory, policy, and/or prior work: prior business ownership, education, urban location, income level, prior formal credit experience, prior formal bank account experience, and prior informal savings group experience. Data for four of these seven $S_{\mathrm{i}}$ come from the baseline survey, and for these characteristics we can estimate (2) only for the subset of individuals in our panel. We also examine heterogeneity with respect to preferences (risk aversion, time inconsistency and patience). These $S_{\mathrm{i}}$ are only available for the panel sample frame, and also yield more speculative inferences as the questions in the survey are likely noisy measures of the underlying parameters of interest.

\section{Dealing with Multiple Outcomes}

We consider multiple outcomes, some of which belong to the same "family" in the sense that they proxy for some broader outcome or channel of impact (e.g., we have several outcomes that one could think of as proxies for business size: number of employees, revenues, expenditures, and profits). This creates multiple inference problems that we deal with in two ways. For an outcome family where we are not especially interested in impacts on particular variables, we create an index - a standardized average across each outcome in the family - and test whether the overall effect of the treatment on the index is zero (see Kling et al (2007)). For outcome variables that are interesting in their own right but plausibly belong to the same family, we calculate adjusted critical values following the approach introduced by Benjamini and Hochberg (1995). ${ }^{19}$ In such cases we report whether the outcome is significant using their procedure. The unadjusted pvalue is most useful for making inferences about the treatment effect on a particular outcome. The adjusted critical levels are most useful for making inferences about the treatment effect on a family of outcomes.

\section{Results}

In tracking our results please keep in mind that sample sizes vary across different analyses for several reasons: using the panel sample only, using sub-samples conditioned on the relevance of a particular outcome (e.g, decision power questions were only asked of married respondents living with another adult), and item non-response. Appendix Table 3 provides additional details.

\section{A. Average Intent-to-Treat Effects}

Figure 2 summarizes results obtained from estimating equation (1) separately for each outcome. Panel A in each of Tables 3-7 provides more details on the results. We group outcomes thematically.

${ }^{18}$ However, we also estimate a version of equation 2 in which we add all the subgroups - and their interaction with the treatment dummy - in the right hand side

19 An alternative approach is to calculate adjusted p-values following Aker et al (2011). We calculate both and find nearly identical results. 


\section{A.1. $\quad$ Credit and Other Financial Services}

Table 3 Panel A and the top panel of Figure 2 present AIT estimates on credit and other financial services. These outcomes provide a sort of " 1 st -stage" underlying any impacts on more ultimate impacts like business performance, household income, and well-being.

As noted above, strong compliance with the experimental design produced more lending in treatment (18.9\% reporting taking a loan from Compartamos) than control clusters (5.8\%). Column 1 shows that the treatment group has $0.121(\mathrm{se}=0.035)$ more loans on average in the past two years than the control group, and Column 2 shows an increase in the total amount borrowed $(\$ M 1248$ more, se $=\$ M 471) .{ }^{20}$ Columns 3 and 4 show the analogous results for Compartamos borrowing (see also Appendix Figure 2 for more detail on treatment group borrowing); ${ }^{21}$ comparing these to the total borrowing effects we find no evidence of crowd-out and some suggestion of crowd-in on amount borrowed. Columns 5 and 6 show imprecisely estimated null effects on informal borrowing. ${ }^{22}$ All told, these results suggest that there was little substitution of Compartamos loans for other debt.

Next we examine several other indicators of financial access. Column 7 shows that the increase in formal sector borrowing does not increase the likelihood that someone would go to a formal source if they needed a $\$$ M6,000 loan tomorrow (although it does increase the perceived likelihood of getting the loan), ${ }^{23}$ and Column 8 shows that overall satisfaction with access to financial services has not changed (point estimate $=-0.005$, $\mathrm{se}=0.012$, dependent variable is binary for being satisfied). Column 9 shows a significant negative effect of 1.9 percentage points on participation in an informal savings group, on a base of $22.8 \% .^{24}$ We lack data that directly addresses whether this reduction is by choice or constraint (where constraints could bind if increased formal access disrupts informal networks), but the overall pattern of results is more consistent with choice: there

${ }^{20}$ All of the loan counts and loan amounts are right-skewed, so we re-estimate after top-coding each at the $99 \%$ percentile. The estimates remain statistically significant with $>99 \%$ confidence.

${ }^{21}$ Results are similar if we use Compartamos' administrative data instead of survey data to measure Compartamos borrowing. Interestingly, we find less underreporting of Compartamos borrowing than in a comparable study in South Africa (Karlan and Zinman 2008). Here 22\% of borrowers who we know, from administrative data, to have borrowed from Compartamos during the previous two years report no borrowing from Compartamos over the previous two years.

${ }^{22}$ Note that the (self-reported) prevalence of such borrowing is quite low relative to formal sources; e.g., less than $3 \%$ of the sample reports any use of moneylenders or pawnshops among their last 3 loans. We did prompt specifically for specific lender types, including moneylenders and pawnshops, so the low prevalence of informal borrowing in our sample is not simply due to respondent (mis)conceptions that money owed to these sources is not a "loan".

${ }^{23}$ The effect on the likelihood that someone would go to an informal source is also not significant. But we do find a reduction in the likelihood of expected problems with getting the \$M6,000 loan: 0.04 percentage points on a base of 0.21 . Taken together, these results suggest that the presence of Compartamos increases option value on the intensive but not extensive margin: it does not change, e.g., whether someone is (primarily) a formal or informal sector borrower, but it does increase the overall amount of credit one can access.

${ }^{24}$ We do not find a significant effect on the likelihood of having a bank account. 
is no effect on the ability to get credit from friends or family in an emergency (results not shown in table), and a positive effect on trust in people (Table 7, to be discussed below).

In all, the results in Table 3 show that Compartamos' expansion increased household borrowing from Compartamos and borrowing overall, decreased the use of informal savings groups (likely by choice not by constraint), but did not shift satisfaction with financial services.

\section{A.2. Business Outcomes}

Table 4 Panel A and the second panel of Figure 2 present AIT estimates of impacts on some key business outcomes. Columns 1 and 2 show null effects on business ownership: current and ever $(-0.4$ percentage points and -0.1 percentage points, both se's $=0.9$, means in control groups are 0.24 and 0.39$).{ }^{25}$ Column 3 reports a 0.8 percentage point increase ( $\mathrm{se}=0.4$, control mean 0.05 ) on using loan proceeds to grow a business.

Turning to various measures of business size, Column 4 shows a null effect on the number of employees $(0.003$, se $=0.010)$. Note that having any employees is rare-only $9 \%$ of households in the control group have a business with any employees. Columns 5-6 show that revenues and expenditures over the past two weeks increase by similar amounts (M\$121 and $\mathrm{M} \$ 118$, which are 27\% and 36\% of the control group means). Columns 7 and 8 show imprecisely estimated null effects on profits, whether measured as revenues minus expenditures (Column 7) or in response to "How much business income did you earn?" (de Mel et al (2009)). Adjusting the critical levels for these results, under the assumption that the outcomes in Columns 4-8 all belong to the same family (e.g., business size), does not change the significance of the coefficients. These results are consistent with Column 3, which finds a significant positive treatment effect on the likelihood of ever having used a loan to grow a business.

Column 9 shows positive but not statistically significant evidence that the loans helped people manage risk: specifically, an increase of 0.7 percentage points $(\mathrm{se}=0.5)$ in the likelihood that the business did not experience financial problems in the past year (note this could be a direct effect of increased access to credit if failure to get access to credit is itself deemed a financial problem).

In all, the results on business outcomes suggest that expanded credit access increased the size of some existing businesses. But we do not find effects on business ownership or profits.

\section{A.3. Household Consumption and Expenditures}

Table 5, and the third panel of Figure 2, report AITs on measures of household consumption and expenditures over various horizons. In theory, treatment effects on these

${ }^{25}$ Respondents identified whether they currently had a business by responding to the following prompt: "How many businesses or economic activities do you currently have? It can be, for example, the sale of a product or food, either through catalogue, in an establishment or in your home." We find a similar result on the number of businesses owned (not shown in table); this is not surprising given that fewer than $10 \%$ of owners have multiple businesses. 
variables could go in either direction. Loan access might increase expenditures through at least two channels. One is consumption smoothing. A second is income-generation that leads to higher overall spending; although we do not find an effect on business profits or income in Table 4 (or on other income sources, reported in Table 6), it is important to keep in mind that any single measure of income or wealth is likely to be noisy. So one might detect (income) effects on spending even in the absence of detecting effects on income itself. On the other hand, loan access might lead to declines in our spending variables if loans primarily finance short-term consumption smoothing or durable purchases that must then be repaid, with interest, at the expense of longer-term consumption. Also, if people "overborrow" on average, making bad investments (broadly defined) with the loan proceeds, then spending might need to fall to cover losses on these investments.

The first two columns of Table 5 present estimated effects on uses of loan proceeds (also recall the result from Table 4 Column 3 showing a significant impact on using loan proceeds to grow a business). Column 1 shows a positive effect on the likelihood that someone did not sell an asset to help pay for a loan; i.e., this result suggests that increased credit access reduces the likelihood of costly "fire sales" by one percentage point (se $=0.4$ percentage points), a $20 \%$ reduction. This is a striking result, since the positive treatment effect on debt mechanically pushes against a reduction in fire sales (more debt leads to greater likelihood of needing to sell an asset to pay off debt, all else equal). Also, given that such sales are low-prevalence (only $4.9 \%$ of households in the 2 years prior to the endline), they may be practices that people resort to in extreme circumstances. In this case, the treatment might be beneficial for people in people considerable financial distress. We do not find a significant effect on using loans for asset purchases (column 2).

Columns 3-10 present results for eight expenditure categories. Groceries and hunger are not affected by the treatment, which is not surprising, given that our sample is generally not poor. The two statistically significant effects-reductions in temptation goods and asset purchases - do not survive adjusting the critical values under the assumption that the eight expenditure categories belong to the same outcome family.

One of the individually significant results (Column 3) is a $6 \%$ reduction in temptation goods (cigarettes, sweets, and soda); Banerjee et al (2009) attribute their similar finding to household budget tightening required to service debt (i.e., temptation spending is relatively elastic with respect to the shadow value of liquidity). An alternative explanation is that female empowerment (discussed below in Table 7) leads to reduced spending on unhealthy items.

The other individually significant result is a five percentage point (10\%) reduction in durable assets purchased in the past two years (Column 8). ${ }^{26}$ In tandem with the reduction in asset sales to pay off a loan (Column 1), this result could be interpreted as a reduction in asset "churn." If secondary markets yield relatively low prices (due, e.g., to a

${ }^{26}$ Our survey instrument did not ask in detail about the value of assets bought and sold unless they were bought or sold in relation to a loan. Consequently, we report the counts of assets here instead of their values. 
lemons problem), then reduced churn could actually be welfare-improving. Note however that we do not find a treatment effect on a broader measure of asset sales than the debt service-motivated one in Column 1: Column 9 shows an imprecisely estimated increase in the likelihood that the household did not sell an asset over the previous two years $(0.007$, se $=0.007)$.

\section{A.4. Household Income and Saving}

Table 6, and the top part of the "Income and Consumption" panel in Figure 2, examines additional measures of income: total household income, labor income, participation in any economic activity, remittance income, and positive saving in the last six months. The motivation for examining these measures is twofold. Methodologically, as discussed above, any individual measure of income, wealth, or economic activity is likely to be noisy, so it is useful to examine various measures. Substantively, there is prior evidence of microloan access increasing job retention and wage income (Karlan and Zinman 2010), and speculation that credit access might be used to finance investments in migration or immigration (that pay off in the form of remittances, e.g.). ${ }^{27}$

We do not find significant effects on any of the five measures. Most of the estimates are fairly precise: the only confidence interval containing effect sizes that would be large relative to the control group mean is remittance income.

\section{A.5. Welfare}

Table 7 reports AITs on various measures of welfare. We start with perhaps the most important, a measure of depression, ${ }^{28}$ where we estimate a $0.045(\mathrm{se}=0.024)$ standard deviation increase in happiness (i.e., the absence of signs of depression). Job stress, locus of control, and trust in institutions are unaffected, and the upper ends of these confidence intervals contain effects that are only +/- 0.06 standard deviations (Columns 2-4). An index of trust in people (family, neighbors, personal acquaintances, people just met, business acquaintances, borrowers, and strangers) increases by an estimated 0.05 standard deviations ( $\mathrm{se}=0.027$ ). This could be a by-product of the group aspect of the lending product. Satisfaction with one's life and harmony with others, and with economic situation, are unaffected on average (Columns 6 and 7). There is a small but nearly significant positive effect on physical health status: a one percentage point increase in the likelihood of self-reporting good or better health, on a base of 0.78 , with a p-value of 0.13 (Column 8). The point estimate on the proportion of children not working is also small and positive: 0.007 , on a base of 0.915 among the sample of households with a schoolaged child, with a p-value of 0.24 .

27 The treatment effect on a more direct measure of out-migration-whether anyone left the household for work in the last 2 years without returning —is .002 , se $=.003$.

${ }^{28}$ The depression measure is an index of responses to questions about the incidence of the following: being bothered by things that do not normally bother you, having a poor appetite, not being able to shake off the blues even with support from friends and family, feeling just as good as other people, having trouble focusing, feeling depressed, feeling like everything required extra effort, being hopeful about the future, thinking your life was a failure, feeling fearful, having restless sleep, feeling happy, talking less than usual, being lonely, thinking people were unfriendly, having crying spells, enjoying life, feeling sad, thinking people dislike you, and feeling like you couldn't keep going on. 
The last three columns (10-12) show effects on the respondent's intrahousehold decision making power, for the subsample of women who are not single and not the only adult in their household (recall that all survey respondents are women). ${ }^{29}$ These are key outcomes given the strong claims (by, e.g., financial institutions, donors, and policymakers) that microcredit empowers women by giving them greater access to resources and a supportive group environment (Hashemi et al 1996; Kabeer 1999). On the other hand, there is evidence that large increases in the share of household resources controlled by women threatens the identity of some men (Maldonado et al 2002), causing increases in domestic violence (Angelucci 2008). Column 10 shows an increase on the extensive margin of household financial decision making: treatment group women are 0.8 percentage points more likely to have any say. This is a large proportional effect on the left tail-i.e., on extremely low-power women-since $97.5 \%$ of control group respondents say they participate in any financial decision making; this effect represents an improvement for almost one third of the $2.5 \%$ of respondents that otherwise had no financial decision making. Column 11 shows a small but significant increase in the number of issues for which the woman has any say: 0.07 (se=0.03) on a base of 2.78 . Both Column 10 and Column 11 show significant effects after adjustment for multiple hypothesis testing. Column 12 shows no increase in the amount of intra-household conflict. Note the expected sign of the treatment effect on this final outcome and its interpretation is ambiguous: less conflict is more desirable all else equal, but all else may not be equal in the sense that greater decision power could produce more conflict. In practice we find little evidence of any treatment effects on the amount of intra-household conflict.

In all, the results in this table paint a generally positive picture of the average impacts of expanded credit access on well-being: depression falls, trust in others rises, and female household decision power increases.

\section{A.6. Big Picture}

Viewing the average treatment effect results holistically, using Figure 2, we can draw four broad conclusions. First, increasing access to microcredit increases borrowing and does not crowd-out other loans. Second, loans seem to be used for both investment-in particular for expanding previously existing businesses - and for risk management. Third, there is evidence of positive average impacts on business size, avoiding fire sales, lack of depression, trust, and female decision making. Fourth, there is little evidence of negative average impacts: we find only three statistically significant negative treatment effects on individual outcomes, out of 45 outcomes. Moreover, each of the three "negative" results

29 The dependent variable in column 10, "Participates in any financial decisions," is a binary variable equal to one if the respondent participates in at least one of the household financial decisions, and equal to zero if she participates in none of the decisions. The dependent variable in column 11, "\# of household decisions she has a say on," represents the number of household issues (of four) that the respondent either makes alone, or has some say on when a disagreement arises if she makes the decision jointly. The dependent variable in column 12, the "\# of household issues in which a conflict arises," represents the number of household issues (of four) in which a disagreement sometimes arises if the respondent makes the decision jointly. 
actually has a normatively positive or neutral interpretation, as discussed above, and two of them lose statistical significance with the family-wise correction for multiple hypothesis testing.

\section{B. Heterogeneous Treatment Effects}

\section{B.1. Distributions}

We first test the hypothesis of common treatment effects on borrowers and non-borrowers by comparing the standard deviations in treatment and control groups: these two standard deviations are identical under the null of constant treatment effects. We reject this null hypothesis for 9 of the 10 continuous outcomes for which we detect statistically significant AITs in Tables 3-7. (Results reported in the bottom rows of Panel A for each of Tables 3-7. We do not test binary outcomes and do not have any categorical outcomes.) Moreover, we find that loan access significantly changes the standard deviations for 6 out of the 19 continuous outcomes whose means do not change significantly. The prevalence of treatment effects on standard deviations is evidence of heterogeneous effects. In these 15 outcomes where the standard deviation differs, it increases under treatment compared to control in 8 , and decreases in 7 . If the treatment causes a decrease in outcome variance, there is a negative correlation between impact size and the outcome in the absence of the treatment (see Appendix 1). Adjustment for multiple hypothesis testing does not change any of these results.

Next we use the panel data to test whether the variance treatment effects are driven entirely by the characteristics we can observe, by comparing the variances of treatment versus control residuals obtained from regressing outcomes on treatment assignment, baseline characteristics, and interactions between these characteristics and treatment assignment. The "apples-to-apples" comparisons here are between the "panel only" row and the "residuals" rows. Controlling for our observables eliminates the statistically significant treatment effect on standard deviation in only 1 of the 15 cases. In three of the 14 cases without a statistically significant effect in the panel sample controlling for observables actually generates statistical significance (for profits and household business income), both with and without adjustment for multiple hypothesis testing. These results suggest that heterogeneous treatment effects are not readily explained by observables, and implies that treatment effects likely vary even within the subgroups we examine in Section V.B.3.

Figure 3 shows QTE estimates for number of employees, revenues, expenditures, and profits. These are all conditional on business ownership, since Table 4 finds no treatment effects on ownership. For businesses with any employees, treatment decreases the likelihood of 1 employee but increases the likelihood of having 3 employees. Revenues, expenditures, profits, and business income each appear to increase in the right tail (Figures $3 \mathrm{c}$ to $3 \mathrm{f}$ ), although the increases in expenditures are not statistically significant at the estimated percentiles. In addition, profits also fall at low percentiles (although the left tail effects are not statistically significant), hinting that the treatment might cause profit losses to some. In all, the results on business outcomes indicate that expanded credit access increases business size and profitability to the right of the median. 
Figure 4 presents the QTEs we could estimate for the continuous expenditure outcomes in Table 5. Although most individual QTEs are not statistically significant, the overall pattern suggests right-tail increases in several spending categories. Treated households are more likely to have bought zero new assets, and very nearly less likely to have bought any of the non-zero asset counts. This is consistent with the previously documented reduction in fire sales of assets.

Figure 5 shows QTE estimates for two of the three continuous measures of income used in Table 6. Many of these QTE estimates are imprecise, and none is significantly different from zero at the estimated percentiles. Remittances are not included in the QTE graphs because fewer than five percent receive any remittances.

Figure 6 shows QTE estimates for eight of the nine continuous outcomes measures used in Table 7 (the QTE estimates for children working did not converge). The depression index improves throughout the entire distribution, with larger point estimates to the left of the median (Figure 6a). QTEs for trust in people show a similar pattern, although only one of the individual QTEs is statistically significant (Figure 6e). We find no strong patterns for the stress, control, or institutional trust indices (Figures 65.b to 65.d), although there is a negative effect on locus of control at the 5th percentile, which confirms the possibility of some people being negatively affected by the treatment. The point estimates for the satisfaction and harmony index are all zero (and often precisely estimated), excepting a significant increase at the $75^{\text {th }}$ percentile (Figure 6f). Likewise, the two decision power variables show mostly precise zeros at each number of issues, with the exception of statistically significant increase for the likelihood of having say on all four household issues asked about (Figure 6g).

Overall, we glean three key patterns from the QTE estimates. First, there are several variables with positive treatment effects in the right tail: revenues, expenses, profits, and school/medical expenses (and several of the other expenditure categories have nearly significant positive QTEs at the $90^{\text {th }}$ percentile or above). Second, we see positive effects on depression and trust throughout their distributions. Third, there are few hints of negative impacts in the left tail of distributions - with the exception of profits and locus of control-alleviating concerns that expanded credit access might adversely impact people with the worst baseline outcomes. However, as we discussed above, the results thus far tell us relatively little about whether and to what extent distributional changes produced winners and losers. We now turn to two additional sets of analyses that help us understand if the treatment creates winners and losers.

\section{B.2. Winners and Losers? Average Intent to Treat Effects on Changes (Panel Only)}

We start by estimating treatment effects on likelihoods of outcomes increasing, and of outcomes declining, from baseline to follow-up. These results are presented in Panels B and $\mathrm{C}$ of Tables 3, 4, 5, 6 and 7, corresponding to the AIT endline estimates in the Panel A's of those same tables. We estimate these effects using logits, for the subset of outcomes and respondents with panel data. Given the typically positive average treatment effects, we are particularly interested in treatment effects on the likelihood that an outcome worsens over time, in order to examine whether the AIT is masking important dispersion. 
Before discussing the results on increases and decreases in detail, we pause to examine the internal and external validity of the panel sample. As discussed earlier, presence in the panel is uncorrelated with treatment status, supporting internal validity. The external validity of the panel is more subjective. We have panel data on only about $11 \%$ of our full sample, and the panel sample represents 33 of 238 clusters in our full sample. The smaller sample and cluster count also reduce our power. Appendix Figure 1 summarizes AITs for the panel sample, in order to compare the AIT's on just the panel to the AITs for the full endline. Two key patterns emerge. First, we find only three significantly different treatment effects from the full sample, although this lack of significant differences is due in large part to large confidence intervals (for the panel sample treatment effects in particular). Second, although the remaining differences are not statistically significant, the overall pattern of results for the panel is less positive than for the full sample.

With the above caveats in mind, we now return to Tables 3-7. We have a limited set of variables collected both at baseline and endline. For credit activity (Table 3), there is no statistical evidence that access to Credito Mujer crowds out loans from money lenders and pawnshops (Panel C), or changes the likelihood of membership in informal savings groups.

For the more ultimate outcomes, the general picture is weakly positive, and hence consistent with the AITs in the Panel A's. Table 4 shows no significant effects on likelihoods of business ownership increasing or decreasing (Columns 1 and 2). The likelihood of using a loan to grow a business is more likely to increase in the treatment group ( 0.016 on a base of 0.040 , se $=0.009)$, and no more likely to decrease $(0.001$, $\mathrm{se}=0.006)$. There is no evidence that businesses shrink or get less profitable (Columns 48 , Panel C). Indeed, the likelihoods of having a larger number of employees (Column 4) and a higher business income (Column 8) go up by 7 and 6 percent compared to the changes in the control group, although only the former is significant at conventional levels (and not significant after adjustment for multiple hypothesis testing). Besides business income, we have panel data for two other income sources: total household income and remittances (Table 6). Neither of these sources is more likely to decline in treatment areas (Panel C), and the treatment effect on the likelihood of remittance income increasing is positive $(0.017$ on a base of 0.027 , se $=0.010)$, but not significant after adjustment. Table 7 Panel $\mathrm{C}$ shows no ill-effects on any of available welfare measures (depression index, health status, child labor). Panel B shows a 2.6 percentage point (se = 1.5) increase in the likelihood of better health, on a base of 0.11 .

In sum, this analysis from the panel data shows some evidence that expanded credit access increases the likelihood of outcomes improving over the treatment horizon, and no evidence of treatment effects on the likelihood of outcomes declining. I.e., we do not find any evidence here that Credito Mujer makes outcomes worse over time.

\section{B.3. Who Wins and Who Loses? Heterogeneous AITs}

Next we examine whether any of 20 sub-groups experience negative treatment effects. We organize the analyses by heterogeneity in socioeconomic characteristics and in 
preferences. Socioeconomic status is readily observed by lenders, other service providers, regulators, etc., so documenting any systematically negative or positive treatment effects for specific sub-groups provides guidance for screening and targeting microcredit. Preferences are more difficult to observe and measure accurately, but understanding whether and how the effects of access to credit vary with proxies for risk and time preferences can shed light on how prospective borrowers are deciding whether and how much to borrow.

The sub-group analyses are summarized in Table 8, with more detail provided in Figures 7-13 for the socioeconomic variables, and Figures 14-16 for the preference variables. The Figures show effect sizes in standard deviation units for all outcomes except for the borrowing outcomes on number of loans. The effect sizes on these three variables are not scaled (i.e., the units are number of loans), because for these we are primarily interested in the magnitude of the "first-stage", including the extent of any crowd-out of other loan sources by Compartamos borrowing.

We focus our discussion, as before, on whether there are statistically significant positive and/or negative impacts on our various outcomes. In addition, we check whether there are differential impacts for mutually exclusive subgroups. When considering these differential impacts, one should keep in mind that if there are differential take-up rates by subgroup the estimated AITs may be statistically different for a pair of subgroups even if the actual average treatment effects are the same for borrowers and non-borrowers in those groups. The take-up rates are statistically different for women without and with prior business ownership (16.3\% and $25.4 \%)$ and formal credit experience $(10.5 \%$ and $15.4 \%)$. This is not an issue, however, when the signs of the two AITs differ.

Table 8 provides counts of positive and negative significant treatment effects for each of the 20 sub-groups, and of significant differences in treatment effects and their direction within the 10 groups. We use adjusted critical levels for these counts; Figures 7-16 also show when the adjustment causes a treatment effect that is significant without adjustment to become not significant. We focus often on the "Totals" (Columns 9 and 10), which sum across categories of the 34 ultimate outcomes of interest: business ( 9 outcomes), income and consumption (14 outcomes), and other welfare (11 outcomes). We count each of these outcomes individually, with two exceptions. First, we exclude spending on temptation goods and the number of issues with conflict, because the normative interpretation of any treatment effects on these outcomes is especially difficult (see discussion in Section V.A). Second, we combine information on overall asset sales and purchases, since sales may somewhat mechanically induce subsequent purchases. Specifically, if asset sales and purchases each fall for a given sub-group, we count this as a single, positive treatment effect in the Total. In all, this means that our summary counts allow for a maximum of 34 significant treatment effects for each subgroup, and a minimum of zero. 
Prior business ownership

First, we examine treatment effects for prior business owners versus non-prior business owners, using two retrospective questions from the endline data on business ownership prior to treatment. $24 \%$ of the sample owned a business prior to treatment. We find a strong first stage for this sub-group (Figure 7.a), and positive effects on several business outcomes and on total household income, and positive effects on trust in people and the extensive margin of household decision making. All told there are 8 or 9 positive treatment effects, depending on whether we use adjusted critical levels. (Below and Table 8 focuses on adjusted critical values, but Figures 7-16 show both). The two (nearly) significant negative effects (on informal savings and asset purchases) are actually consistent with improvement in financial resiliency and risk management; as discussed above, we consider these potentially "good" outcomes from a policy perspective.

The picture is less uniformly sanguine for the non-business owner sub-group (Figure 7.b), but still positive. This group also has a strong first stage. Effects on business outcomes are not significant, and several are statistically significantly lower than for business owners (Figure 7.c). However, this may simply be caused by the lower take-up rate for this subgroup. There is a nearly significant reduction in the likelihood of working in the last 30 days, and this treatment effect is significantly lower for non-business owners than business owners. On the other hand, non-business owners in treatment areas have fewer asset sales for debt service, less depression, and more decision power. On balance, the results suggest that non-business owners use the loans to pay off more expensive debt, work less, and are happier for it. We cannot rule out some negative effects on this subgroup, but the pattern does not suggest clear welfare reductions.

\section{Education}

We measure education using endline data, despite the fact that it could in principle be affected by credit access (in practice, adults returning to school in Mexico is rare), because we find no effects of treatment assignment on educational attainment. The subgroup with relatively high-education (the $71 \%$ of the sample > primary school) fares pretty well (Figure 8.a). We see increases in business revenues and expenditures, a reduction in asset sales to pay loans, and a nearly significant reduction in financial problems with the business $(\mathrm{p}$-value $=0.11$ ). Depression falls and decision power rises. The one somewhat worrisome treatment effect is that home improvements fall (and are significantly below the low-education sub-group). But overall we can rule out systematically negative effects on the relatively high-education sub-group, and furthermore the treatment effects mirror those of the average treatment effects for the full sample.

The low-education sub-group (the $29 \%$ of the sample with primary school or less) does not have any significant treatment effects among the 34 outcomes we count as normatively interesting. The first stage is strong (Figure 8.b), but all of the point estimates on business outcomes are clustered around zero. There is a bit of evidence that household income (in particular from wage labor) falls, as does temptation spending. There are no significant effects on well-being measures, although several of the point 
estimates are positive and close-to-significant. In all, we do not find robust evidence that low-education individuals are systematically harmed by expanded access to credit; although the hints that income falls is worrisome, there are no corroborating mechanisms to generate that effect and thus it seems just as likely to be a consequence of multiple outcome testing as a true negative result. Only 2 of the 34 treatment effects are significantly different for the two education sub-groups using the adjusted critical levels.

\section{$\underline{\text { Urban/rural }}$}

We next examine impacts in rural and then urban areas (27 and $73 \%$ of the sample). ${ }^{30} \mathrm{We}$ find a strong first stage of similar magnitudes (Figure 9.c) for both sub-groups (Figures 9.a and 9.b).

However, the loans are used differently. In rural areas (Figure 9.a), loan access increases investment: business ownership, expenditures, revenues, and business income show statistical and economically significant increases, and higher increases than in urban areas. The effect on participation in an economic activity is also significantly higher in rural areas. There is some evidence of improvements in decision power, but no other statistically significant treatment effects on the welfare measures.

In urban areas (Figure 9.b), on the other hand, loans seem to be primarily used for risk and debt management. Access to loans causes a reduction in fire sales for loan repayment, and membership in informal savings groups declines (although not by significantly more than for rural individuals). Labor supply and business ownership decrease. Happiness, trust in people, and decision power all improve (though not significantly more than in rural areas). One interpretation of these results is that urban-area women can smooth consumption using credit instead of low-return, unpleasant "survival" activities (e.g. being a street vendor).

Socio-economic variables using the panel sub-sample

From here forward we use baseline data to measure sub-group characteristics and hence are limited to the panel sub-sample. This explains why the confidence intervals are wider in Figures 10-16 than in Figures 7-9. One should also keep in mind the caveats re: the external validity of the panel-sub sample; on balance, we find some evidence that AIT effects are less favorable here than in the full sample (Appendix Figure 1; compare to Figure 2).

\section{Income}

Figures 10.a and 10.b summarize results by baseline income per adult in the household. We do not find differences in the first stage, although the effects for the high-income group are weaker than for most other groups. Overall there are few significantly different treatment effects across the two sub-groups (Figure 10.c). Nevertheless, the pattern of results is weakly suggestive of some important heterogeneity in treatment effects. Those with above-median income (Figure 10.a) have few significant treatment effects: one

${ }^{30}$ In unreported results, we find no impact on "anyone has left" the household in the last 2 years or "number of people who have left" in the last 2 years. Here an urban area is defined as having a population above 16,000 people. 
positive (on children not working) and two negative (on business ownership and locus of control). Those with below-median income (Figure 10.b) have one positive treatment effect (on the intensive margin of decision power), and five negative ones (on profits, business problems, locus of control, trust in institutions, and life satisfaction).

Formal credit experience

Figures 11.a and 11.b show results for those with and without formal credit experience at baseline. $^{31}$ This could be a particularly important categorization, with theories in both directions. One could argue that experience gives people better financial management skills (including the decision to borrow in the first place), and hence the moreexperienced would fare better from expanded credit access. Formal credit experience might also be correlated with other inputs that increase returns to borrowing. On the other hand, if learning is incomplete then formal credit experience might actually proxy for proclivity to overborrow.

We find similar first stages for the two groups (Figure 11.c). There are six significantly different treatment effects on more ultimate outcomes, with five of them (all measures of "Other Welfare") favoring the formal credit experience group. The point estimates also suggest that the formal group has higher profits ( $\mathrm{p}$-value 0.2 ). These differences are likely even larger than they appear at first sight, considering that the take-up rate is significantly higher in the formal group (15.4\%, vs. $10.5 \%$ in the group without formal credit experience).

Looking at the groups individually, those with formal credit experience have four significant treatment effects using adjusted critical values. Three are positive (on growing a business, health, and decision power), and one is negative (fire sales increase). Those without formal credit experience have five significant treatment effects. One is positive (on the extensive margin of decision power), and four are negative (on job stress, locus of control, life satisfaction, and economic satisfaction).

In all, the results here provide some evidence that those with no formal credit experience fare worse when credit access expands, mostly with respect to subjective well-being outcomes. We discuss this more in the conclusion.

\section{Formal Account Experience}

Figures 12.a and 12.b show results for those with and without prior experience with an account with a bank or cooperative (20\% and $80 \%$ of the panel). Part of the motivation here is unpacking the results on formal credit experience: if those lacking experience fare worse because they lack skills and knowledge obtained from participating in the formal sector per se (not just managing loans), then we would expect to see a similar pattern of results for those lacking formal account experience. While the two variables are positively correlated, we do not find a similar pattern: those lacking experience have two significant treatment effects out of 34. Moreover, of the four significant differences in treatment effects between the groups (Figure 12.c), three favor the inexperienced.

${ }^{31}$ We define formal credit experience as having ever taken out a loan from a bank or financial institution. 


\section{Informal Savings Group Experience}

Figures 13.a and 13.b show results for those with and without prior informal savings group participation. Again, part of the motivation is unpacking the results on formal credit experience. The idea here is that those with informal savings group experience have already learned how to manage their finances in a group context, and one that encourages weekly payments (Gugerty 2006; Basu 2011). Those lacking experience may lack the requisite financial knowledge and skills to succeed in a group lending setting, in which case we might expect to see a pattern of results that parallels those for the no formal credit experience sub-group. These two variables are positively correlated, but we again do not see a similar pattern: those without experience have 4 positive and 3 negative treatment effects, while those with experience have 2 and 4 . Of the 7 significant differences, four favor the inexperienced (all business outcomes) and three favor the experienced (all "other welfare" outcomes).

\section{Preferences}

We next group people by their risk and time preferences, as elicited at baseline. Although these preference measures would be difficult for lenders to use in targeting or screening, this exercise helps explore mechanisms underlying the somewhat negative effects we find above for those with lower income and less experience with formal credit. E.g., are the negative effects due to resource constraints (which might leave resource-constrained, non-borrowing households vulnerable to negative spillovers from borrowing households), and/or to differences in decision making that lead to "overborrowing"?

\section{Risk preferences}

We form two sub-groups based on elicited risk preferences: risk tolerant, or not. Our elicitation method is to give the respondent an opportunity to choose which one of four heads-or-tails lotteries they would like to play, hypothetically: $\{150,5\},\{100,10\},\{80$, $25\}$, or $\{50,50\}$. From left to right the choices decrease in expected value, but increase in the minimum possible payoff. All payoffs are denominated in pesos, so there is no payoff larger than \$12USD. Given the sharp decline in expected value from the first choice to the others, we label the $28 \%$ of respondents who choose $\{150,5\}$ "risk tolerant", and everyone else "risk intolerant".

Risk tolerance is an interesting margin for exploring heterogeneous treatment effects for at least two reasons. First, risk tolerance may be a necessary condition for pursuing risky but profitable-in-expectation opportunities that open up with the expansion of credit access. Hence we would expect risk tolerant respondents to have higher mean treatment effects. Second, small-stakes risk aversion is incompatible with standard preferences, and hence may be indicative of behavioral biases (e.g., loss aversion) or cognitive limitations that could produce overborrowing.

At baseline, risk tolerant individuals are more likely to have a business and a larger business (as measured by expenses; the point estimates on revenues, profits, and business income are also positive and marginally significant or nearly so). These correlations 
suggest that our proxies for risk preferences do have some validity, despite being elicited using a single, hypothetical survey question. ${ }^{32}$

Turning to treatment effects for the risk tolerant or intolerant (Figure 14), the results are surprising: treatment effects are not clearly positive, or more positive, for the risk tolerant (despite the fact that the first stage seems weakly stronger for the risk tolerant). Rather, both groups have few significant treatment effects, and there are only three significant differences between the risk tolerant and intolerant (Figure 14.c).

Next we categorize respondents as "patient" (56\% of the panel) or "impatient" $(44 \%)$, based on responses to two standard, hypothetical, smaller-sooner vs. larger-later questions. ${ }^{33}$ Figure 15 shows that we again find few significant treatment effects for each group. There are three significantly different treatment effects, with two favoring the patient and one favoring the impatient.

Finally, we categorize respondents as "present-biased" (30\% of the panel) or not $(70 \%)$, based on responses to four standard, hypothetical, smaller-sooner vs. larger-later questions. ${ }^{34}$ Bauer et al (2012) find that present-biased Indian villagers are more likely to use microcredit, and speculate that installment debt and/or joint liability serve as commitment devices that improve financial discipline ${ }^{35}$. We do not find that presentbiased individuals are more likely to borrow, however (Table 2). And we do not find evidence that the present-biased clearly benefit much from microcredit: Figure 16.a shows zero significant treatment effects beyond the first-stage. ${ }^{36}$ The non-present-biased have only one significant treatment effect (Figure 16.b), and we do not find any significant differences between the two groups (Figure 16c).

\section{Summary of Treatment Effects by Subgroup}

The main takeaway is some, albeit far from overwhelming, evidence that some people fare worse when faced with expanded access to credit. Several of the sub-groups have more negative treatment effects than positive ones, with the patterns of results for those who are poorer or without prior use of formal credit access perhaps the most eyeopening.

${ }^{32}$ Risk preferences are typically elicited using more elaborate methods, although some simpler methods for measuring risk attitudes have produced measures that are conditionally correlated with behavior (Dohmen et al. 2011; Kimball, Sahm, and Shapiro 2008).

33 The first is: "If you could choose between 200 pesos tomorrow and 300 pesos in one month, which would you prefer?" If the respondent chooses 200, a follow-up question ups the one-month payoff to 400. We label the respondent "patient" if she chooses either larger-later reward.

34 The first two questions are detailed in the above footnote. The second two questions offer the same payoffs at 6 months from today vs. 7 months from today. We label someone present-biased if they choose the smaller-sooner amount in the tomorrow vs. 1-month frame, but at least sometime choose the larger-later amount in the 6-month vs. 7-month frame.

${ }^{35}$ Bauer et al (2012) measure present bias using ten smaller-sooner vs. larger-later questions and gave the payoff from a randomly-selected choice to a random selection of respondents.

${ }^{36}$ When estimating treatment effects for the present-biased or not-biased, we do not control for patience. 
However, we emphasize the lack of a preponderance of evidence that expanded credit access is welfare-reducing for any of the 20 sub-groups examined. First, even within the sub-groups that seem to fare worst here - people with below-median income and no prior formal credit - there are only 5 and 4 negative treatment effects out of 34 (Table 8 Column 10). The likelihood that we would find two or three sub-groups out of twenty with at least four negative treatment effects out 34, purely by chance (i.e., due to false negatives), is high. Second, there is little evidence that those with lower income fare worse than their higher income counterparts, statistically speaking (Table 8 Column 11).

As such, and consistent with the findings from the test of equality of outcome variances, we view the results here as motivating further exploration of heterogeneity in treatment effects of expanded access to financial services. They are far from definitive statements about who wins and loses, or about how many lose. In fact, the full picture of results in this paper points more strongly to impacts that are positive on balance, for most borrowers and potential borrowers.

\section{B.4. Differential Treatment Effects by Subgroup: all Sub-Group Tests in Same Model}

Our analysis so far has focused on differences by one type of heterogeneity at a time. This approach yields policy-relevant results, especially if lenders can readily target potential clients by sub-group. But this approach does not reveal what causes any heterogeneity in treatment effects; e.g., are differences between risk tolerant and risk intolerant driven by risk preferences per se, or by a correlation between risk preference on some third variable like prior business ownership?

We explore the drivers of heterogeneous treatment effects by including all of the heterogeneity tests in the same model; i.e., instead of the two interaction terms in equation (2), we include three interactions in models estimated on the endline sample: treatment assignment interacted with each of prior business ownership, education>primary, and rural. We also include main effects for each of the three variables interacted with treatment assignment. Models estimated on the panel sample take the same form, but with nine interactions and main effects instead of three (see Table 9 Panel $\mathrm{B}$ for the complete list, and note that we cannot include the tenth characteristic, rural vs. urban, in the panel sample model because that entire sample is rural).

Table 9 reports counts of the number of times each interaction term is significant and significantly positive across outcomes (outcome categories in Columns 1-8, and all 34 outcomes of ultimate interest in Columns 9-10). Column 9 here is comparable to the count across the univariate tests in Table 8 Column 11.

For the most part, the number of significant differences for the majority of characteristics decreases or remains the same (e.g. the number of significant differences by formal account experience decreases from 4 to 3). The only exceptions are business ownership in the full sample, and income and risk tolerance in the panel sample, all of which show just one more significant difference when the other covariates are included in the regression. Most other subgroups show the same number of differences or one fewer difference. Only those subgroups showing more than four differences in Table 8 show a decrease of 
more than 1 significant difference: location (rural vs. urban), formal credit experience, and informal savings experience each show two or more fewer differences.

Overall, Table 9 indicates that few significant differences exist between members of subgroups we examine. Relative to other characteristics, prior business ownership, location, and informal savings experience appear to differentiate impacts the most. Still, the highest number of significant differences for one characteristic (prior business ownership) only represents about one fifth of the possible number of differences (7/34).

\section{Conclusion}

We use randomized program placement and household surveys to measure various impacts of Compartamos Banco's entry into north-central Sonora, Mexico.

Over our three-year evaluation horizon, we find generally positive average effects on our sample of borrowers and prospective borrowers: there is evidence that businesses grow, that households are better able to manage liquidity and risk, and that (prospective) borrowers are happier, more trusting, and have greater intra-household decision power. But there is little evidence of wealth-building: we do not find evidence that profits, household income, or consumption increase on average. It may be that wealth-building impacts take years to germinate: future research would do well to evaluate impacts over longer horizons than 2-3 years.

Compartamos Banco's expansion also causes heterogeneous treatment effects: we find significant differences between treatment and control groups in the standard deviations for half of the outcomes tested. Moreover, we also find some evidence of local effects on the shapes of outcome distributions; in particular, quantile treatment effects show righttail increases in several outcomes, including business profits. Treatment effects on happiness and on trust in people increase throughout their distributions. One way future work might better discern the welfare implications of credit expansions (and other interventions) is to use theories to generate distinct testable predictions about impacts on higher moments and distributions.

Perhaps most importantly, we do not find strong evidence that the credit expansion creates large numbers of "losers" as well as winners. First, there are few significant and negative quantile treatment effects in the left tails, i.e. people in the left tail of the distribution of outcomes are not hurt by the program. Second, none of the 17 outcomes for which we have panel data show significant increases in the likelihood of worsening over time in treatment relative to control areas. Third, in the sub-group analysis, there is no clear pattern of strongly negative impacts on any of the 20 sub-groups we examine. But there are hints that some sub-groups - in particular, those with lower incomes, and those without prior formal credit experience-experience negative treatment effects on balance.

Concerns about the possibility that expanded access to (expensive) credit does more harm than good motivate several lines of inquiry going forward. Understanding what drives any "overborrowing" is critical, and much remains to be done to unpack empirical 
relationships underpinning the many behavioral biases and heuristics hypothesized to affect financial decisions.

There is also more work to be done on mechanism design; e.g., on how different screening, targeting, and liability rules affect both average impact and heterogeneous treatment effects. The issue of organizational form looms large in microfinance policy debates: our study concerns a lender that has been both widely praised (for expanding access to group credit for millions of people) and widely criticized (for being for-profit and publicly traded, and for charging higher interest rates than similar lenders do in other countries). ${ }^{37}$ Would a non-profit lender generate different impacts? More uniform ones? Better ones?

Closely related questions concern how product presentation (e.g., marketing, disclosures) and pricing mediate impacts. New evidence from a nationwide, non-overlapping study with Compartamos on interest rates shows that demand is quite elastic: cutting APRs by roughly 10 percentage points (also a 10\% decrease) substantially increased lending on both the extensive and intensive margins, while proving sustainable (i.e., profit-neutral) for Compartamos (Karlan and Zinman 2013). Much work remains to be done to ascertain the impacts of price changes on borrowers: how do they change the marginal borrower (relative to branch expansion)? Are lower prices unambiguously better for consumer welfare, or do some higher prices provide a form of behavioral discipline against overborrowing?

The impacts study here, combined with the interest rates study discussed directly above, provide some unusual evidence on the mechanics of "double bottom lines." Compartamos, like many other for-profits (especially in microfinance), has labeled itself a "social enterprise" that maximizes social welfare subject to a profit maximization constraint. The interest rate study suggests that Compartamos can move along the profitmaximizing frontier by cutting prices in the face of very elastic demand, thereby substantially expanding access to credit without making major changes to its operations. I.e., there is a range of prices in which Compartamos has satisfied the profit maximization constraint, and therefore the bank has a degree of freedom to choose a price that maximizes social welfare. The results from the two papers suggest that maximizing access, via lower prices, is a simple solution to the social enterprise's maximization problem.

A key question remains of course, particularly with respect to those without prior formal credit: is this about the type of person, or this is about their lack of experience using credit. The first implies improved screening tools in order to help individuals self-select into financial transactions that will help them further their own stated goals. In other words, how does Compartamos nudge individuals to borrow, or not, to maximize their wellbeing as they would self-report in a moment of reflection (Thaler and Sunstein 2009). Or, alternatively, how does Compartamos provide additional training to individuals

${ }^{37}$ The rates, to be clear, are actually below average compared to both for-profit and non-profit microcredit market in Mexico; they are only high when compared to other countries and continents. 
without prior formal credit experience so that they manage their loan more optimally? Importantly, can such training be provided in a profit-neutral way? Evidence from one randomized trial on business education found that the increased profits roughly equaled the costs from adding in entrepreneurship training to a group-based microcredit program (Karlan and Valdivia 2011).

In all, our study adds to the mounting evidence that microcredit is generally beneficial on average, but not necessarily transformative in the ways often advertised by practitioners, policymakers, and donors. The most consistent impacts come out in the more subjective, qualitative wellbeing outcomes, rather than the more traditional economic outcomes such as income and consumption. We also provide new evidence on various distributional impacts suggesting that expanded credit access has multifaceted, complex, and heterogeneous effects on businesses and households. Better understanding of these distributional impacts may hold a key for making progress on the modeling, application, and evaluation of credit market innovations and interventions. 


\section{Appendix 1}

This Appendix explains (1) why Levene's test of equality of variances is a test of homogeneous effects and (2) when we can conclude that subjects with the lowest counterfactual outcome are the ones who benefit the most from the treatment.

Define $Y_{0}$ and $Y_{1}$ as the potential outcomes in the absence and presence of the treatment. The treatment is living in a cluster where Compartamos Banco actively advertises Credito Mujer and which has access to this product. If the treatment effects are constant within compliers $(c=1)$ and within non-compliers $(c=0)$ and amount to $T_{c}$ and $T_{(1-c)}$, then $Y_{0}=Y_{O c} c+Y_{O(1-c)}(1-c)$ and $Y_{1}=c\left(Y_{O c} c+T_{c}\right)+(1-c)\left(Y_{O(1-c)}+T_{(1-c)}\right)$. In this case the variances of $Y_{0}$ and $Y_{1}$ are identical, i.e. $\operatorname{Var}\left(Y_{0}\right)=\operatorname{Var}\left(Y_{1}\right)$. Note, however, that one could have heterogeneous effects even if $\operatorname{Var}\left(Y_{0}\right)=\operatorname{Var}\left(Y_{1}\right)$, if the covariance of the treatment effects, $T$, with $Y_{0}$ is negative and such that $\operatorname{Cov}\left(Y_{0}, T\right)=1 / 2\left[\operatorname{Var}\left(Y_{0}\right)+\operatorname{Var}(T)\right]$. Therefore, this test is informative only if we reject the null.

To simplify the notation, write down the individual-specific potential outcomes as $Y_{1}$ $=Y_{0}+T$. In this case, $\operatorname{Var}\left(Y_{1}\right)=\operatorname{Var}\left(Y_{0}+T\right)=\operatorname{Var}\left(Y_{0}\right)+\operatorname{Var}(T)+2 \operatorname{Cov}\left(Y_{0}, T\right)$. If $\operatorname{Var}\left(Y_{1}\right)<\operatorname{Var}\left(Y_{0}\right)$, the covariance $\operatorname{Cov}\left(Y_{0}, T\right)$ is negative. This finding suggests that the benefits of the availability of Credito Mujer may be larger for people with lower outcomes in the absence of the treatment. 


\section{References}

Angelucci, Manuela. 2008. "Love on the Rocks: Domestic Violence and Alcohol Abuse in Rural Mexico.” B.E Journal of Economic Analysis and Policy 8 (1).

Attanasio, Augsburg, Britta Augsburg, Ralph de Haas, Fitz Fitzsimons, and Heike Harmgart. 2011. "Group Lending or Individual Lending? Evidence from a Randomised Field Experiment in Mongolia.” EBRD Working Paper 136 (December).

Augsburg, Britta, Ralph de Haas, Heike Harmgart, and Costas Meghir. 2012. "Microfinance at the Margin: Experimental Evidence from Bosnia and Herzegovina." Working Paper (September).

Banerjee, Abhijit, Esther Duflo, Rachel Glennerster, and Cynthia Kinnan. 2009. "The Miracle of Microfinance? Evidence from a Randomized Evaluation”. Working paper.

Basu, Karna. 2011. "Hyperbolic Discounting and the Sustainability of Rotational Savings Arrangements." American Economic Journal: Microeconomics 3 (4) (November): 143-171. doi:10.1257/mic.3.4.143.

Bauer, Michal, Julie Chytilová, and Jonathan Morduch. 2012. "Behavioral Foundations of Microcredit: Experimental and Survey Evidence from Rural India." American Economic Review 102 (2) (April): 1118-1139. doi:10.1257/aer.102.2.1118.

Berge, Lars, Kjetil Bjorvatn, and Bertil Tungooden. 2011. "Human and Financial Capital for Microenterprise Development: Evidence from a Field and Lab Experiment."

Crepon, Bruno, Florencia Devoto, Esther Duflo, and William Pariente. 2011. "Impact of Microcredit in Rural Areas of Morocco: Evidence from a Randomized Evaluation." M.I.T. Working Paper (March).

De Mel, Suresh, David J. McKenzie, and Christopher Woodruff. 2009. "Measuring Microenterprise Profits: Must We Ask How the Sausage Is Made?" Journal of Development Economics 88 (1) (January): 19-31. doi:10.1016/j.jdeveco.2008.01.007.

De Mel, Suresh, David McKenzie, and Christopher Woodruff. 2008. "Returns to Capital in Microenterprises: Evidence from a Field Experiment." Quarterly Journal of Economics 123 (4): 1329-1372.

DellaVigna, Stefano. 2009. "Psychology and Economics: Evidence from the Field." Journal of Economic Literature 47 (2) (June): 315-372.

Dohmen, Thomas, Armin Falk, David Huffman, Uwe Sunde, Jürgen Schupp, and Gert G. Wagner. 2011. "Individual Risk Attitudes: Measurement, Determinants, and Behavioral Consequences." Journal of the European Economic Association 9 (3) (June 1): 522-550. doi:10.1111/j.1542-4774.2011.01015.x.

Fafchamps, Marcel, David McKenzie, Simon Quinn, and Christopher Woodruff. 2011. "When Is Capital Enough to Get Female Microenterprises Growing? Evidence from a Randomized Experiment in Ghana." Working Paper.

Giné, Xavier, and Ghazala Mansuri. 2011. "Money or Ideas? A Field Experiment on Constraints to Entrepreneurship in Rural Pakistan."

Gugerty, Mary Kay. 2006. "You Can't Save Alone: Testing Theories of Rotating Savings and Credit Organizations." Economic Development and Cultural Change forthcoming. 
Hashemi, Syed, Sidney Schuler, and Ann Riley. 1996. "Rural Credit Programs and Women's Empowerment in Bangladesh." World Development 24 (4): 635-53.

Iachine, Ivan, Hans Chr. Petersen, and Kirsten O. Kyvik. 2010. "Robust Tests for the Equality of Variances for Clustered Data." Journal of Statistical Computation and Simulation 80, no. 4: 365-377. doi:10.1080/00949650802641841.

Kabeer, Naila. 1999. "Conflicts Over Credit: Re-Evaluating the Empowerment Potential of Loans to Women in Rural Bangladesh." World Development 29.

Karlan, Dean, Ryan Knight, and Christopher Udry. 2012. "Hoping to Win, Expected to Lose: Theory and Lessons on Micro Enterprise Development." National Bureau of Economic Research Working Paper w18325.

Karlan, Dean, and Jonathan Morduch. 2009. “Access to Finance." In Handbook of Development Economics. Vol. 5. Edited by Dani Rodrik Mark Rosenzweig. Elsevier.

Karlan, Dean, and Martin Valdivia. 2011. "Teaching Entrepreneurship: Impact of Business Training on Microfinance Clients and Institutions." Review of Economics and Statistics 93 (2): 510-527.

Karlan, Dean, and Jonathan Zinman. 2008. "Lying About Borrowing." Journal of the European Economic Association 6 (2-3). Journal of the European Economic Association: 510-521.

- 2010. "Expanding Credit Access: Using Randomized Supply Decisions to Estimate the Impacts." Review of Financial Studies 23 (1): 433-464.

- 2011. "Microcredit in Theory and Practice: Using Randomized Credit Scoring for Impact Evaluation." Science 332 (6035) (June 10): 1278-1284.

_. 2013. "Long-Run Price Elasticities of Demand for Microcredit: Evidence from a Countrywide Field Experiment in Mexico."

Kimball, Miles, Claudia Sahm, and Matthew Shapiro. 2008. "Imputing Risk Tolerance From Survey Responses." Journal of the American Statistical Association 103 (483): 1028-1038.

Kling, Jeffrey, Jeffrey Liebman, and Lawrence Katz. 2007. "Experimental Analysis of Neighborhood Effects." Econometrica 75 (1) (January): 83-120.

Maldonado, Jorge, Claudio Gonzales-Vega, and Vivanne Romero. 2002. "The Influence of Microfinance on Human Capital Formation: Evidence from Bolivia." Contributed Paper at 2002 LACEA Conference.

McKenzie, D., and C. Woodruff. 2008. "Experimental Evidence on Returns to Capital and Access to Finance in Mexico." The World Bank Economic Review 22 (3) (October 22): 457-482. doi:10.1093/wber/lhn017.

McKenzie, David J., and Christopher Woodruff. 2006. "Do Entry Costs Provide an Empirical Basis for Poverty Traps? Evidence from Mexican Microenterprises." Economic Development and Cultural Change 55 (1) (October): 3-42. doi:10.1086/505725.

Thaler, Richard H, and Cass R Sunstein. 2009. Nudge: Improving Decisions About Health, Wealth, and Happiness. New York: Penguin Books. 


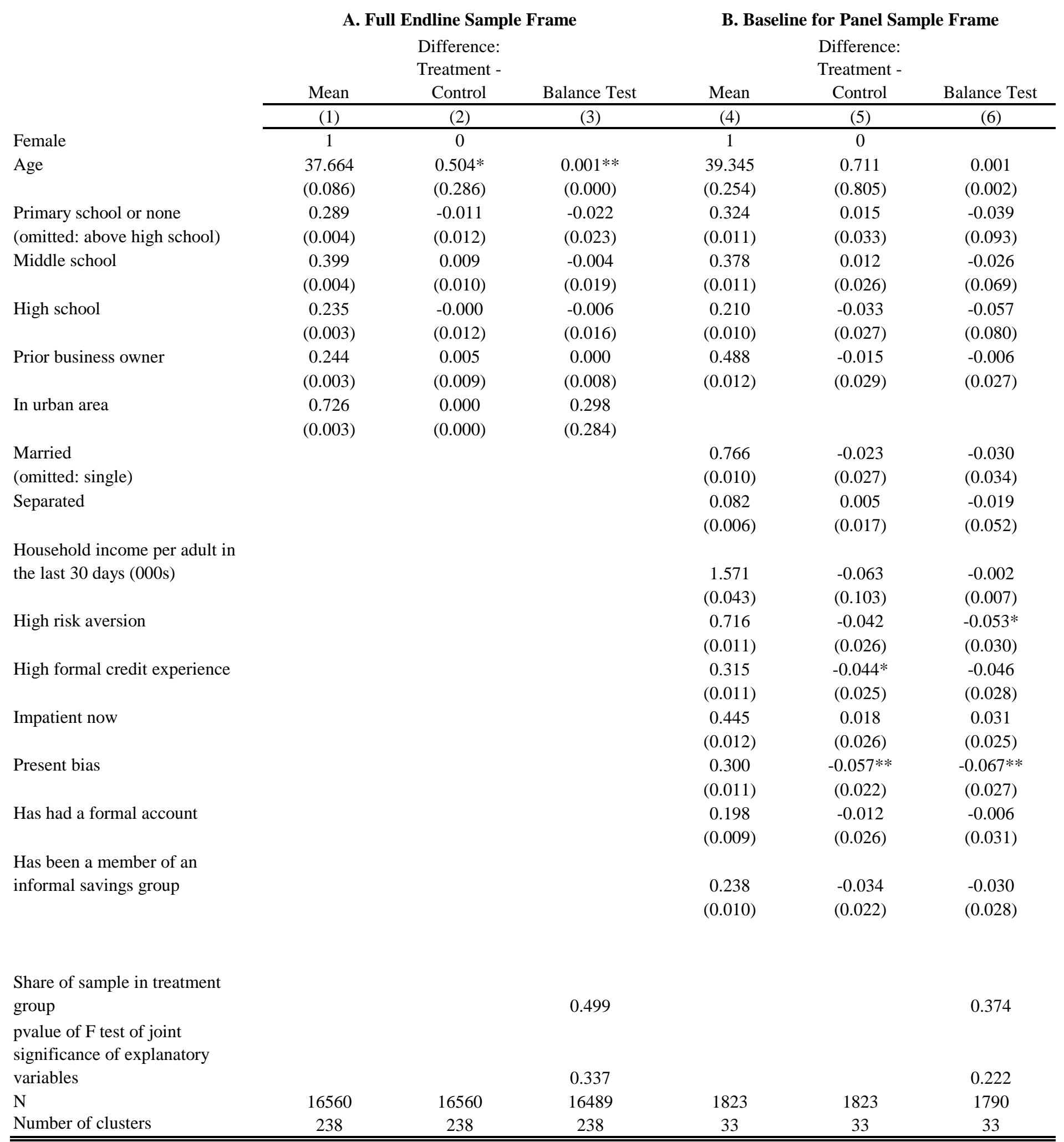

Respondents are Mexican women aged 18-60. Respondents in the panel sample all reside in rural areas. Columns 2 and 5 report the coefficient on treatment assignment ( $1=$ Treatment, $0=$ Control) when the variable in the row is regressed on treatment assignment. Columns 3 and 6 report the results of balance tests. The cells show the coefficient for each variable when they are all included in one regression with treatment assignment as the dependent variable. Standard errors are in parentheses below the coefficients. All regressions include supercluster fixed effects and standard errors clustered by the unit of randomization. $* \mathrm{p}<0.10, * * \mathrm{p}<0.05, * * * \mathrm{p}<.01$. 
Table 2: Takeup analysis

Female

Age 31 - 40

(omitted: 18-30)

Age 41 - 50

Age $51-60$

Primary school or none (omitted: above high school) Middle school

High school

Prior business owner

In urban area

Married

(omitted: single)

Separated

Household income per adult in the last 30 days $(000 \mathrm{~s})$

High risk aversion

High formal credit experience

Impatient now

Present bias

Has had a formal account

Has been a member of an informal savings group

Variables for:

Household demographics

Household materials

Wealth and Expenditures

Subjective welfare

Business size

Business expectations

Credit expectations

Credit familiarity

Credit experience

\begin{tabular}{ccc} 
Takeup & Takeup & $\begin{array}{c}\text { Partial Adjusted R- } \\
\text { Squared }\end{array}$ \\
\hline$(1)$ & $(2 \mathrm{a})$ & $(2 \mathrm{~b})$ \\
\hline 0 & 0 & \\
$\left(0.030^{* *}\right.$ & -0.007 & \\
$0.030^{* *}$ & $(0.050)$ & \\
$(0.014)$ & -0.044 & \\
0.025 & $(0.048)$ & \\
$(0.016)$ & 0.033 & \\
$0.034^{*}$ & $(0.063)$ & \\
$(0.019)$ & $-0.114^{* *}$ & \\
$0.065^{* * *}$ & $(0.045)$ & \\
$(0.020)$ & -0.043 & \\
$0.037^{*}$ & $(0.046)$ & \\
$(0.021)$ & $-0.092^{*}$ & \\
$0.096^{* * *}$ & $(0.049)$ & \\
$(0.011)$ & 0.047 & \\
$0.092 *$ & $(0.033)$ &
\end{tabular}

0.083

(0.067)

$-0.001$

(0.075)

$-0.010$

(0.006)

$-0.046$

(0.031)

0.014

(0.072)

0.002

(0.030)

0.025

(0.030)

$-0.006$

(0.036)

0.000

(0.000)

P-value for Joint

Significance

$0.531-0.0006$

$0.677-0.0013$

$0.437-0.0063$

$0.286 \quad 0.0005$

$0.153-0.0068$

$0.561-0.0018$

$0.008 \quad 0.0361$

$0.003 \quad 0.0036$

$0.000-0.0064$

$\begin{array}{lll}\text { Share of sample that took up } & 0.189 & 0.119\end{array}$

Adjusted R2 $\quad 0.044 \quad 0.023$

$\begin{array}{lll}\mathrm{N} & 8262 & 682\end{array}$

Number of clusters

120

682

Respondents are Mexican women aged 18-60. Respondents in the panel sample all reside in rural areas. Columns 1 and $2 \mathrm{a}$ show the coefficient for each variable when they are all included in one OLS regression with takeup as the dependent variable. The standard errors are in parentheses below the coefficients and are clustered by the unit of randomization. Column $2 \mathrm{~b}$ shows the value of the Adjusted R-Squared when the regression includes the variable(s) in the row minus the value of the Adjusted RSquared when the regression does not include the variable(s) in the row. Other baseline variables, listed below the line, are also included in the regression for the panel sample. The P-Value for Joint Significance column for the panel sample reports the pvalue for a test that the coefficients on the variables in the row are jointly equal to zero. All regressions include supercluster fixed effects. The coefficient on membership in an informal savings group is 0 because it was dropped from the regression due to collinearity with other variables. $* \mathrm{p}<0.10, * * \mathrm{p}<0.05, * * * \mathrm{p}<.01$. 


\begin{tabular}{|c|c|c|c|c|c|c|c|c|c|}
\hline \multirow[b]{2}{*}{ Outcome: } & \multicolumn{6}{|c|}{ Household Loans in the Last 2 Years } & \multicolumn{3}{|c|}{ Financial Access } \\
\hline & Total \# & Total amount & $\begin{array}{c}\text { \# from } \\
\text { Compartamos }\end{array}$ & $\begin{array}{l}\text { Amount from } \\
\text { Compartamos }\end{array}$ & $\begin{array}{c}\text { \# from a } \\
\text { moneylender } \\
\text { or pawnshop }\end{array}$ & $\begin{array}{c}\text { Amount from } \\
\text { a } \\
\text { moneylender } \\
\text { or pawnshop }\end{array}$ & $\begin{array}{l}\text { Formal credit } \\
\text { is } 1 \text { st choice } \\
\text { for credit }\end{array}$ & $\begin{array}{c}\text { Satisfied } \\
\text { w/access to } \\
\text { financial } \\
\text { services }(1 / 0)\end{array}$ & $\begin{array}{c}\text { Member of } \\
\text { informal } \\
\text { savings group }\end{array}$ \\
\hline & $(1)$ & $(2)$ & (3) & (4) & $(5)$ & $(6)$ & $(7)$ & $(8)$ & $(9)$ \\
\hline \multicolumn{10}{|c|}{ Panel A: Average intent-to-treat effects (OLS, full sample) } \\
\hline Treatment & $\begin{array}{c}0.121 * * * \\
(0.035)\end{array}$ & $\begin{array}{l}1248.488 * * * * \\
(470.749)\end{array}$ & $\begin{array}{c}0.108 * * * \\
(0.012)\end{array}$ & $\begin{array}{l}644.844 * * * \\
(75.732)\end{array}$ & $\begin{array}{l}-0.001 \\
(0.004)\end{array}$ & $\begin{array}{c}28.156 \\
(26.373)\end{array}$ & $\begin{array}{c}-0.01 \\
(0.011)\end{array}$ & $\begin{array}{l}-0.005 \\
(0.012)\end{array}$ & $\begin{array}{c}-0.019 * * * \\
(0.007)\end{array}$ \\
\hline $\begin{array}{l}\text { Baseline value } \\
\text { controlled for }\end{array}$ & No & Yes & No & No & Yes & Yes & No & No & Yes \\
\hline Adjusted R-squared & 0.013 & 0.005 & 0.039 & 0.023 & 0.003 & 0.001 & 0.008 & 0.008 & 0.023 \\
\hline $\mathrm{N}$ & 16177 & 15602 & 15788 & 15768 & 15968 & 15963 & 14076 & 14879 & 16551 \\
\hline Number missing & 383 & 958 & 772 & 792 & 592 & 597 & 2484 & 1681 & 9 \\
\hline Unadjusted p-value & 0.001 & 0.009 & 0.000 & 0.000 & 0.841 & 0.287 & 0.347 & 0.675 & 0.009 \\
\hline Significant adjusted? & Yes & Yes & Yes & Yes & No & No & No & No & Yes \\
\hline Control group mean & 0.95 & 6702.579 & 0.051 & 286.851 & 0.026 & 71.127 & 0.341 & 0.453 & 0.228 \\
\hline$\%=0$ in control & 46.323 & 47.924 & 96.1 & 96.199 & 98.006 & 98.068 & 65.94 & 54.657 & 77.209 \\
\hline $\begin{array}{l}\text { Treatment effect on } \\
\text { likelihood non-zero }\end{array}$ & $\begin{array}{c}0.051 * * * \\
(0.011)\end{array}$ & $\begin{array}{l}0.050 * * * \\
(0.012)\end{array}$ & $\begin{array}{c}0.077 * * * \\
(0.007)\end{array}$ & $\begin{array}{c}0.076 * * * \\
(0.007)\end{array}$ & $\begin{array}{c}0.001 \\
(0.002)\end{array}$ & $\begin{array}{c}0.000 \\
(0.002)\end{array}$ & $\begin{array}{l}-0.010 \\
(0.011)\end{array}$ & $\begin{array}{l}-0.005 \\
(0.012)\end{array}$ & $\begin{array}{c}-0.020^{* * * *} \\
(0.008)\end{array}$ \\
\hline $\begin{array}{l}\text { Treatment group } \\
\text { standard deviation }\end{array}$ & 1.436 & 32197.997 & 0.495 & 3985.405 & 0.188 & 1268.178 & & & \\
\hline $\begin{array}{l}\text { Control group } \\
\text { standard deviation }\end{array}$ & 1.299 & 22156.605 & 0.282 & 2039.400 & 0.204 & 957.999 & & & \\
\hline $\begin{array}{l}\text { p-value for test of } \\
\text { equality of standard } \\
\text { deviations }\end{array}$ & 0.006 & 0.027 & 0.000 & 0.000 & 0.090 & 0.964 & & & \\
\hline Significant adjusted? & Yes & Yes & Yes & Yes & No & No & & & \\
\hline \multicolumn{10}{|l|}{$\begin{array}{l}\text { p-value for test of } \\
\text { equality of standard }\end{array}$} \\
\hline Significant adjusted? & Yes & No & Yes & Yes & No & No & & & \\
\hline $\begin{array}{l}\mathrm{p} \text {-value for test of } \\
\text { equality of variance } \\
\text { for residuals, SES }\end{array}$ & 0.026 & 0.488 & 0.000 & 0.000 & 0.589 & 0.084 & & & \\
\hline Significant adjusted? & Yes & No & Yes & Yes & No & No & & & \\
\hline $\begin{array}{l}\text { p-value for test of } \\
\text { equality of variance } \\
\text { for residuals, SES + } \\
\text { preferences } \\
\text { Significant adjusted? }\end{array}$ & $\begin{array}{c}0.024 \\
\text { Yes }\end{array}$ & $\begin{array}{c}0.453 \\
\text { No } \\
\end{array}$ & $\begin{array}{c}0.000 \\
\text { Yes }\end{array}$ & $\begin{array}{c}0.000 \\
\text { Yes }\end{array}$ & $\begin{array}{c}0.625 \\
\text { No }\end{array}$ & $\begin{array}{c}0.077 \\
\text { No }\end{array}$ & & & \\
\hline \multicolumn{10}{|c|}{ Panel B: Likelihood of increase from baseline (logit, panel sample) } \\
\hline Treatment & & $\begin{array}{c}0.090 * * * \\
(0.032)\end{array}$ & & & $\begin{array}{c}0.007 \\
(0.008)\end{array}$ & $\begin{array}{c}0.006 \\
(0.009)\end{array}$ & & & $\begin{array}{l}-0.017 \\
(0.014)\end{array}$ \\
\hline Significant adjusted? & & Yes & & & No & No & & & \\
\hline $\begin{array}{l}\text { Mean in the control } \\
\text { group }\end{array}$ & & 0.441 & & & 0.012 & 0.015 & & & 0.116 \\
\hline \multicolumn{10}{|c|}{ Panel C: Likelihood of decrease from baseline (logit, panel sample) } \\
\hline Treatment & & $\begin{array}{c}0.004 \\
(0.016)\end{array}$ & & & $\begin{array}{c}0.011 \\
(0.012)\end{array}$ & $\begin{array}{c}0.011 \\
(0.012)\end{array}$ & & & $\begin{array}{l}-0.008 \\
(0.016)\end{array}$ \\
\hline Significant adjusted? & & No & & & No & No & & & \\
\hline $\begin{array}{l}\text { Mean in the control } \\
\text { group } \\
\mathrm{N} \text { for panels } \mathrm{B} \& \mathrm{C}\end{array}$ & & $\begin{array}{r}0.091 \\
1705\end{array}$ & & & $\begin{array}{c}0.038 \\
1751\end{array}$ & $\begin{array}{c}0.038 \\
1749\end{array}$ & & & $\begin{array}{c}0.114 \\
1823\end{array}$ \\
\hline
\end{tabular}

Specification: Standard errors, clustered by 238 geographic clusters (the unit of randomization), are in parentheses. Treatment effect on likelihood non-zero shows probit marginal effects with standard errors below; panels B and C report logit marginal effects. Controls for randomization strata (i.e. 45 supercluster fixed effects and 3 branches) are included but not shown. Controls for the baseline value of the outcome (its value, and missing/non-missing value) are included when the outcome was measured in the baseline. To account for multiple hypothesis testing, we adjust critical levels following the approach by Benjamini and Hochberg. The significance of each coefficient following this adjustment (if applied) is shown in Panel A. If a control was added for the baseline value of the outcome, any missing values for the baseline observation of the outcome were coded as zero and a variable was added that is equal to one if the baseline value is missing and zero otherwise.

Outcome(s): The number of loans in columns 2 and 3 refer to the most recent 3 loans, first among the respondent's loans and then within the household. The dependent variable in column 7 represents responses to a question asking respondents where they would go to obtain a loan of 6,000 pesos tomorrow. The adjusted critical values were calculated by treating columns 1-6 and 7-9 each as a separate family of outcomes. 
Table 4: Average Intent-to-Treat Effects on Business Outcomes

\begin{tabular}{|c|c|c|c|c|c|c|c|c|c|}
\hline Outcome: & $\begin{array}{c}\text { Has a } \\
\text { business }\end{array}$ & $\begin{array}{l}\text { Has ever } \\
\text { owned a } \\
\text { business }\end{array}$ & $\begin{array}{c}\text { Used a loan to } \\
\text { grow a } \\
\text { business }\end{array}$ & $\begin{array}{l}\text { Number of } \\
\text { employees }\end{array}$ & $\begin{array}{c}\text { Revenues in } \\
\text { the last } 2 \\
\text { weeks }\end{array}$ & $\begin{array}{c}\text { Expenditures } \\
\text { in the last } 2 \\
\text { weeks }\end{array}$ & $\begin{array}{l}\text { Profits in the } \\
\text { last } 2 \text { weeks }\end{array}$ & $\begin{array}{l}\text { Household } \\
\text { business } \\
\text { income last } \\
\text { month }\end{array}$ & $\begin{array}{l}\text { No financial } \\
\text { problems } \\
\text { managing } \\
\text { business in } \\
\text { the last year }\end{array}$ \\
\hline & $(1)$ & $(2)$ & $(3)$ & (4) & $(5)$ & $(6)$ & $(7)$ & $(8)$ & (9) \\
\hline \multicolumn{10}{|c|}{ Panel A: Average intent-to-treat effects (OLS, full sample) } \\
\hline Treatment & $\begin{array}{l}-0.004 \\
(0.009)\end{array}$ & $\begin{array}{l}-0.001 \\
(0.009)\end{array}$ & $\begin{array}{c}0.008 * * \\
(0.004)\end{array}$ & $\begin{array}{c}0.003 \\
(0.010)\end{array}$ & $\begin{array}{l}121.004 * * \\
(52.512)\end{array}$ & $\begin{array}{c}118.814 * * \\
(47.419)\end{array}$ & $\begin{array}{c}-0.208 \\
(38.983)\end{array}$ & $\begin{array}{c}60.58 \\
(63.891)\end{array}$ & $\begin{array}{c}0.007 \\
(0.005)\end{array}$ \\
\hline $\begin{array}{l}\text { Baseline value } \\
\text { controlled for }\end{array}$ & Yes & Yes & Yes & Yes & Yes & Yes & Yes & Yes & No \\
\hline Adjusted R-squared & 0.025 & 0.085 & 0.011 & 0.016 & 0.009 & 0.001 & 0 & 0.02 & 0.003 \\
\hline $\mathrm{N}$ & 16560 & 16557 & 16529 & 16560 & 16093 & 16184 & 15994 & 15577 & 16534 \\
\hline Number missing & 0 & 3 & 31 & 0 & 467 & 376 & 566 & 983 & 26 \\
\hline Unadjusted p-value & 0.657 & 0.882 & 0.042 & 0.738 & 0.022 & 0.013 & 0.996 & 0.344 & 0.119 \\
\hline Significant adjusted? & & & & No & Yes & Yes & No & No & \\
\hline Control group mean & 0.243 & 0.389 & 0.05 & 0.145 & 450.328 & 327.595 & 145.388 & 839.818 & 0.944 \\
\hline$\%=0$ in control & 75.693 & 61.143 & 94.961 & 90.648 & 81.105 & 86.156 & 82.171 & 73.67 & 5.602 \\
\hline $\begin{array}{l}\text { Treatment effect on } \\
\text { likelihood non-zero }\end{array}$ & $\begin{array}{l}-0.004 \\
(0.009)\end{array}$ & $\begin{array}{l}-0.001 \\
(0.010)\end{array}$ & $\begin{array}{c}0.008 * * \\
(0.004)\end{array}$ & $\begin{array}{l}-0.001 \\
(0.005)\end{array}$ & $\begin{array}{c}0.001 \\
(0.008)\end{array}$ & $\begin{array}{l}-0.004 \\
(0.007)\end{array}$ & $\begin{array}{c}0.001 \\
(0.007)\end{array}$ & $\begin{array}{l}-0.002 \\
(0.010)\end{array}$ & $\begin{array}{c}0.007 \\
(0.004)\end{array}$ \\
\hline $\begin{array}{l}\text { Treatment group } \\
\text { standard deviation }\end{array}$ & & & & 0.532 & 3082.823 & 5184.061 & 5015.812 & 3292.372 & \\
\hline $\begin{array}{l}\text { Control group } \\
\text { standard deviation }\end{array}$ & & & & 0.539 & 2321.344 & 1753.038 & 1711.938 & 2783.683 & \\
\hline $\begin{array}{l}\text { p-value for test of } \\
\text { equality of standard } \\
\text { deviations }\end{array}$ & & & & 0.233 & 0.000 & 0.000 & 0.233 & 0.723 & \\
\hline Significant adjusted? & & & & No & Yes & Yes & No & No & \\
\hline $\begin{array}{l}\text { p-value for test of } \\
\text { equality of standard } \\
\text { deviations - panel only }\end{array}$ & & & & 0.809 & 0.032 & 0.003 & 0.298 & 0.066 & \\
\hline Significant adjusted? & & & & No & Yes & Yes & No & No & \\
\hline $\begin{array}{l}\mathrm{p} \text {-value for test of } \\
\text { equality of variance }\end{array}$ & & & & & & & & & \\
\hline for residuals, SES & & & & 0.900 & 0.000 & 0.000 & 0.006 & 0.015 & \\
\hline Significant adjusted? & & & & No & Yes & Yes & Yes & Yes & \\
\hline $\begin{array}{l}\text { p-value for test of } \\
\text { equality of variance } \\
\text { for residuals, SES + } \\
\text { preferences } \\
\text { Significant adjusted? }\end{array}$ & & & & $\begin{array}{c}0.954 \\
\text { No }\end{array}$ & $\begin{array}{c}0.000 \\
\text { Yes }\end{array}$ & $\begin{array}{c}0.000 \\
\text { Yes }\end{array}$ & $\begin{array}{c}0.001 \\
\text { Yes }\end{array}$ & $\begin{array}{c}0.013 \\
\text { Yes }\end{array}$ & \\
\hline \multicolumn{10}{|c|}{ Panel B: Likelihood of increase from baseline (logit, panel sample) } \\
\hline Treatment & $\begin{array}{l}-0.016 \\
(0.018)\end{array}$ & $\begin{array}{l}-0.017 \\
(0.019)\end{array}$ & $\begin{array}{l}0.016^{*} \\
(0.009)\end{array}$ & $\begin{array}{l}0.070 * * \\
(0.031)\end{array}$ & $\begin{array}{l}-0.002 \\
(0.044)\end{array}$ & $\begin{array}{c}0.088 \\
(0.057)\end{array}$ & $\begin{array}{l}-0.018 \\
(0.054)\end{array}$ & $\begin{array}{c}0.058 \\
(0.037)\end{array}$ & \\
\hline Significant adjusted? & & & & No & No & No & No & No & \\
\hline $\begin{array}{l}\text { Mean in the control } \\
\text { group }\end{array}$ & 0.133 & 0.143 & 0.040 & 0.184 & 0.540 & 0.394 & 0.502 & 0.489 & \\
\hline \multicolumn{10}{|c|}{ Panel C: Likelihood of decrease from baseline (logit, panel sample) } \\
\hline Treatment & $\begin{array}{c}0.004 \\
(0.016)\end{array}$ & & $\begin{array}{c}0.001 \\
(0.006)\end{array}$ & $\begin{array}{c}0.019 \\
(0.041)\end{array}$ & $\begin{array}{l}-0.023 \\
(0.044)\end{array}$ & $\begin{array}{l}-0.039 \\
(0.045)\end{array}$ & $\begin{array}{c}0.006 \\
(0.061)\end{array}$ & $\begin{array}{l}-0.048 \\
(0.037)\end{array}$ & \\
\hline Significant adjusted? & & & & No & No & No & No & No & \\
\hline Mean in the control & 0.098 & 1823 & $\begin{array}{r}0.021 \\
1820\end{array}$ & $\begin{array}{c}0.156 \\
498\end{array}$ & $\begin{array}{c}0.352 \\
445\end{array}$ & $\begin{array}{c}0.329 \\
454\end{array}$ & $\begin{array}{c}0.375 \\
430\end{array}$ & 0.375 & \\
\hline
\end{tabular}

Specification: Standard errors, clustered by 238 geographic clusters (the unit of randomization), are in parentheses. Treatment effect on likelihood non-zero shows probit marginal effects with standard errors below; panels B and C report logit marginal effects. Controls for randomization strata (i.e. 45 supercluster fixed effects and 3 branches) are included but not shown. Controls for the baseline value of the outcome (its value, and missing/non-missing value) are included when the outcome was measured in the baseline. To account for multiple hypothesis testing, we adjust critical levels following the approach by Benjamini and Hochberg. The significance of each coefficient following this adjustment (if applied) is shown in Panel A. If a control was added for the baseline value of the outcome, any missing values for the baseline observation of the outcome were coded as zero and a variable was added that is equal to one if the baseline value is missing and zero otherwise.

Outcome(s): Business profits (column 7) are calculated by substracting responses for expenses from responses for revenues of the businesses. Income in column 8 is calculated from a question asking an explicit, all-in question about household income from business or productive activity. Sample sizes are lower in columns 4-8 of Panels B and C because, having found no effect on transitions into business ownership in columns 1 and 2 , we select only business owners in columns $4-8$. The adjusted critical values were calculated by treating columns 4-8 as an outcome family. 
Table 5: Average Intent-to-Treat Effects on Household Consumption and Expenditures

\begin{tabular}{|c|c|c|c|c|c|c|c|c|c|c|}
\hline \multirow[b]{2}{*}{ Outcome: } & \multicolumn{2}{|c|}{ Use of loan proceeds } & \multirow{2}{*}{$\begin{array}{c}\text { Last week } \\
\\
\text { Amount spent } \\
\text { on temptation } \\
\text { goods }\end{array}$} & \multirow{2}{*}{$\begin{array}{c}\text { Last } 2 \text { weeks } \\
\\
\text { Amount spent } \\
\text { on groceries }\end{array}$} & \multirow{2}{*}{$\begin{array}{c}\text { Last } 30 \text { days } \\
\\
\text { Nights did not } \\
\text { go hungry }\end{array}$} & \multicolumn{2}{|c|}{ Last year } & \multicolumn{3}{|c|}{ Last 2 years } \\
\hline & $\begin{array}{c}\text { Did not sell } \\
\text { an asset to } \\
\text { help pay for a } \\
\text { loan }\end{array}$ & $\begin{array}{l}\text { Used a loan to } \\
\text { buy any asset }\end{array}$ & & & & $\begin{array}{l}\text { Amount spent } \\
\text { on school and } \\
\text { medical } \\
\text { expenses } \\
\end{array}$ & $\begin{array}{c}\text { Amount spent } \\
\text { on family } \\
\text { events }\end{array}$ & $\begin{array}{c}\text { Asset } \\
\text { categories } \\
\text { bought item } \\
\text { from } \\
\end{array}$ & $\begin{array}{c}\text { Did not sell } \\
\text { an asset }\end{array}$ & $\begin{array}{l}\text { Made home } \\
\text { improvement }\end{array}$ \\
\hline & (1) & (2) & (3) & (4) & (5) & (6) & (7) & $(8)$ & (9) & $(10)$ \\
\hline \multicolumn{11}{|c|}{ Panel A: Average intent-to-treat effects (OLS, full sample) } \\
\hline Treatment & $\begin{array}{c}0.010^{* *} \\
(0.004)\end{array}$ & $\begin{array}{c}-0.004 \\
(0.008)\end{array}$ & $\begin{array}{c}-5.857 * * \\
(2.704)\end{array}$ & $\begin{array}{c}-1.179 \\
(29.257)\end{array}$ & $\begin{array}{c}0.053 \\
(0.065)\end{array}$ & $\begin{array}{c}863.846 \\
(852.120)\end{array}$ & $\begin{array}{c}-29.8 \\
(89.766)\end{array}$ & $\begin{array}{c}-0.049 * * \\
(0.022)\end{array}$ & $\begin{array}{c}0.007 \\
(0.007)\end{array}$ & $\begin{array}{l}-0.014 \\
(0.010)\end{array}$ \\
\hline $\begin{array}{l}\text { Baseline value } \\
\text { controlled for }\end{array}$ & No & No & No & No & No & No & No & No & No & No \\
\hline Adjusted R-squared & 0.002 & 0.007 & 0.009 & 0.026 & 0.008 & -0.001 & 0.001 & 0.011 & 0.006 & 0.007 \\
\hline $\mathrm{N}$ & 16552 & 16534 & 16164 & 16201 & 16429 & 16413 & 16373 & 16494 & 16483 & 16507 \\
\hline Number missing & 8 & 26 & 396 & 359 & 131 & 147 & 187 & 66 & 77 & 53 \\
\hline Unadjusted p-value & 0.011 & 0.566 & 0.031 & 0.968 & 0.415 & 0.312 & 0.740 & 0.030 & 0.330 & 0.181 \\
\hline Significant adjusted? & & & No & No & No & No & No & No & No & No \\
\hline Control group mean & 0.951 & 0.171 & 99.463 & 1683.656 & 29.2 & 3475.976 & 870.874 & 0.505 & 0.862 & 0.377 \\
\hline$\%=0$ in control & 4.907 & 82.894 & 21.519 & 1.133 & 0.498 & 29.242 & 88.237 & 64.898 & 13.792 & 62.334 \\
\hline $\begin{array}{l}\text { Treatment effect on } \\
\text { likelihood non-zero }\end{array}$ & $\begin{array}{c}0.009 * * * \\
(0.004)\end{array}$ & $\begin{array}{l}-0.004 \\
(0.008)\end{array}$ & $\begin{array}{l}-0.003 \\
(0.009)\end{array}$ & $\begin{array}{l}-0.002 \\
(0.003)\end{array}$ & $\begin{array}{l}0.002 * \\
(0.001)\end{array}$ & $\begin{array}{l}-0.006 \\
(0.010)\end{array}$ & $\begin{array}{l}-0.000 \\
(0.006)\end{array}$ & $\begin{array}{c}-0.027 * * \\
(0.012)\end{array}$ & $\begin{array}{c}0.006 \\
(0.007)\end{array}$ & $\begin{array}{l}-0.014 \\
(0.010)\end{array}$ \\
\hline $\begin{array}{l}\text { Treatment group } \\
\text { standard deviation }\end{array}$ & & & 126.696 & 1195.798 & 2.890 & 55084.963 & 5018.143 & 0.764 & & \\
\hline $\begin{array}{l}\text { Control group } \\
\text { standard deviation }\end{array}$ & & & 126.886 & 1034.827 & 3.177 & 14780.896 & 5762.358 & 0.801 & & \\
\hline $\begin{array}{l}\text { p-value for test of } \\
\text { equality of standard } \\
\text { deviations }\end{array}$ & & & 0.992 & 0.014 & 0.029 & 0.047 & 0.764 & 0.001 & & \\
\hline Significant adjusted? & & & No & Yes & Yes & Yes & No & Yes & & \\
\hline $\begin{array}{l}\text { p-value for test of } \\
\text { equality of standard }\end{array}$ & & & & & & & & & & \\
\hline deviations - panel only & & & 0.893 & 0.258 & 0.047 & 0.101 & 0.017 & 0.001 & & \\
\hline Significant adjusted? & & & No & No & Yes & No & Yes & Yes & & \\
\hline $\begin{array}{l}\text { p-value for test of } \\
\text { equality of variance }\end{array}$ & & & & & & & & & & \\
\hline for residuals, SES & & & 0.907 & 0.591 & 0.133 & 0.119 & 0.022 & 0.000 & & \\
\hline Significant adjusted? & & & No & No & No & No & Yes & Yes & & \\
\hline $\begin{array}{l}\text { p-value for test of } \\
\text { equality of variance } \\
\text { for residuals, SES + } \\
\text { preferences } \\
\text { Significant adjusted? }\end{array}$ & & & $\begin{array}{c}0.864 \\
\text { No }\end{array}$ & $\begin{array}{l}0.620 \\
\text { No }\end{array}$ & $\begin{array}{l}0.120 \\
\text { No }\end{array}$ & $\begin{array}{l}0.150 \\
\text { No }\end{array}$ & $\begin{array}{c}0.022 \\
\text { Yes }\end{array}$ & $\begin{array}{c}0.000 \\
\text { Yes }\end{array}$ & & \\
\hline
\end{tabular}

$* \mathrm{p}<0.10, * * \mathrm{p}<0.05, * * * \mathrm{p}<.01$

Specification: Standard errors, clustered by 238 geographic clusters (the unit of randomization), are in parentheses. Treatment effect on likelihood non-zero shows probit marginal effects with standard errors below. Controls for randomization strata (i.e. 45 supercluster fixed effects and 3 branches) are included but not shown. Controls for the baseline value of the outcome (its value, and missing/non-missing value) are included when the outcome was measured in the baseline. To account for multiple hypothesis testing, we adjust critical levels following the approach by Benjamini and Hochberg. The significance of each coefficient following this adjustment (if applied) is shown in Panel A.

Outcome(s): All amounts are in pesos. Responses in dollars were converted at a rate of 12 pesos per dollar. Column 3 includes cigarettes, sweets, and soda. Column 7 refers to important events such as weddings, baptisms, birthdays, graduations, or funerals. The survey instrument did not include details about the value of assets bought and sold unless they were bought or sold in relation to a loan. Consequently, we report the count of assets in column 8 instead of their value. The adjusted critical values were calculated by treating outcomes in columns 3-10 as one outcome family. 
Table 6: Average Intent-to-Treat Effects on Household Income and Savings

\begin{tabular}{|c|c|c|c|c|c|}
\hline \multirow[b]{2}{*}{ Outcome: } & \multicolumn{3}{|c|}{ Last 30 days } & \multicolumn{2}{|c|}{ Last 6 months } \\
\hline & Total income & $\begin{array}{c}\text { Income from } \\
\text { salaried and } \\
\text { non-salaried } \\
\text { jobs }\end{array}$ & $\begin{array}{l}\text { Participated in } \\
\text { an economic } \\
\text { activity }\end{array}$ & $\begin{array}{l}\text { Amount of } \\
\text { remittances } \\
\text { received }\end{array}$ & $\begin{array}{l}\text { Income } \\
\text { greater than or } \\
\text { equal to } \\
\text { expenses }\end{array}$ \\
\hline & (1) & (2) & (3) & (4) & $(5)$ \\
\hline \multicolumn{6}{|c|}{ Panel A: Average intent-to-treat effects (OLS, full sample) } \\
\hline Treatment & $\begin{array}{c}26.062 \\
(156.972)\end{array}$ & $\begin{array}{c}-29.791 \\
(127.732)\end{array}$ & $\begin{array}{l}-0.011 \\
(0.009)\end{array}$ & $\begin{array}{l}-26.152 \\
(34.934)\end{array}$ & $\begin{array}{c}0.01 \\
(0.009)\end{array}$ \\
\hline $\begin{array}{l}\text { Baseline value } \\
\text { controlled for }\end{array}$ & Yes & No & No & Yes & No \\
\hline Adjusted R-squared & 0.019 & 0.01 & 0.008 & 0.002 & 0.004 \\
\hline $\mathrm{N}$ & 15240 & 16155 & 16560 & 16368 & 16426 \\
\hline Number missing & 1320 & 405 & 0 & 192 & 134 \\
\hline Unadjusted p-value & 0.868 & 0.816 & 0.252 & 0.455 & 0.255 \\
\hline Significant adjusted? & No & No & No & No & No \\
\hline Control group mean & 6176.089 & 4540.709 & 0.478 & 198.35 & 0.385 \\
\hline$\%=0$ in control & 1.216 & 17.928 & 52.217 & 96.056 & 61.549 \\
\hline $\begin{array}{l}\text { Treatment effect on } \\
\text { likelihood non-zero }\end{array}$ & $\begin{array}{l}-0.001 \\
(0.002)\end{array}$ & $\begin{array}{l}-0.009 \\
(0.008)\end{array}$ & $\begin{array}{l}-0.011 \\
(0.010)\end{array}$ & $\begin{array}{c}0.002 \\
(0.004)\end{array}$ & $\begin{array}{c}0.010 \\
(0.009)\end{array}$ \\
\hline $\begin{array}{l}\text { Treatment group } \\
\text { standard deviation }\end{array}$ & 6428.145 & 5268.009 & & 1579.322 & \\
\hline $\begin{array}{l}\text { Control group } \\
\text { standard deviation }\end{array}$ & 6034.154 & 5115.035 & & 2067.668 & \\
\hline $\begin{array}{l}\text { p-value for test of } \\
\text { equality of standard } \\
\text { deviations }\end{array}$ & 0.638 & 0.285 & & 0.032 & \\
\hline Significant adjusted? & No & No & & Yes & \\
\hline \multicolumn{6}{|l|}{$\begin{array}{l}\text { p-value for test of } \\
\text { equality of standard }\end{array}$} \\
\hline deviations - panel only & 0.728 & 0.684 & & 0.020 & \\
\hline Significant adjusted? & No & No & & Yes & \\
\hline \multicolumn{6}{|l|}{$\begin{array}{l}\text { p-value for test of } \\
\text { equality of variance }\end{array}$} \\
\hline for residuals, SES & 0.858 & 0.912 & & 0.042 & \\
\hline Significant adjusted? & No & No & & No & \\
\hline $\begin{array}{l}\text { p-value for test of } \\
\text { equality of variance } \\
\text { for residuals, SES + } \\
\text { preferences }\end{array}$ & 0.720 & 0.770 & & 0.052 & \\
\hline Significant adjusted? & No & No & & No & \\
\hline \multicolumn{6}{|c|}{ Panel B: Likelihood of increase from baseline (logit, panel sample) } \\
\hline Treatment & $\begin{array}{l}-0.012 \\
(0.027)\end{array}$ & & & $\begin{array}{l}0.017 * \\
(0.010)\end{array}$ & \\
\hline Significant adjusted? & No & & & No & \\
\hline $\begin{array}{l}\text { Mean in the control } \\
\text { group }\end{array}$ & 0.626 & & & 0.027 & \\
\hline \multicolumn{6}{|c|}{ Panel C: Likelihood of decrease from baseline (logit, panel sample) } \\
\hline Treatment & $\begin{array}{c}0.019 \\
(0.030)\end{array}$ & & & $\begin{array}{c}0.009 \\
(0.010)\end{array}$ & \\
\hline Significant adjusted? & No & & & No & \\
\hline $\begin{array}{l}\text { Mean in the control } \\
\text { group }\end{array}$ & 0.339 & & & 0.049 & \\
\hline $\mathrm{N}$ for panels B \& $\mathrm{C}$ & 1679 & & & 1800 & \\
\hline
\end{tabular}

Specification: Standard errors, clustered by 238 geographic clusters (the unit of randomization), are in parentheses. Treatment effect on likelihood non-zero shows probit marginal effects with standard errors below; panels B and C report logit marginal effects. Controls for randomization strata (i.e. 45 supercluster fixed effects and 3 branches) are included but not shown. Controls for the baseline value of the outcome (its value, and missing/non-missing value) are included when the outcome was measured in the baseline. To account for multiple hypothesis testing, we adjust critical levels following the approach by Benjamini and Hochberg. The significance of each coefficient following this adjustment (if applied) is shown in Panel A. If a control was added for the baseline value of the outcome, any missing values for the baseline observation of the outcome were coded as zero and a variable was added that is equal to one if the baseline value is missing and zero otherwise.

Outcome(s): Anyone reporting having a job or a business is classified as participating in an economic activity (column 3 ). For column 5 , anyone reporting having income greater than expenses, less purchase of a house or a car or a big investment or debt, in the last 6 months is coded as a 1. The adjusted critical values were calculated by treating all outcomes in the table as one outcome family. 


\begin{tabular}{|c|c|c|c|c|c|c|c|c|c|c|c|c|}
\hline \multirow{3}{*}{ Outcome: } & \multicolumn{8}{|c|}{ Subjective well-being } & \multirow{2}{*}{$\begin{array}{c}\text { Child welfare } \\
\\
\text { Fraction of } \\
\text { children 4-17 } \\
\text { not working }\end{array}$} & \multicolumn{3}{|c|}{ Intra-household decision power } \\
\hline & $\begin{array}{l}\text { Depression } \\
\text { index (higher } \\
\text { = happier) }\end{array}$ & $\begin{array}{l}\text { Job stress } \\
\text { index (higher } \\
=\text { less stress) }\end{array}$ & $\begin{array}{c}\text { Locus of } \\
\text { control index }\end{array}$ & $\begin{array}{l}\text { Trust in } \\
\text { institutions } \\
\text { index }\end{array}$ & $\begin{array}{c}\text { Trust in } \\
\text { people index }\end{array}$ & $\begin{array}{l}\text { Satisfaction } \\
\text { (life and } \\
\text { harmony) } \\
\text { index }\end{array}$ & $\begin{array}{l}\text { Satisfied with } \\
\text { economic } \\
\text { situation }\end{array}$ & $\begin{array}{l}\text { Good health } \\
\text { status }\end{array}$ & & $\begin{array}{c}\text { Participates in } \\
\text { any financial } \\
\text { decisions }\end{array}$ & $\begin{array}{c}\text { \# of } \\
\text { household } \\
\text { issues she has } \\
\text { a say on }\end{array}$ & $\begin{array}{c}\text { \# of } \\
\text { household } \\
\text { issues in } \\
\text { which conflict } \\
\text { arises }\end{array}$ \\
\hline & $(1)$ & $(2)$ & $(3)$ & $(4)$ & $(5)$ & $(6)$ & $(7)$ & $(8)$ & $(9)$ & $(10)$ & $(11)$ & $(12)$ \\
\hline \multicolumn{13}{|c|}{ Panel A: Average intent-to-treat effects (OLS, full sample) } \\
\hline Treatment & $\begin{array}{l}0.045^{*} \\
(0.024)\end{array}$ & $\begin{array}{l}-0.004 \\
(0.025)\end{array}$ & $\begin{array}{c}0.003 \\
(0.024)\end{array}$ & $\begin{array}{l}-0.011 \\
(0.025)\end{array}$ & $\begin{array}{l}0.049 * \\
(0.027)\end{array}$ & $\begin{array}{c}0.017 \\
(0.024)\end{array}$ & $\begin{array}{l}-0.009 \\
(0.011)\end{array}$ & $\begin{array}{c}0.012 \\
(0.008)\end{array}$ & $\begin{array}{c}0.007 \\
(0.006)\end{array}$ & $\begin{array}{c}0.008 * * * \\
(0.003)\end{array}$ & $\begin{array}{l}0.071 * * \\
(0.030)\end{array}$ & $\begin{array}{c}0.023 \\
(0.033)\end{array}$ \\
\hline $\begin{array}{l}\text { Baseline value } \\
\text { controlled for }\end{array}$ & Yes & No & No & No & No & No & No & Yes & Yes & No & No & No \\
\hline Adjusted R-squared & 0.031 & 0.004 & 0.009 & 0.009 & 0.027 & 0.009 & 0.007 & 0.025 & 0.013 & 0.001 & 0.01 & 0.016 \\
\hline $\mathrm{N}$ & 16336 & 7656 & 16549 & 16530 & 16558 & 16553 & 16526 & 16556 & 12305 & 12183 & 12379 & 12400 \\
\hline Number missing & 224 & 8904 & 11 & 30 & 2 & 7 & 34 & 4 & 4255 & 4377 & 4181 & 4160 \\
\hline Unadjusted p-value & 0.059 & 0.870 & 0.915 & 0.653 & 0.067 & 0.473 & 0.418 & 0.125 & 0.236 & 0.009 & 0.020 & 0.479 \\
\hline Significant adjusted? & & & & & & & & & & Yes & Yes & No \\
\hline Control group mean & 0 & 0 & 0 & 0 & 0 & 0 & 0.458 & 0.779 & 0.915 & 0.975 & 2.78 & 1.525 \\
\hline$\%=0$ in control & 0 & 0 & 0 & 0 & 0 & 0 & 54.239 & 22.061 & 5.896 & 2.503 & 9.252 & 35.043 \\
\hline $\begin{array}{l}\text { Treatment effect on } \\
\text { likelihood non-zero }\end{array}$ & & & & & & & $\begin{array}{l}-0.009 \\
(0.011)\end{array}$ & $\begin{array}{c}0.012 \\
(0.008)\end{array}$ & $\begin{array}{c}0.002 \\
(0.005)\end{array}$ & $\begin{array}{c}0.007 * * * \\
(0.003)\end{array}$ & $\begin{array}{c}0.007 \\
(0.006)\end{array}$ & $\begin{array}{c}0.004 \\
(0.012)\end{array}$ \\
\hline $\begin{array}{l}\text { Treatment group } \\
\text { standard deviation }\end{array}$ & 0.973 & 1.019 & 0.996 & 1.007 & 0.985 & 0.999 & & & 0.245 & & 1.312 & 1.421 \\
\hline $\begin{array}{l}\text { Control group } \\
\text { standard deviation }\end{array}$ & 1.000 & 1.000 & 1.000 & 1.000 & 1.000 & 1.000 & & & 0.254 & & 1.336 & 1.415 \\
\hline $\begin{array}{l}\text { p-value for test of } \\
\text { equality of standard } \\
\text { deviations } \\
\text { Significant adjusted? }\end{array}$ & 0.032 & 0.259 & 0.447 & 0.242 & 0.299 & 0.959 & & & 0.013 & & $\begin{array}{c}0.016 \\
\text { Yes }\end{array}$ & $\begin{array}{c}0.826 \\
\text { No }\end{array}$ \\
\hline $\begin{array}{l}\text { p-value for test of } \\
\text { equality of standard }\end{array}$ & & & & & & & & & & & & \\
\hline $\begin{array}{l}\text { deviations - panel only } \\
\text { Significant adjusted? }\end{array}$ & 0.326 & 0.467 & 0.149 & 0.067 & 0.108 & 0.647 & & & 0.632 & & $\begin{array}{l}0.833 \\
\text { No }\end{array}$ & $\begin{array}{c}0.191 \\
\text { No }\end{array}$ \\
\hline $\begin{array}{l}\text { p-value for test of } \\
\text { equality of variance }\end{array}$ & & & & & & & & & & & & \\
\hline $\begin{array}{l}\text { for residuals, SES } \\
\text { Significant adjusted? }\end{array}$ & 0.464 & 0.325 & 0.307 & 0.054 & 0.147 & 0.234 & & & 0.848 & & $\begin{array}{l}0.701 \\
\text { No }\end{array}$ & $\begin{array}{l}0.188 \\
\text { No }\end{array}$ \\
\hline $\begin{array}{l}\text { p-value for test of } \\
\text { equality of variance } \\
\text { for residuals, SES + } \\
\text { preferences } \\
\text { Significant adjusted? }\end{array}$ & 0.492 & 0.668 & 0.356 & 0.057 & 0.134 & 0.184 & & & 0.853 & & $\begin{array}{c}0.649 \\
\text { No }\end{array}$ & $\begin{array}{c}0.298 \\
\text { No }\end{array}$ \\
\hline \multicolumn{13}{|c|}{ Panel B: Likelihood of increase from baseline (logit, panel sample) } \\
\hline Treatment & $\begin{array}{c}0.014 \\
(0.031)\end{array}$ & & & & & & & $\begin{array}{l}0.026^{*} \\
(0.015)\end{array}$ & $\begin{array}{c}0.014 \\
(0.020)\end{array}$ & & & \\
\hline $\begin{array}{l}\text { Mean in the control } \\
\text { group }\end{array}$ & 0.535 & & & & & & & 0.112 & 0.871 & & & \\
\hline \multicolumn{13}{|c|}{ Panel C: Likelihood of decrease from baseline (logit, panel sample) } \\
\hline Treatment & $\begin{array}{l}-0.014 \\
(0.031)\end{array}$ & & & & & & & $\begin{array}{l}-0.007 \\
(0.015)\end{array}$ & $\begin{array}{l}-0.004 \\
(0.006)\end{array}$ & & & \\
\hline $\begin{array}{l}\text { Mean in the control } \\
\text { group } \\
\mathrm{N} \text { for panels } \mathrm{B} \& \mathrm{C}\end{array}$ & $\begin{array}{c}0.465 \\
1800\end{array}$ & & & & & & & $\begin{array}{l}0.092 \\
1823\end{array}$ & $\begin{array}{c}0.024 \\
1369\end{array}$ & & & \\
\hline
\end{tabular}

$* \mathrm{p}<0.10, * * \mathrm{p}<0.05, * * * \mathrm{p}<.01$

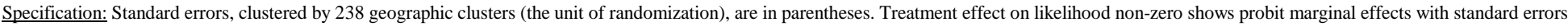

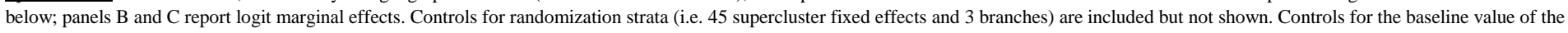

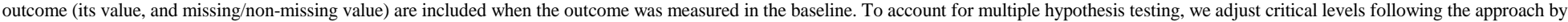

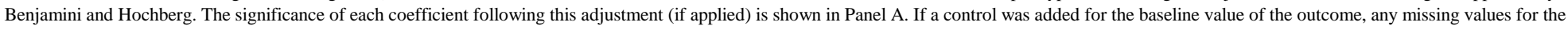
baseline observation of the outcome were coded as zero and a variable was added that is equal to one if the baseline value is missing and zero otherwise.

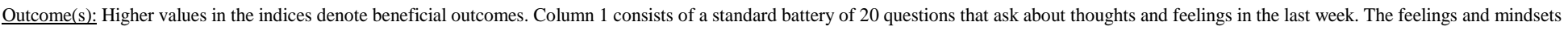

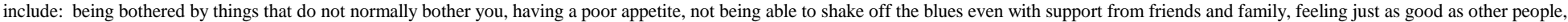

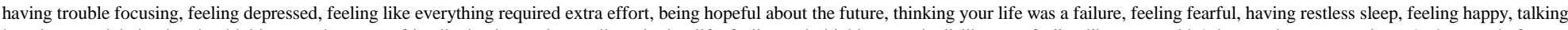

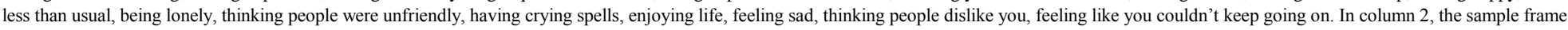

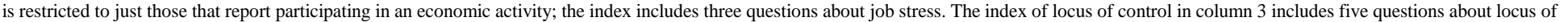

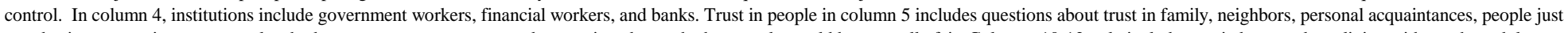

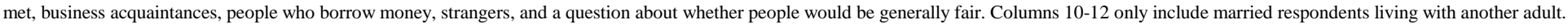




\begin{tabular}{|c|c|c|c|c|c|c|c|c|c|c|c|c|c|}
\hline \multirow[t]{3}{*}{ Outcome area } & & \multicolumn{2}{|c|}{$\begin{array}{c}\text { Measures of Credit } \\
\text { and Other Financial } \\
\text { Services }\end{array}$} & \multicolumn{2}{|c|}{$\frac{\text { Business }}{(9 \text { outcomes })}$} & \multicolumn{2}{|c|}{$\begin{array}{c}\begin{array}{c}\text { Income and } \\
\text { Consumption }\end{array} \\
\text { (14 outcomes) }\end{array}$} & \multicolumn{2}{|c|}{$\begin{array}{l}\text { Other Welfare } \\
\text { (11 outcomes) }\end{array}$} & \multicolumn{2}{|c|}{ Total } & \multicolumn{2}{|c|}{$\begin{array}{c}\begin{array}{c}\text { Significantly different } \\
\text { effects on outcomes }\end{array} \\
\text { (34 outcomes) }\end{array}$} \\
\hline & \multirow[b]{2}{*}{ Sample } & (1) & (2) & (3) & (4) & (5) & (6) & (7) & $(8)$ & (9) & (10) & (11) & (12) \\
\hline & & + & - & + & - & + & - & + & - & + & - & Total & $\mathrm{A}>\mathrm{B}$ \\
\hline A. Full sample & & 4 & 1 & 3 & 0 & 1 & 0 & 4 & 0 & 8 & 0 & \multirow{2}{*}{2} & \multirow{2}{*}{2} \\
\hline B. Panel sample & & 2 & 0 & 0 & 0 & 0 & 0 & 1 & 1 & 1 & 1 & & \\
\hline A. Prior business owner & Full & 3 & 1 & 5 & 0 & 1 & 0 & 2 & 0 & 8 & 0 & \multirow{2}{*}{6} & \multirow{2}{*}{6} \\
\hline B. Not a prior business owner & Full & 4 & 0 & 0 & 0 & 1 & 0 & 3 & 0 & 4 & 0 & & \\
\hline A. Education > Primary & Full & 4 & 0 & 3 & 0 & 1 & 0 & 3 & 0 & 7 & 0 & \multirow{2}{*}{2} & \multirow{2}{*}{1} \\
\hline B. Education $<=$ Primary & Full & 3 & 1 & 0 & 0 & 0 & 0 & 0 & 0 & 0 & 0 & & \\
\hline A. In rural area & Full & 3 & 0 & 5 & 0 & 0 & 0 & 1 & 0 & 6 & 0 & \multirow{2}{*}{7} & \multirow{2}{*}{5} \\
\hline B. In urban area & Full & 4 & 1 & 1 & 1 & 1 & 1 & 4 & 0 & 6 & 2 & & \\
\hline A. Above median $\mathrm{HH}$ income per adult & Panel & 0 & 0 & 0 & 1 & 0 & 0 & 1 & 1 & 1 & 2 & \multirow{2}{*}{2} & \multirow{2}{*}{1} \\
\hline B. Below median $\mathrm{HH}$ income per adult & Panel & 2 & 1 & 0 & 2 & 0 & 0 & 1 & 3 & 1 & 5 & & \\
\hline A. Formal prior credit experience & Panel & 0 & 0 & 1 & 0 & 0 & 1 & 2 & 0 & 3 & 1 & \multirow{2}{*}{6} & \multirow{2}{*}{5} \\
\hline B. No formal credit experience & Panel & 2 & 0 & 0 & 0 & 0 & 0 & 1 & 4 & 1 & 4 & & \\
\hline A. Formal account experience & Panel & 0 & 0 & 0 & 1 & 1 & 0 & 1 & 2 & 2 & 3 & \multirow{2}{*}{4} & \multirow{2}{*}{1} \\
\hline B. No formal account experience & Panel & 2 & 0 & 0 & 0 & 0 & 0 & 1 & 1 & 1 & 1 & & \\
\hline \multirow[t]{2}{*}{ A. Member of informal savings group } & Panel & 0 & 0 & 0 & 3 & 0 & 0 & 2 & 1 & 2 & 4 & \multirow{3}{*}{7} & \multirow{3}{*}{3} \\
\hline & & & & & & & & & & & & & \\
\hline B. Not member of informal savings group & Panel & 2 & 0 & 4 & 0 & 0 & 1 & 0 & 2 & 4 & 3 & & \\
\hline A. Risk tolerant & Panel & 2 & 0 & 0 & 0 & 0 & 0 & 2 & 1 & 2 & 1 & \multirow{2}{*}{3} & \multirow{2}{*}{2} \\
\hline B. Risk intolerant & Panel & 0 & 0 & 0 & 0 & 0 & 0 & 1 & 2 & 1 & 2 & & \\
\hline A. Patient now & Panel & 2 & 0 & 0 & 0 & 0 & 0 & 1 & 2 & 1 & 2 & 3 & 2 \\
\hline B. Impatient now & Panel & 2 & 0 & 0 & 0 & 0 & 2 & 1 & 0 & 1 & 2 & 3 & 2 \\
\hline A. Present biased & Panel & 1 & 0 & 0 & 0 & 0 & 0 & 0 & 0 & 0 & 0 & 0 & 0 \\
\hline B. Not present biased & Panel & 2 & 0 & 0 & 0 & 0 & 0 & 0 & 1 & 0 & 1 & 0 & 0 \\
\hline
\end{tabular}

The table summarizes the results presented in Figures 6-15 using adjusted p-values. Each cell is a count of treatment effects that are significant with 90\% confidence using adjusted critical levels following the approach by Benjamini and Hochberg. If asset sales and purchases both fall, we count the overall effect as positive. Measurements of Credit and Other Financial Services are excluded from the total columns. Consumption of temptation goods and the \# of disagreements in which a conflict arises are excluded from all counts. The sample column indicates which sample frame of respondents is included in the estimation. We use the full sample for examining heterogeneous effects we can identify using variables in the endline assumed to be static over the treatment period or that are retrospective. We use the panel sample for examining heterogeneous effects we can identify using variables in the baseline survey. The final column shows the number of treatment effects that are significantly different between the two groups with $90 \%$ confidence. 


\begin{tabular}{|c|c|c|c|c|c|c|c|c|c|c|}
\hline \multirow[t]{2}{*}{ Outcome area: } & \multicolumn{2}{|c|}{$\begin{array}{c}\text { Credit \& Other } \\
\text { Financial Services }\end{array}$} & \multicolumn{2}{|c|}{$\frac{\text { Business }}{\text { (9 Outcomes) }}$} & \multicolumn{2}{|c|}{$\frac{\text { Income \& Consumption }}{\text { (14 Outcomes) }}$} & \multicolumn{2}{|c|}{$\frac{\text { Other Welfare }}{\text { (11 Outcomes) }}$} & \multicolumn{2}{|c|}{ Total } \\
\hline & $\begin{array}{l}\text { Total } \\
\text { (1) }\end{array}$ & $\begin{array}{l}+ \\
(2)\end{array}$ & $\begin{array}{l}\text { Total } \\
\text { (3) }\end{array}$ & $\begin{array}{c}+ \\
(4) \\
\end{array}$ & $\begin{array}{c}\text { Total } \\
(5)\end{array}$ & $\begin{array}{l}+ \\
(6)\end{array}$ & $\begin{array}{l}\text { Total } \\
(7)\end{array}$ & $\begin{array}{c}+ \\
(8) \\
\end{array}$ & $\begin{array}{l}\text { Total } \\
\text { (9) }\end{array}$ & $\begin{array}{c}+ \\
(10)\end{array}$ \\
\hline \multicolumn{11}{|l|}{ Panel A: Endline Sample } \\
\hline Treatment X Prior business owner & 2 & 2 & 4 & 4 & 2 & 2 & 1 & 1 & 7 & 7 \\
\hline Treatment X Education > Primary & 0 & 0 & 0 & 0 & 1 & 0 & 1 & 1 & 2 & 1 \\
\hline Treatment X In rural area & 0 & 0 & 4 & 3 & 0 & 0 & 1 & 0 & 5 & 3 \\
\hline \multicolumn{11}{|l|}{ Panel B: Panel Sample } \\
\hline Treatment X Prior business owner & 2 & 1 & 1 & 1 & 1 & 1 & 2 & 1 & 4 & 3 \\
\hline Treatment X Education > Primary & 0 & 0 & 0 & 0 & 0 & 0 & 0 & 0 & 0 & 0 \\
\hline Treatment X Above median HH income per adult & 0 & 0 & 1 & 1 & 1 & 0 & 1 & 0 & 3 & 1 \\
\hline Treatment X Formal prior credit experience & 1 & 1 & 0 & 0 & 1 & 0 & 2 & 2 & 3 & 2 \\
\hline Treatment X Formal account experience & 0 & 0 & 0 & 0 & 0 & 0 & 3 & 1 & 3 & 1 \\
\hline Treatment X Member of an informal savings group & 0 & 0 & 3 & 0 & 0 & 0 & 2 & 2 & 5 & 2 \\
\hline Treatment X Risk intolerant & 0 & 0 & 1 & 1 & 0 & 0 & 3 & 1 & 4 & 2 \\
\hline Treatment X Patient now & 0 & 0 & 0 & 0 & 1 & 1 & 2 & 1 & 3 & 2 \\
\hline Treatment X Present biased & 0 & 0 & 0 & 0 & 0 & 0 & 0 & 0 & 0 & 0 \\
\hline
\end{tabular}

The table reports the number of statistically significant coefficients on interaction terms for each subgroup within a given category of outcomes and sample. The coefficients are from an OLS regression which includes each subgroup shown in the left hand column along with their interaction with treatment and treatment itself on the right hand side with an outcome (e.g. business profits) as the dependent variable. Standard errors are clustered by the unit of randomization. The critical levels are adjusted following the approach by Benjamini and Hochberg. 
Figure 1: Study Timeline and Survey Locations

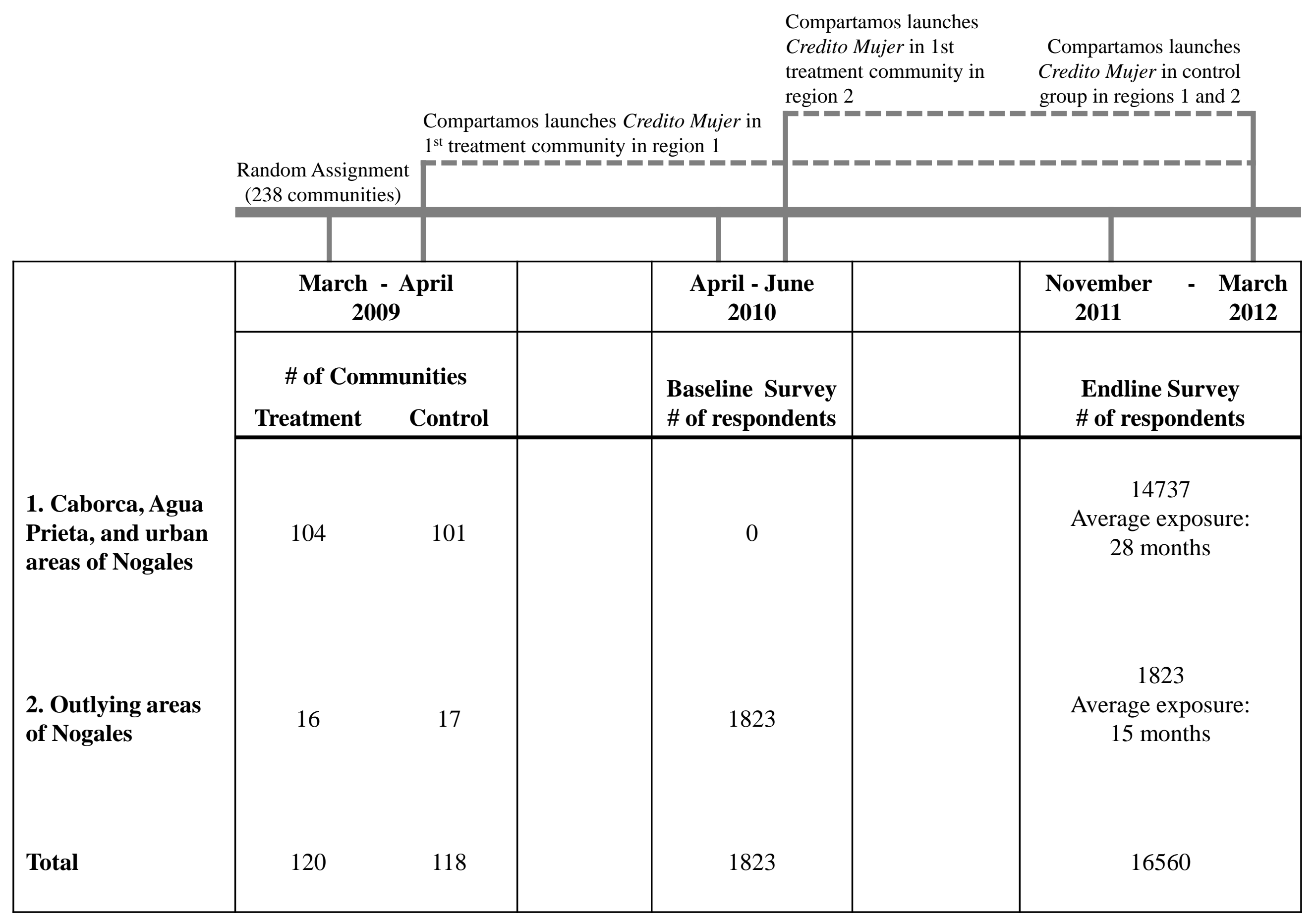


Figure 2: Average Intent-to-Treat Effects for the Full Sample, at a Glance

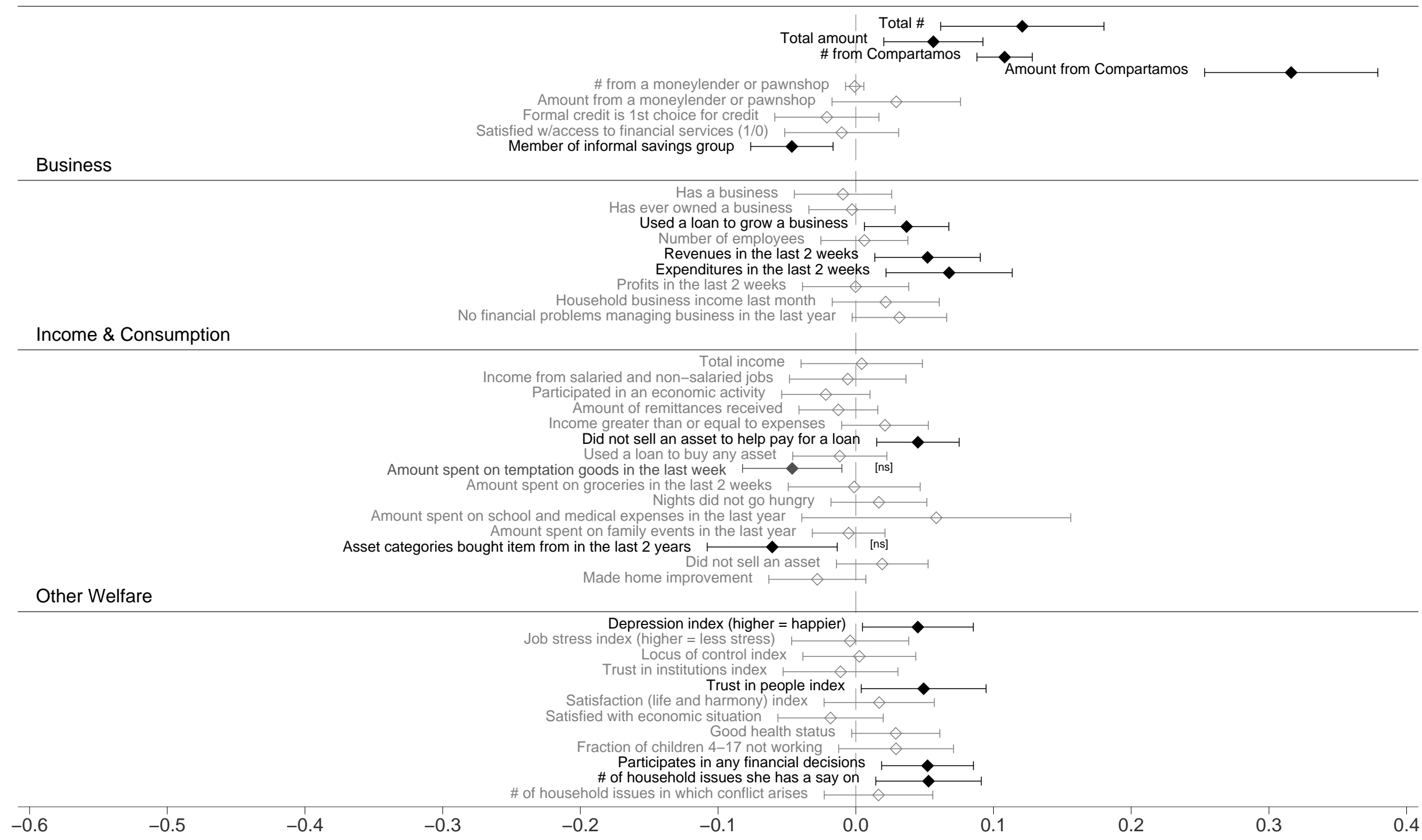

Effect size in standard deviations of the control group or in \# of loans for the borrowing outcomes ("Total \#", "\# from Compartamos" and "\# from a moneylender")

This figure summarizes the treatment effects presented in Tables 3-7. Here treatment effects on continuous variables are presented in standard deviation units or in \# of loans for the borrowing outcomes (Total \#, \# from Compartamos, and \# from a moneylender or pawnshop). Each line shows the OLS point estimate and $90 \%$ confidence interval for that outcome.

For some outcomes, we adjust the critical level following the Benjamini and Hochberg approach. In brackets, we then indicate whether the treatment effect is not significant [ns] at this level if it is significant at the unadjusted level. 
Figure 3: Quantile Treatment Effects for Business Outcomes

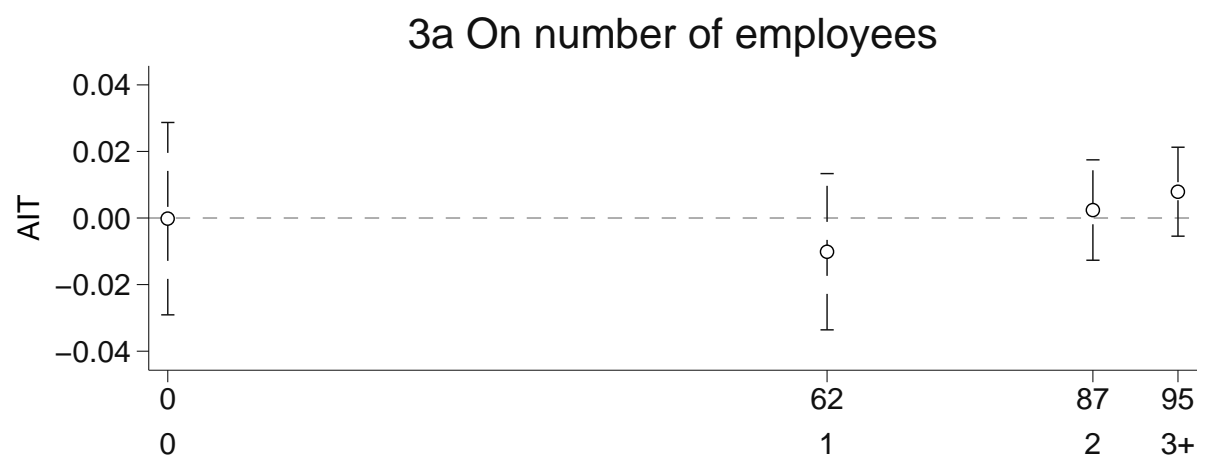

3b On number of employees, only businesses with employees

$3 c$ On revenues in the last 2 weeks

Thousands of pesos
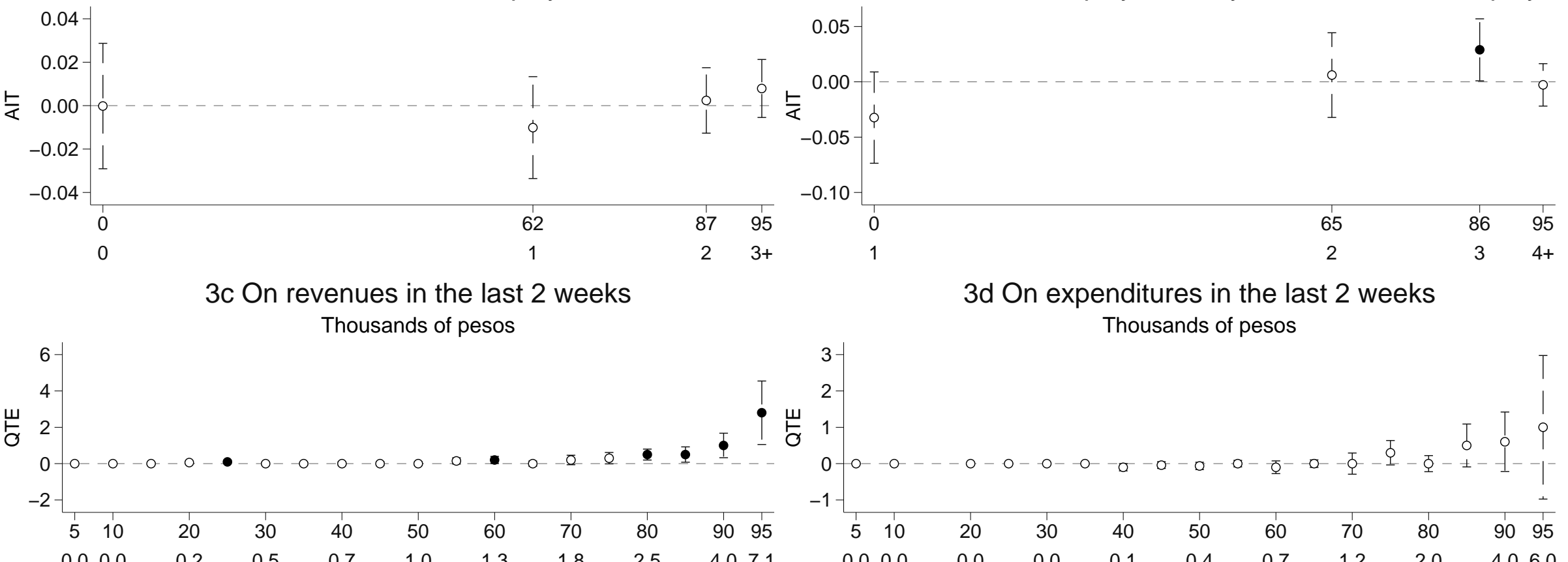

$3 d$ On expenditures in the last 2 weeks

Thousands of pesos

3e On profits in the last 2 weeks

Thousands of pesos

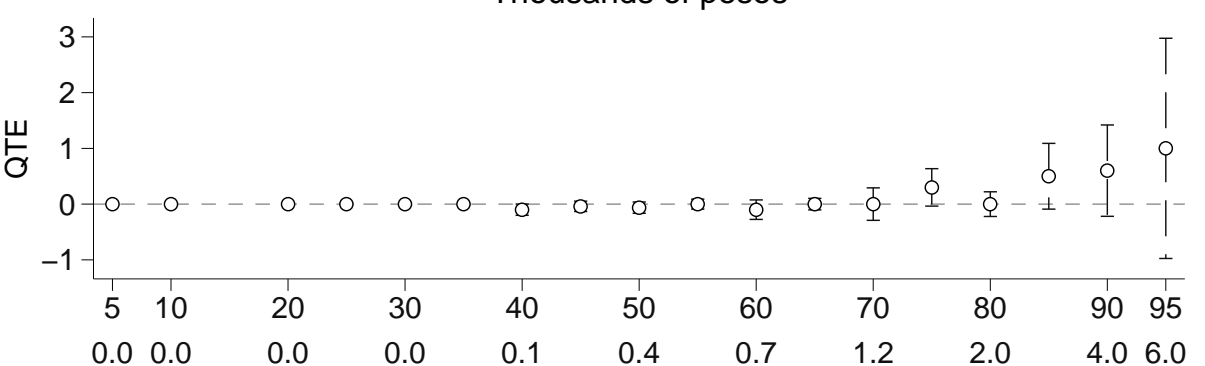

3f On household business income last month

Thousands of pesos
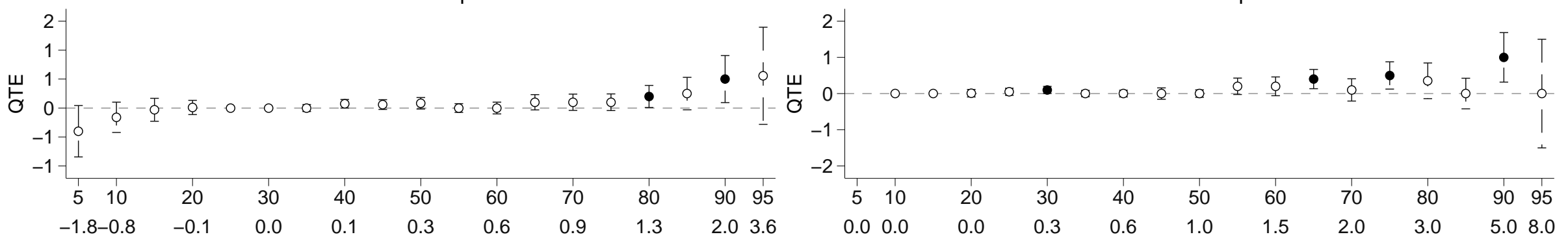

$\mathrm{X}$ axis shows the quantile (top row) and the control group value at that quantile (bottom row)

For continuous variables, vertical lines show $90 \%$ confidence intervals for quantile treatment effects with standard errors block-bootstrapped by cluster with 1,000 replications. For count variables, vertical lines show $90 \%$ confidence intervals for the AIT estimate of the likelihood of treatment group respondents having the value on the $\mathrm{x}$ axis for that outcome relative to the control group respondents having that value. Standard errors are clustered by the unit of randomization. A + sign indicates that the value of the variable is at or above that number. The sample for all estimates includes only business owners, except for the sample in Figure $2 b$, which includes only business owners with $>0$ employees. 
Figure 4: Quantile Treatment Effects for Consumption Outcomes

4a On amount spent on temptation goods

Thousands of pesos
$4 \mathrm{~b}$ On amount spent on groceries

Thousands of pesos

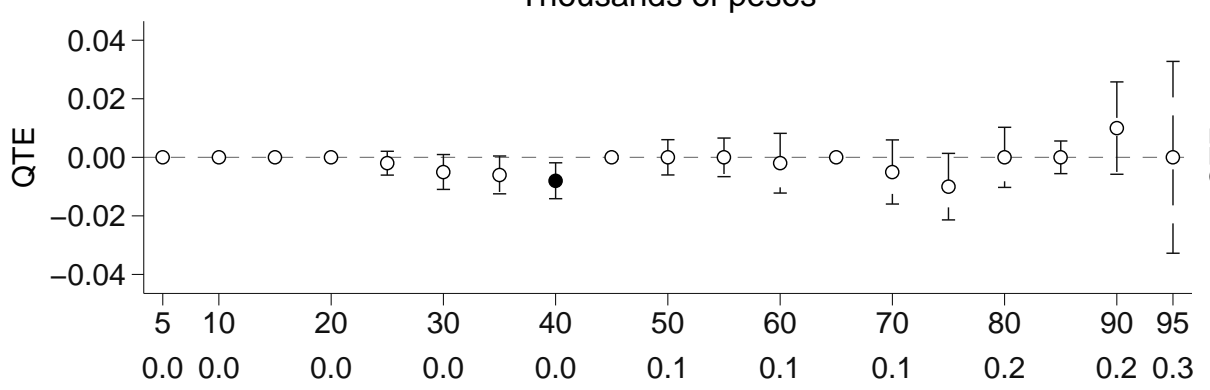

4c On amount spent on school and medical expenses

Thousands of pesos

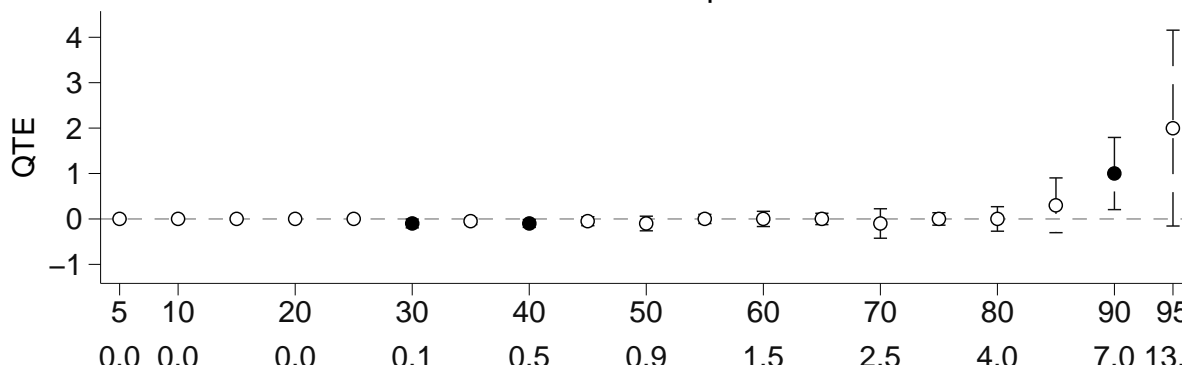

4 e On asset categories bought item from

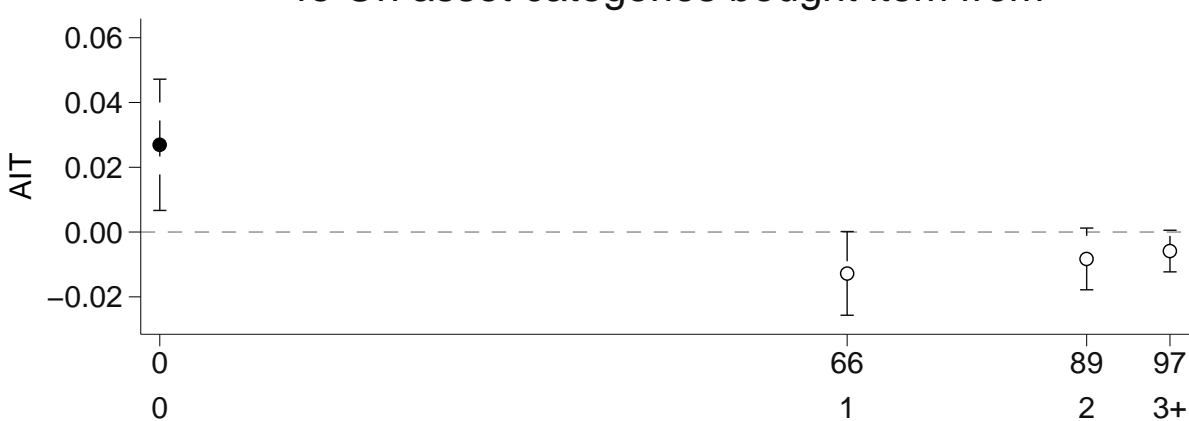

$X$ axis shows the quantile (top row) and the control group value at that quantile (bottom row)

For continuous variables, vertical lines show $90 \%$ confidence intervals for quantile treatment effects with standard errors block-bootstrapped by cluster with 1,000 replications. For count variables, vertical lines show $90 \%$ confidence intervals for the AIT estimate of the likelihood of treatment group respondents having the value on the $x$ axis for that outcome relative to the control group respondents having that value. Standard errors are clustered by the unit of randomization. A + sign indicates that the value of the variable is at or above that number.

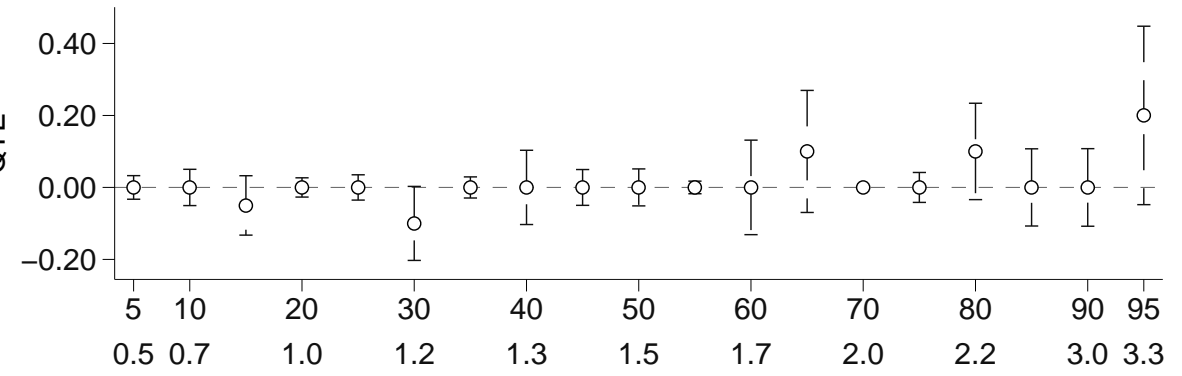

4d On amount spent on family events

Thousands of pesos

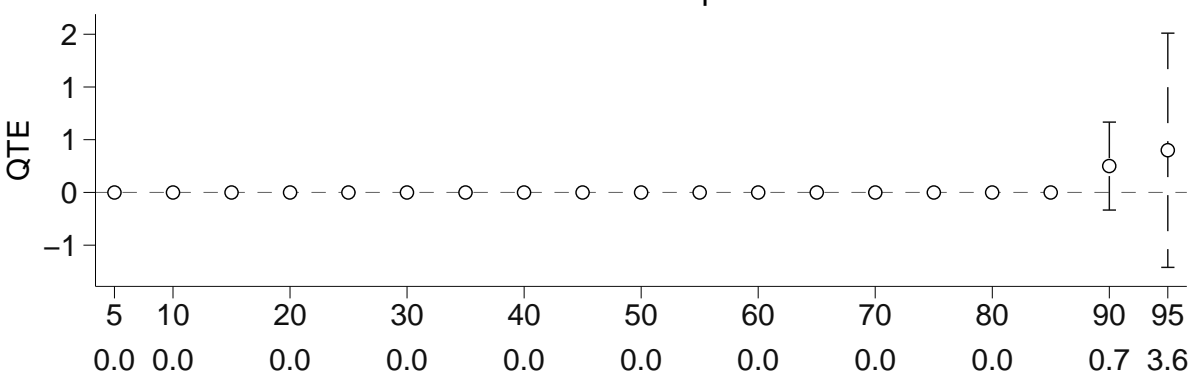

$\begin{array}{ll}95 \\ 0.7 & 3.6\end{array}$ 
Figure 5: Quantile Treatment Effects for Income Outcomes

5 a On total income

Thousands of pesos

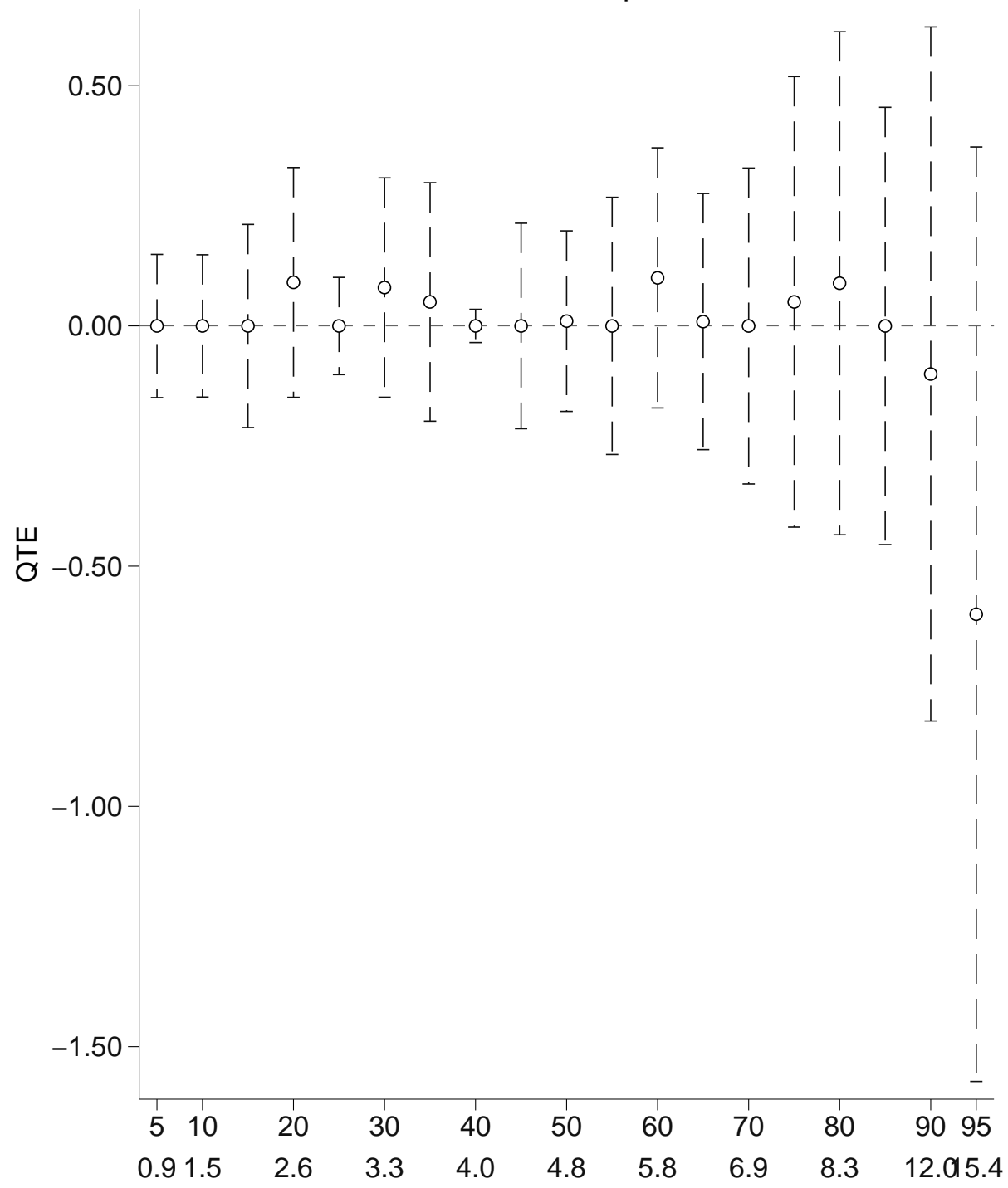

$5 b$ On income from salaried and non-salaried jobs

Thousands of pesos

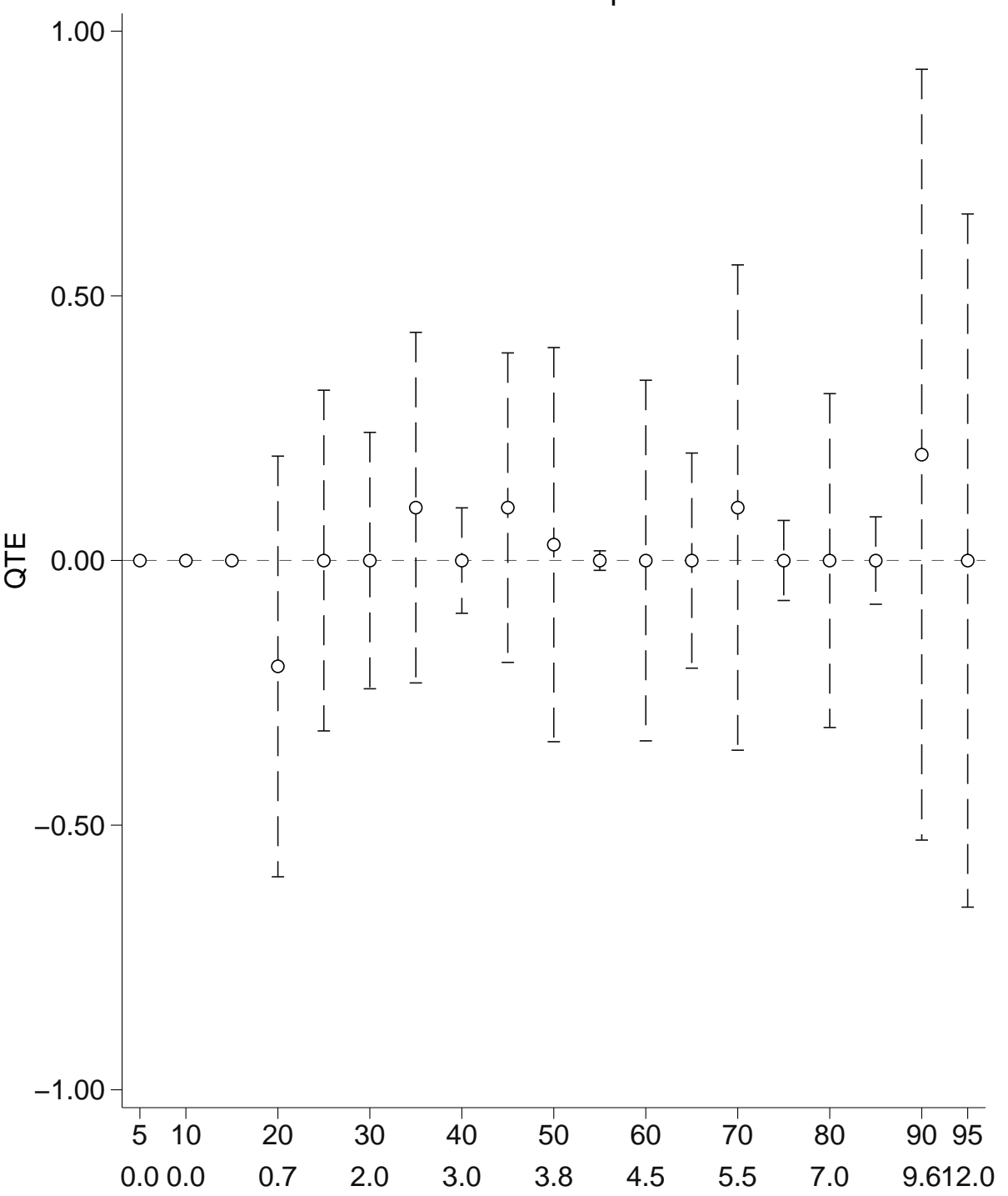

Vertical lines show $90 \%$ confidence intervals for quantile treatment effects with standard errors block-bootstrapped by cluster with 1,000 replications. 


\section{Figure 6: Quantile Treatment Effects for Other Welfare Outcomes}

$6 \mathrm{a}$ On the depression index (higher $=$ happier)

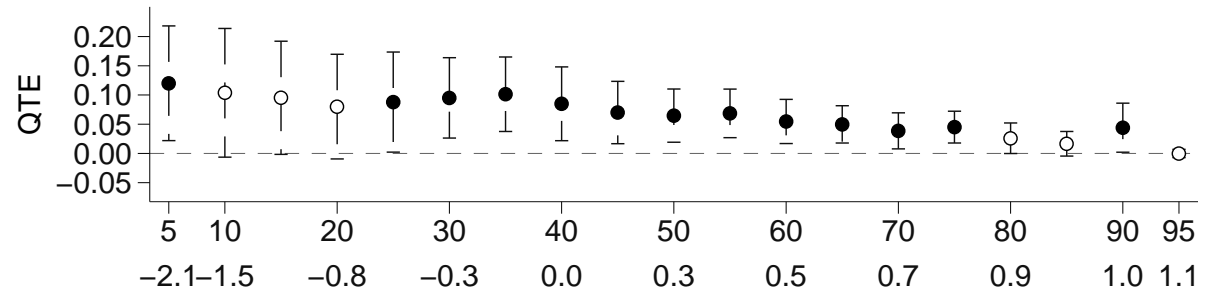

$6 \mathrm{c}$ On the locus of control index

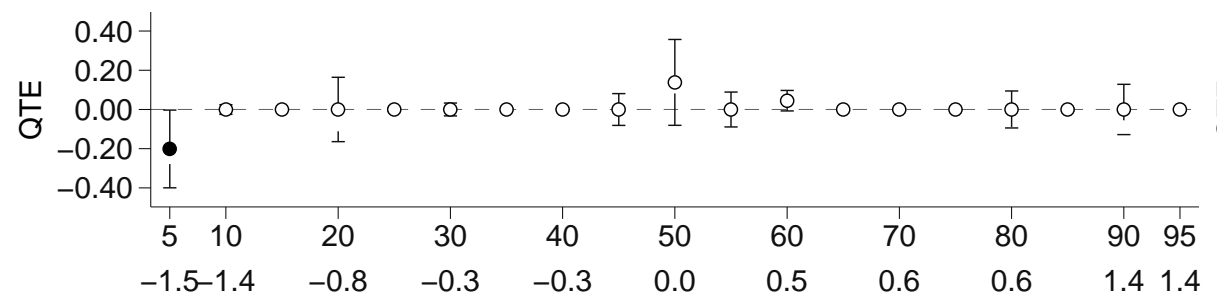

$6 e$ On the trust in people index

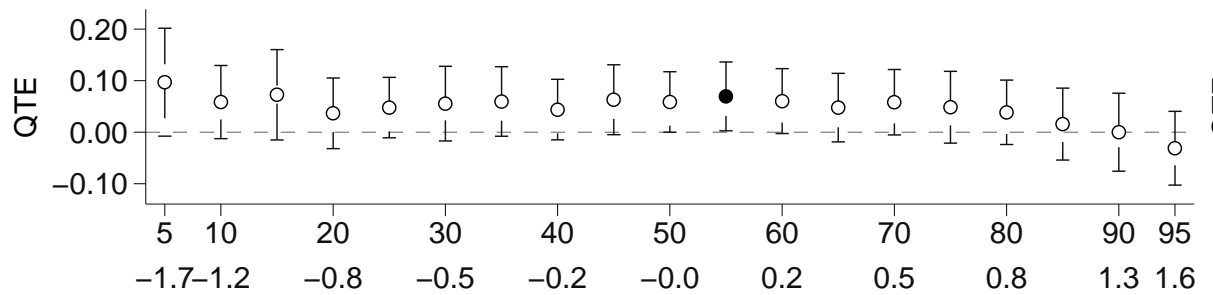

$6 \mathrm{~g}$ On \# of household issues she has a say on
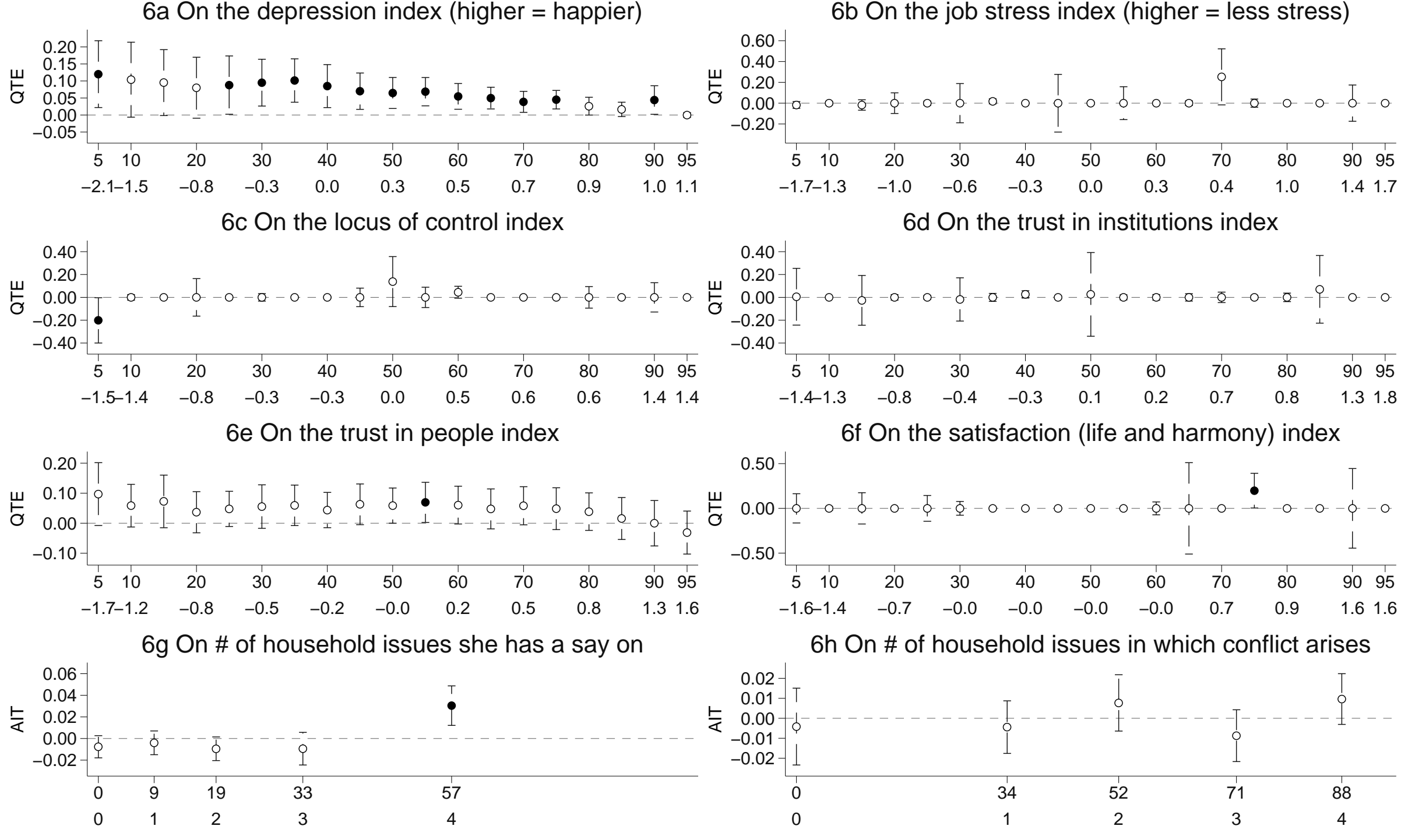

$6 \mathrm{~d}$ On the trust in institutions index

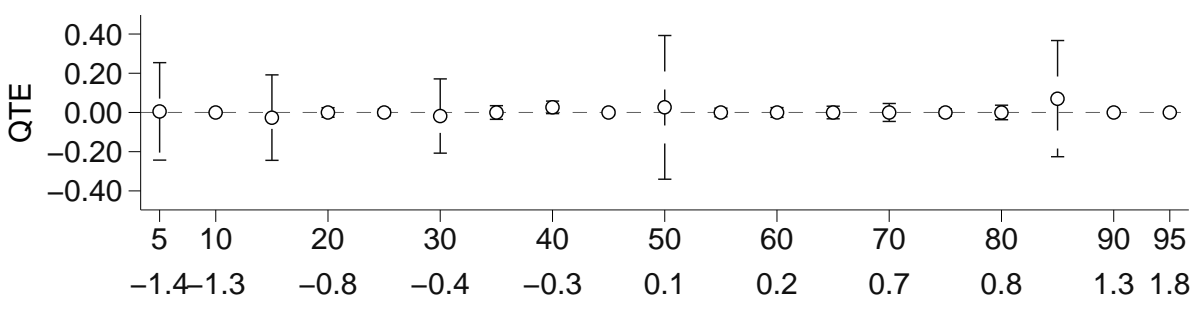

$6 f$ On the satisfaction (life and harmony) index

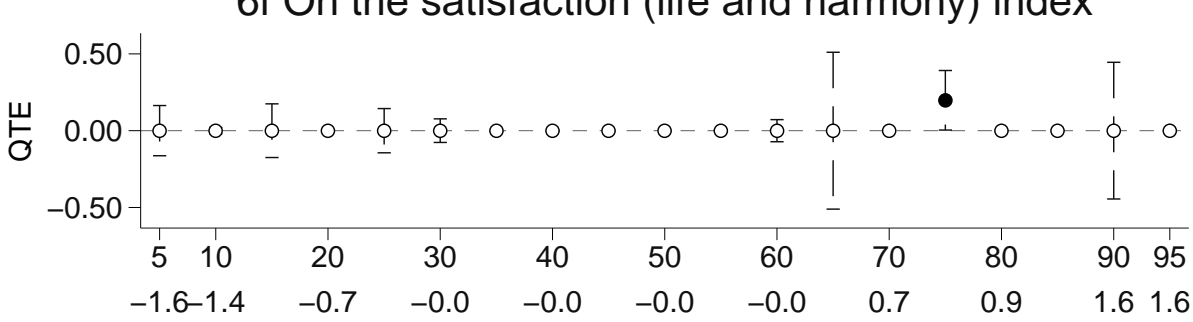

$6 \mathrm{~h}$ On \# of household issues in which conflict arises

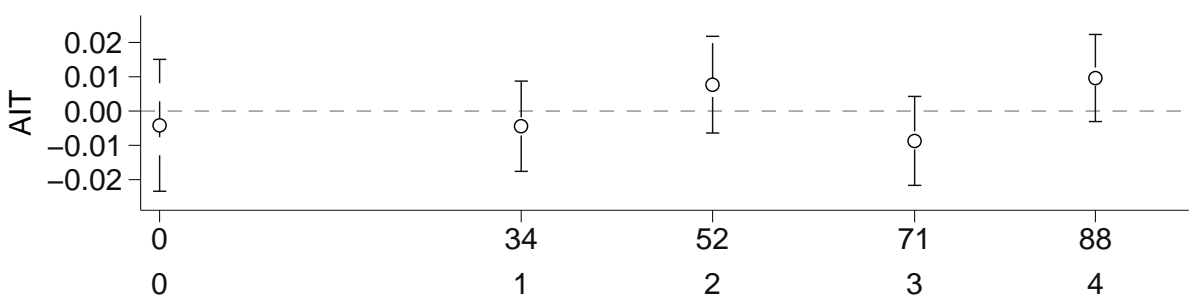

0

$X$ axis shows the quantile (top row) and the control group value at that quantile (bottom row)

For continuous variables, vertical lines show $90 \%$ confidence intervals for quantile treatment effects with standard errors block-bootstrapped by cluster with 1,000 replications. For count variables, vertical lines show $90 \%$ confidence intervals for the AIT estimate of the likelihood of treatment group respondents having the value on the $x$ axis for that outcome relative to the control group respondents having that value. Standard errors are clustered by the unit of randomization. $A+$ sign indicates that the value of the variable is at or above that number. 
Figure 7: Heterogeneous Treatment Effects by Business Ownership

a. Prior business owner $(24.4 \%)$

CREDIT \& OTHER FINANCIAL SERVICES Total amount \# from Compartamos Amount from Compartamos \# from a moneylender or pawnshop Amount from a moneylender or pawnshop Formal credit is 1 st choice for cedit Member of informal savings group Has a business Has ever owned a business Used a loan to grow a business Number of employees

Revenues in the last 2 weeks Reverues in the last 2 weeks Profits in the last 2 weeks

Household business income last month

No financial problems managing business in the last year
INCOME \& CONSUMPTION

Income from salaried and non-salaried jobs Participated in an economic activity Amount of remittances received
Income greater than or equal to expenses Did not sell an asset to help pay for a loan Used a loan to buy any asset Amount spent on temptation goods in the last week Amount spent on groceries in the last 2 weeks
Nights did not go hungry Nights did not go hungry
Amount spent on school and medical expenses in the last year Amount spent on family events in the last year Asset categories bought item from in the last 2 years Did not sell an asset Made home improvement Depression index (higher = happier) Job stress index (higher $=$ less stress) Locus of control index Trust in institutions index Trust in people index Satisfaction (life and harmony) index Satisfied with economic situation

Fraction of children 4-17 not working Participates in any financial decisions \# of household issues she has a say on \# of household issues in which conflict arises

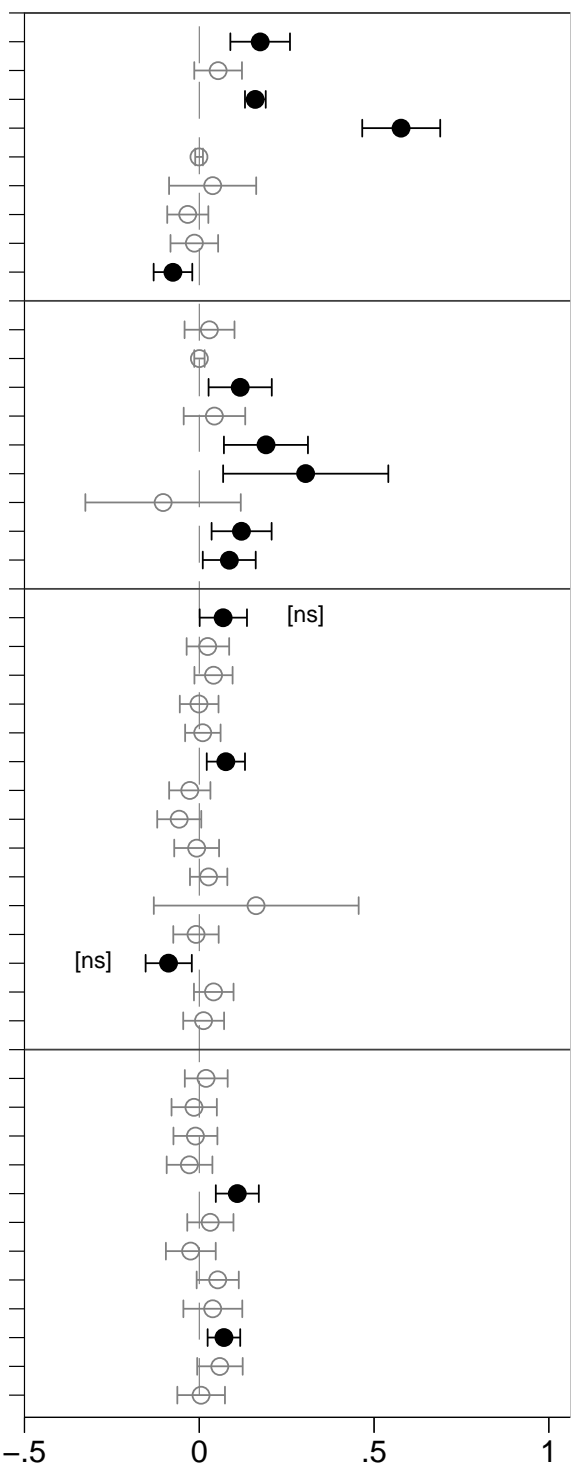

b. Not a prior business owner $(75.6 \%)$

c. $(a-b)$

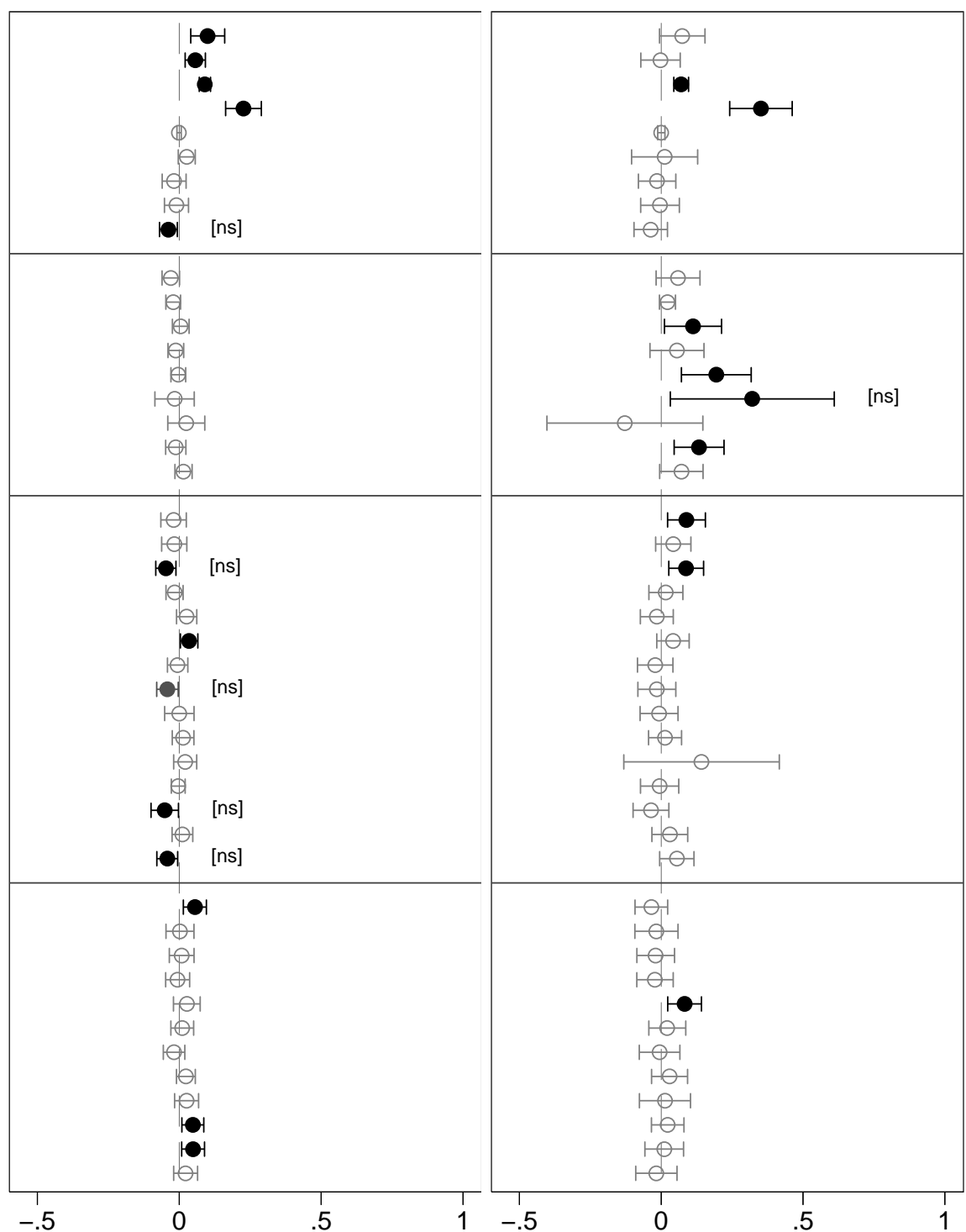

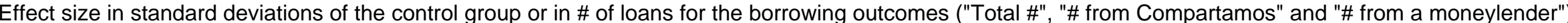
and B. Here treatment effects are presented in standard deviation units or in \# of loans for the borrowing outcomes (Total \#, \# from Compartamos, and \# from a moneylender or pawnshop). Effects that are signicant at $p<.10$ are in black. For some outcomes, we adjust the critical level following the Benjamini and Hochberg approach. In brackets, we then indicate whether the treatment effect is not significant [ns] at this level if it is significant at the unadjusted level. 
Figure 8: Heterogeneous Treatment Effects by Education

a. Education > Primary (71.0\%)

b. Education <= Primary $(29.0 \%)$

c. $(a-b)$

CREDIT \& OTHER FINANCIAL SERVICES Total amount Amount from Compartamos \# from a moneylender or pawnshop nt from a moneylender or pawnshop Formal credit is 1 st choice for credit Member of informal savings group Has a business Has ever owned a business Used a loan to grow a business Number of employees

Revenues in the last 2 weeks Revitures in the last 2 weeks Profits in the last 2 weeks

Household business income last month No financial problems managing business in the last year
INCOME \& CONSUMPTION Total income

Income from salaried and non-salaried jobs Participated in an economic activity Amount of remittances received Income greater than or equal to expenses Did not sell an asset to help pay for a loan
Used a loan to buy any asset Amount spent on temptation goods in the last week Amount spent on groceries in the last 2 weeks Nights did not go hungry Amount spent on school and medical expenses in the last year
Amount spent on family events in the last year Amount spent on family events in the last year Asset categories bought item from in the last 2 years
Did not sell an asset Did not sell an asse OTHER WELFARE Depression index (higher = happier) Job stress index (higher = less stress) Locus of control index rust in institutions index Satisfaction (life and harmony) index Satisfied with economic situation Good health status

Fraction of children 4-17 not working Participates in any financial decisions \# of household issues she has a say on \# of household issues in which conflict arises

[ns]
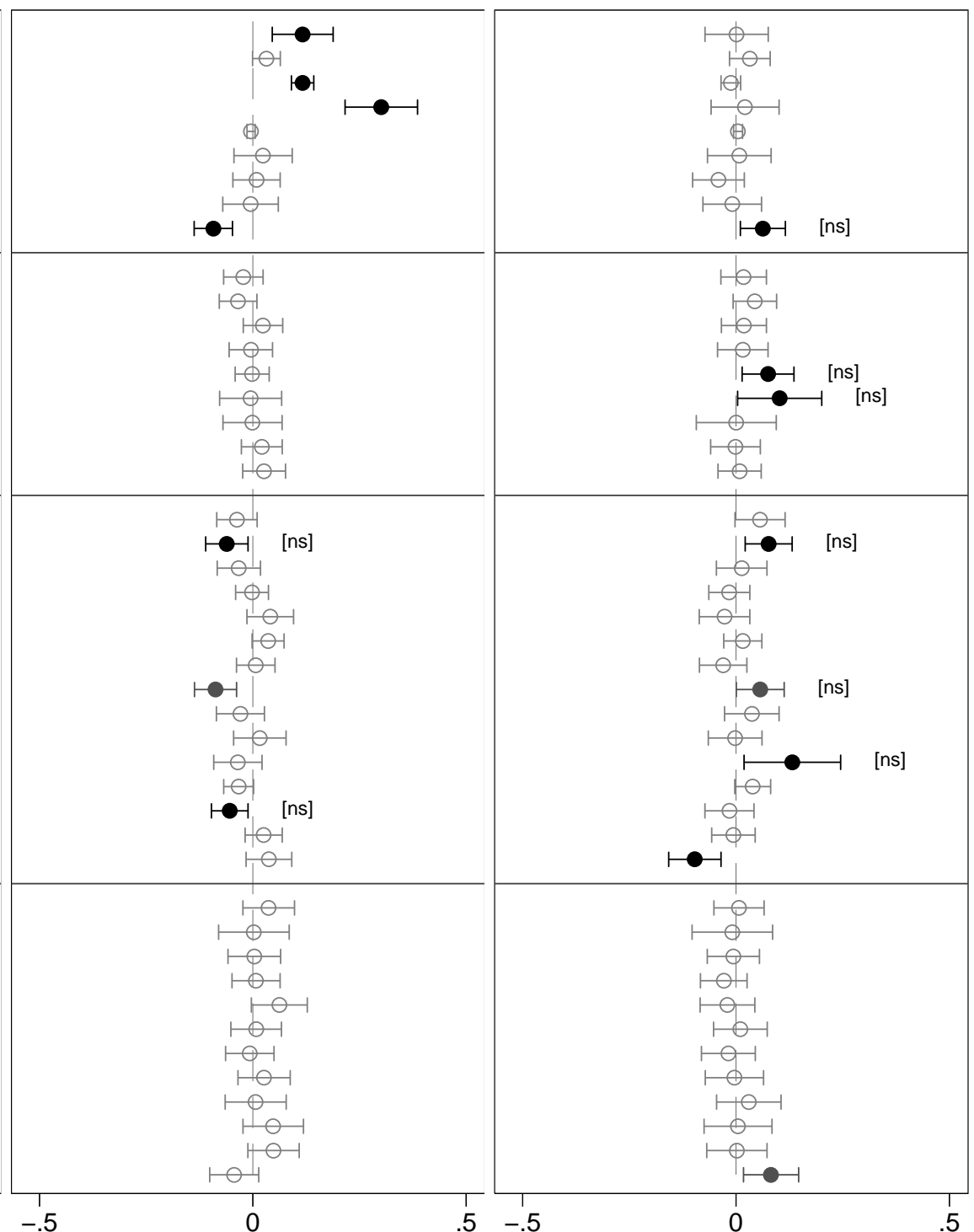

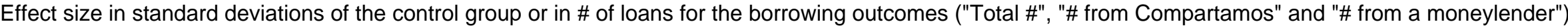

Each line shows the OLS point estimate and $90 \%$ confidence interval for the outcome on the left and group at the top. Panel $\mathrm{C}$ shows the estimate for the difference between the coefficients in panels $\mathrm{A}$ and B. Here treatment effects are presented in standard deviation units or in \# of loans for the borrowing outcomes (Total \#, \# from Compartamos, and \# from a moneylender or pawnshop). Effects that are significant at $p<.10$ are in black. For some outcomes, we adjust the critical level following the Benjamini and Hochberg approach. In brackets, we then indicate whether the treatment effect is not significant [ns] at this level if it is significant at the unadjusted level. 
Figure 9: Heterogeneous Treatment Effects by Location

a. In rural area (27.4\%)

b. In urban area (72.6\%)

c. $(a-b)$

CREDIT \& OTHER FINANCIAL SERVICES Total amount \# from Compartamos Amount from Compartamos \# from a moneylender or pawnshop nt from a moneylender or pawnshop Formal credit is 1 st choice for credit Member of informal savings group Has a business Has ever owned a business Used a loan to grow a business Number of employees

Revenues in the last 2 weeks renditures in the last 2 weeks Profits in the last 2 weeks Household business income last month No financial problems managing business in the last year Total income

Income from salaried and non-salaried jobs Participated in an economic activity Amount of remittances received Income greater than or equal to expenses
Did not sell an asset to help pay for a loan Used a loan to buy any asset Amount spent on temptation goods in the last week Amount spent on groceries in the last 2 weeks Nights did not go hungry Amount spent on school and medical expenses in the last year Amount spent on family events in the last year Asset categories bought item from in the last 2 years Did not sell an asset OTHER WELFARE Depression index (higher = happier) Job stress index (higher $=$ less stress) Locus of control index rust in institutions index Trust in people index Satisfaction (life and harmony) index Satisfied with economic situation

Fraction of children 4-17 not working Participates in any financial decisions \# of household issues she has a say on \# of household issues in which conflict arises

[ns]
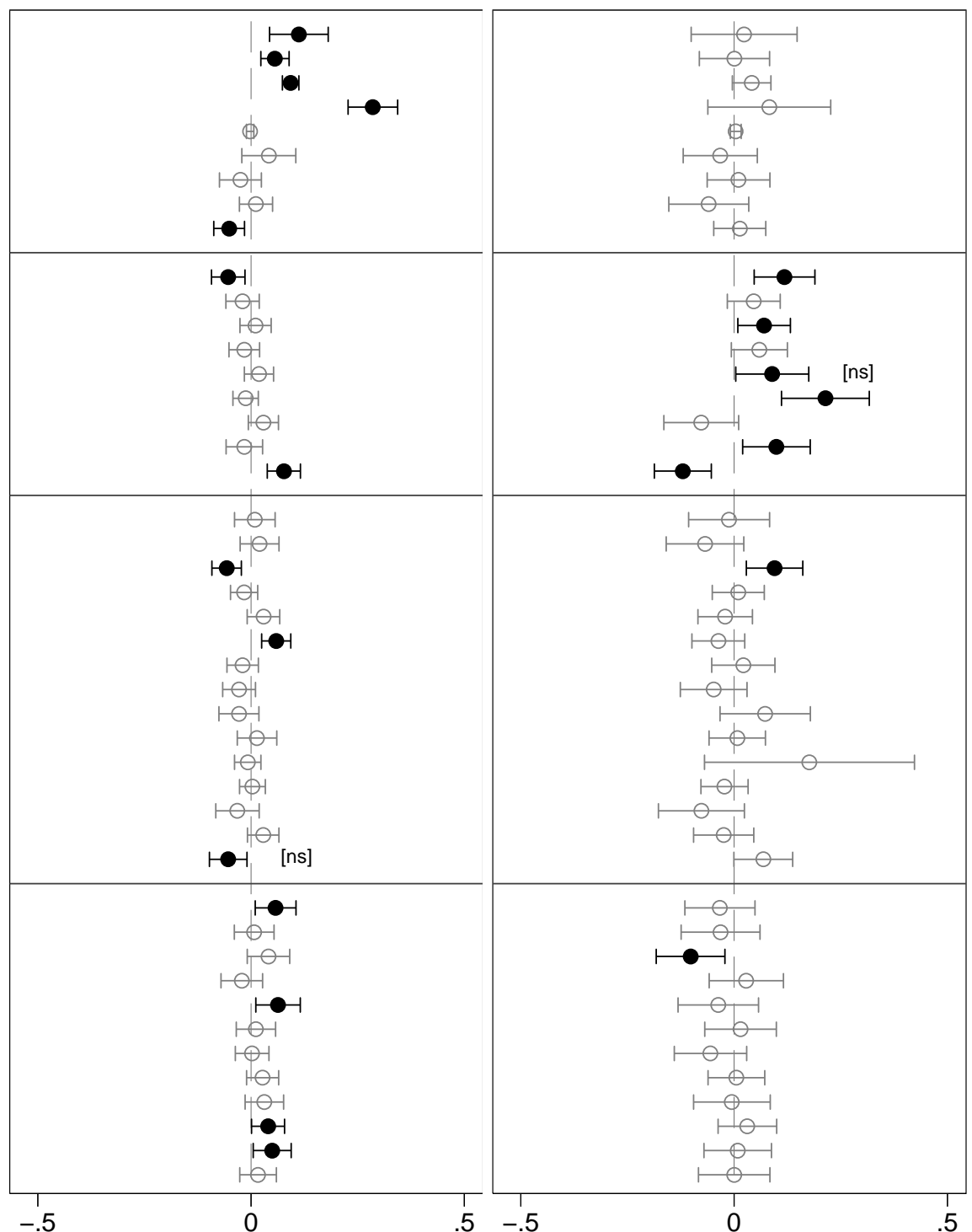

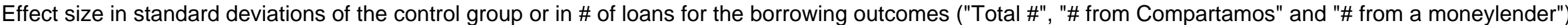

Each line shows the OLS point estimate and $90 \%$ confidence interval for the outcome on the left and group at the top. Panel $\mathrm{C}$ shows the estimate for the difference between the coefficients in panels $\mathrm{A}$ and B. Here treatment effects are presented in standard deviation units or in \# of loans for the borrowing outcomes (Total \#, \# from Compartamos, and \# from a moneylender or pawnshop). Effects that are significant at $p<.10$ are in black. For some outcomes, we adjust the critical level following the Benjamini and Hochberg approach. In brackets, we then indicate whether the treatment effect is not significant [ns] at this level if it is significant at the unadjusted level. 
Figure 10: Heterogeneous Treatment Effects by Household Income

a. Above Median (50.2\%)

\section{CREDIT \& OTHER FINANCIAL SERVICES} Total \#
Total amount \# from Compartamos Amount from Compartamos \# from a moneylender or pawnshop Amount from a moneylender or pawnshop Formal credit is 1 st choice for credit Member of informal savings group Has a business

Has ever owned a business Used a loan to grow a business Number of employees

Revenues in the last 2 weeks revitures in the last 2 weeks Profits in the last 2 weeks

Household business income last month No financial problems managing business in the last year Total income

Income from salaried and non-salaried jobs Participated in an economic activity Amount of remittances received
Income greater than or equal to expenses Income greater than or equal to expenses
Did not sell an asset to help pay for a loan Used a loan to buy any asset Amount spent on temptation goods in the last week Amount spent on groceries in the last 2 weeks

Nights did not go hungry
Amount spent on school and medical expenses in the last year
Amount spent on family events in the last year Amount spent on family events in the last year Asset categories bought item from in the last 2 years Did not sell an asset Made home improvement
OTHER WELFARE Depression index (higher = happier) Job stress index (higher $=$ less stress) Locus of control index Trust in institutions index Trust in people index

Satisfaction (life and harmony) index Satisfied with economic situation

Fraction of children 4-17 health status Participates in any financial decisions \# of household issues she has a say on \# of household issues in which conflict arises

$$
-.5
$$

b. Below Median (49.8\%)

c. $(a-b)$

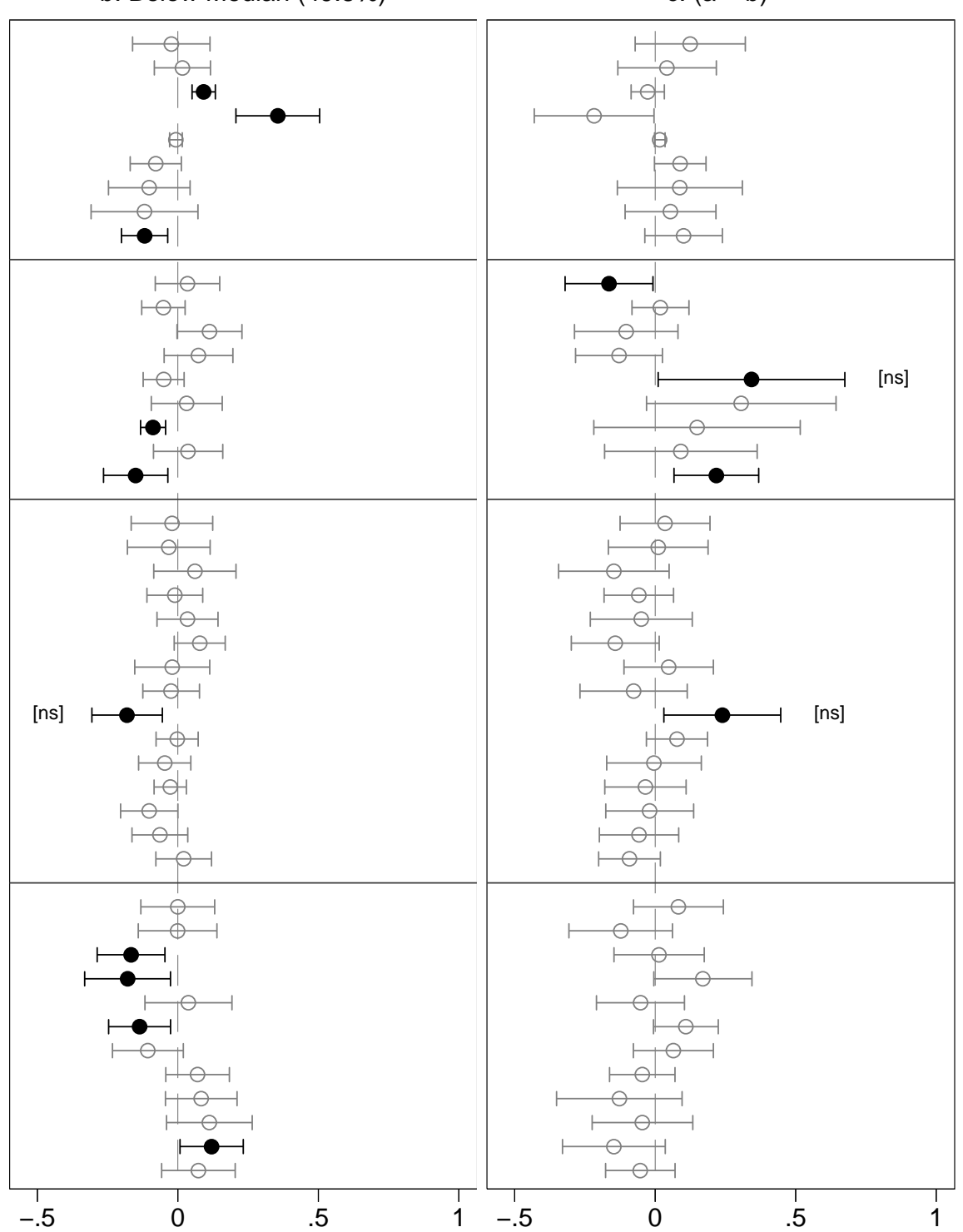

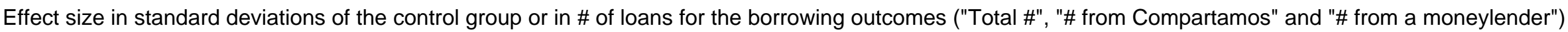

Each line shows the OLS point estimate and $90 \%$ confidence interval for the outcome on the left and group at the top. Panel $\mathrm{C}$ shows the estimate for the difference between the coefficients in panels $\mathrm{A}$ and B. Here treatment effects are presented in standard deviation units or in \# of loans for the borrowing outcomes (Total \#, \# from Compartamos, and \# from a moneylender or pawnshop). Effects that are significant at $\mathrm{c}$. 10 are in black. For some outcomes, we adjust the critical level following the Benjamini and Hochberg approach. In brackets, we then indicate whether the treatment effect is not significant [ns] at this level if it is significant at the unadjusted level. 
Figure 11: Heterogeneous Treatment Effects by Credit Experience

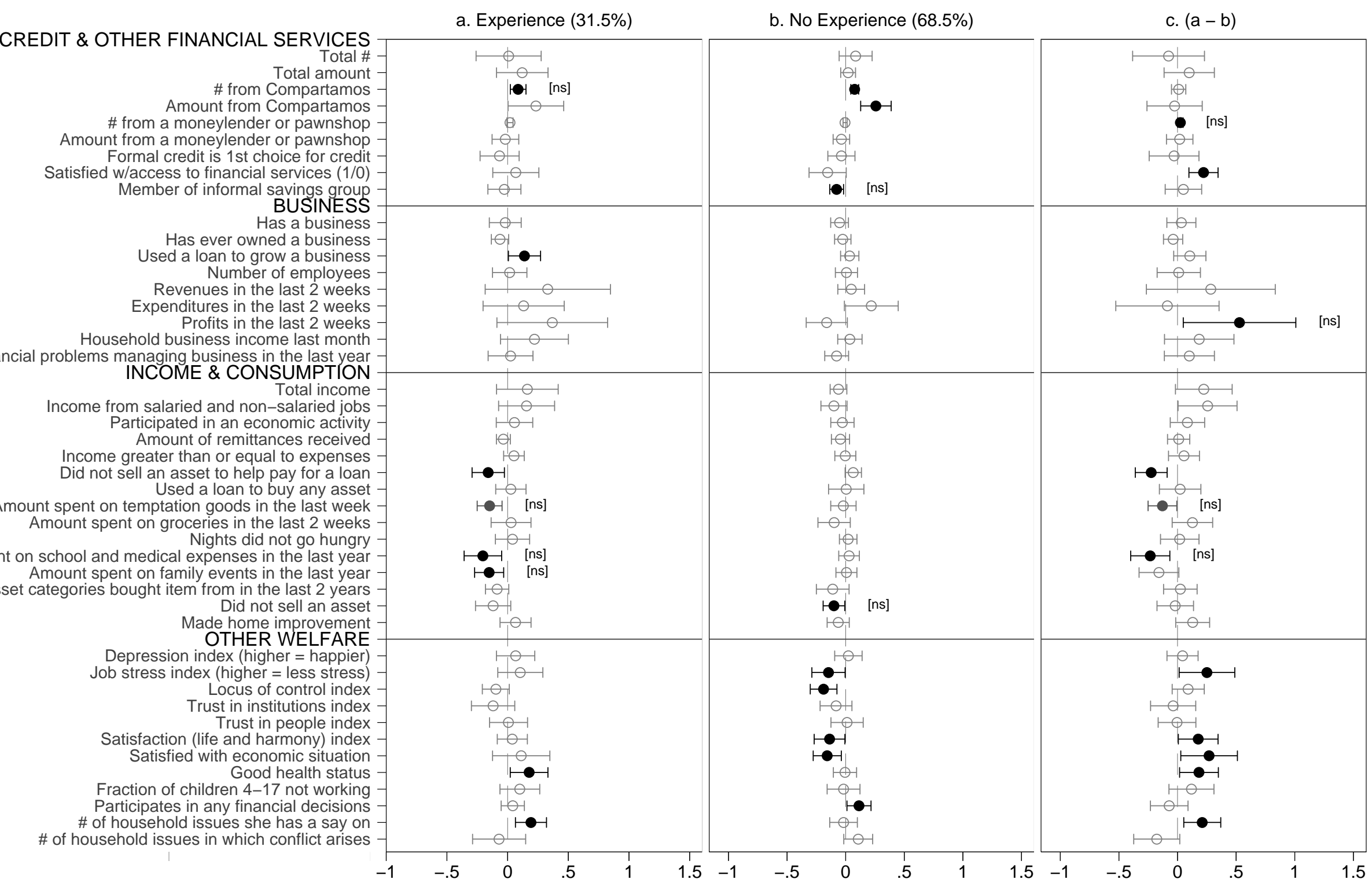

Effect size in standard deviations of the control group or in \# of loans for the borrowing outcomes ("Total \#", "\# from Compartamos" and "\# from a moneylender")

Each line shows the OLS point estimate and $90 \%$ confidence interval for the outcome on the left and group at the top. Panel $\mathrm{C}$ shows the estimate for the difference between the coefficients in panels $\mathrm{A}$ and B. Here treatment effects are presented in standard deviation units or in \# of loans for the borrowing outcomes (Total \#, \# from Compartamos, and \# from a moneylender or pawnshop). Effects that are significant at $\mathrm{k}<.10$ are in black. For some outcomes, we adjust the critical level following the Benjamini and Hochberg approach. In brackets, we then indicate whether the treatment effect is not significant [ns] at this level if it is significant at the unadjusted level. 
Figure 12: Heterogeneous Treatment Effects by Formal Account Experience

a. Experience (19.8\%)

CREDIT \& OTHER FINANCIAL SERVICES Total amount \# from Compartamos Amount from Compartamos \# from a moneylender or pawnshop int from a moneylender or pawnshop Formal credit is 1 st choice for credit Member of informal savings group Has a business Has ever owned a business Used a loan to grow a business Number of employees

Revenues in the last 2 weeks Revitures in the last 2 weeks Profits in the last 2 weeks

Household business income last month No financial problems managing business in the last year Total income

Income from salaried and non-salaried jobs Participated in an economic activity Income greater than or equal to expenses Did not sell an asset to help pay for a loan Used a loan to buy any asset Amount spent on temptation goods in the last week Amount spent on groceries in the last 2 weeks
Nights did not go hungry Nights did not go hungry
Amount spent on school and medical expenses in the last year Amount spent on family events in the last year Asset categories bought item from in the last 2 years Did not sell an asset Made home improvement Depression index (higher $=$ happier) Job stress index (higher $=$ less stress) Locus of control index Trust in institutions index Trust in people index Satisfaction (life and harmony) index Satisfied with economic situation

Fraction of children 4-17 not working Participates in any financial decisions \# of household issues she has a say on \# of household issues in which conflict arises

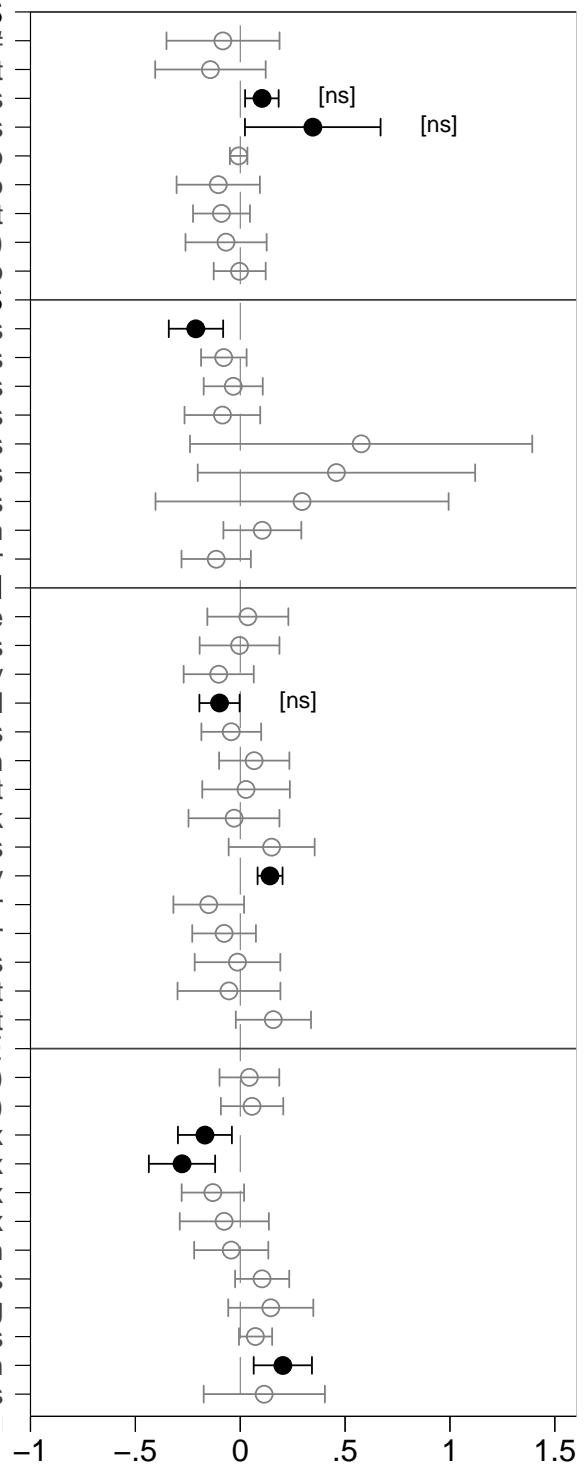

c. $(a-b)$

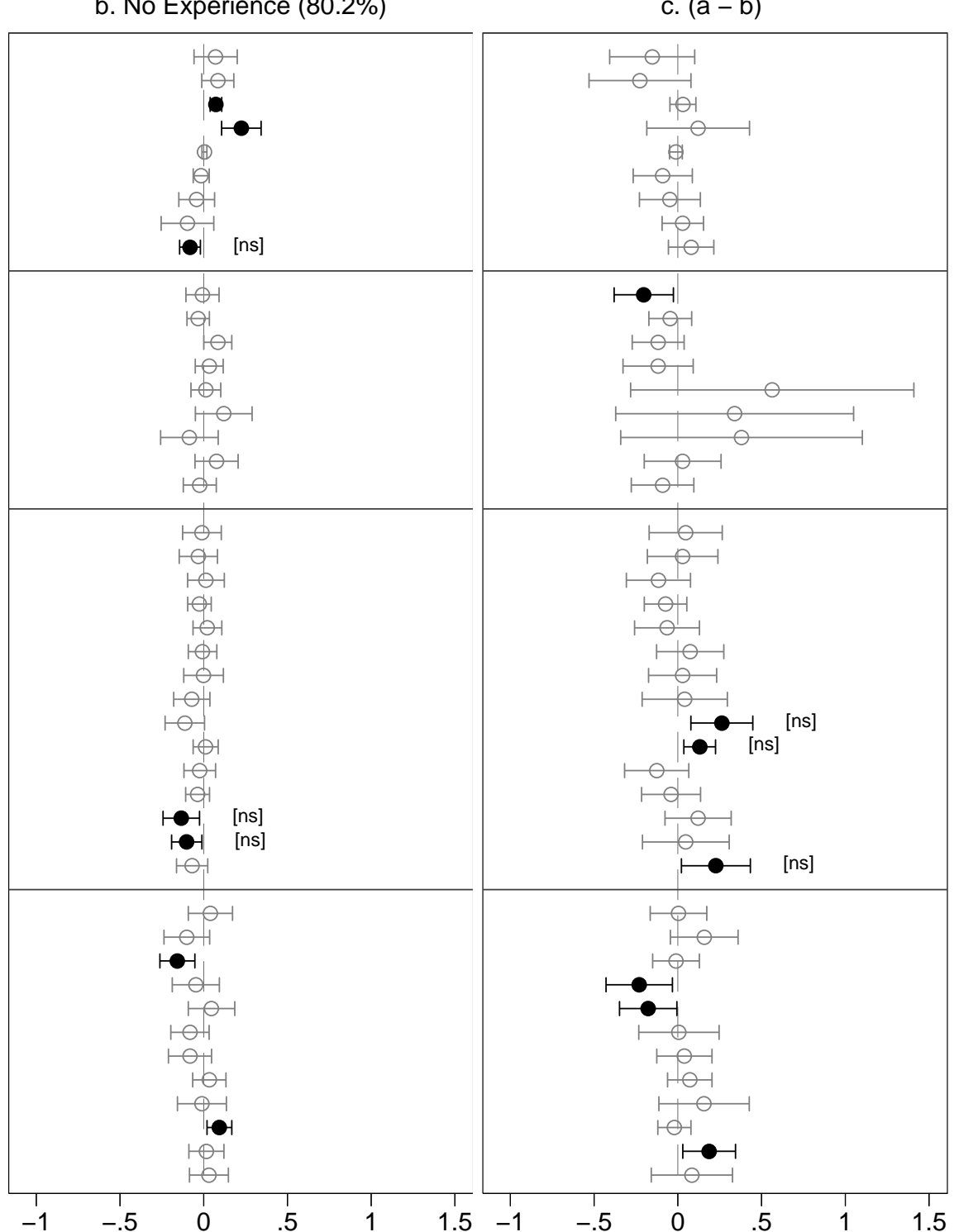

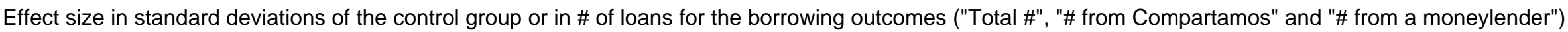

Each line shows the OLS point estimate and $90 \%$ confidence interval for the outcome on the left and group at the top. Panel C shows the estimate for the difference between the coefficients in panels A and B. Here treatment effects are presented in standard deviation units or in \# of loans for the borrowing outcomes (Total \#, \# from Compartamos, and \# from a moneylender or pawnshop). Effects that are significant at $p<.10$ are in black. For some outcomes, we adjust the critical level following the Benjamini and Hochberg approach. In brackets, we then indicate whether the treatment effect is not significant [ns] at this level if it is significant at the unadjusted level. 
Figure 13: Heterogeneous Treatment Effects by Informal Savings Experience

a. Experience $(23.8 \%)$

CREDIT \& OTHER FINANCIAL SERVICES Total amount \# from Compartamos Amount from Compartamos \# from a moneylender or pawnshop nt from a moneylender or pawnshop Formal credit is 1 st choice for credit Member of informal savings group Has a business Has ever owned a business Used a loan to grow a business Number of employees

Revenues in the last 2 weeks xpenditures in the last 2 weeks Profits in the last 2 weeks

Household business income last month No financial problems managing business in the last year Total income

Income from salaried and non-salaried jobs Participated in an economic activity Amount of remittances received Income greater than or equal to expenses Did not sell an asset to help pay for a loan Used a loan to buy any asset Amount spent on temptation goods in the last week Amount spent on groceries in the last 2 weeks
Nights did not go hungry Nights did not go hungry
Amount spent on school and medical expenses in the last year Amount spent on family events in the last year Asset categories bought item from in the last 2 years Did not sell an asset Made home improvement Depression index (higher $=$ happier) Job stress index (higher $=$ less stress) Locus of control index Trust in institutions index Trust in people index Satisfaction (life and harmony) index Satisfied with economic situation

Fraction of children 4-17 not working Participates in any financial decisions \# of household issues she has a say on \# of household issues in which conflict arises

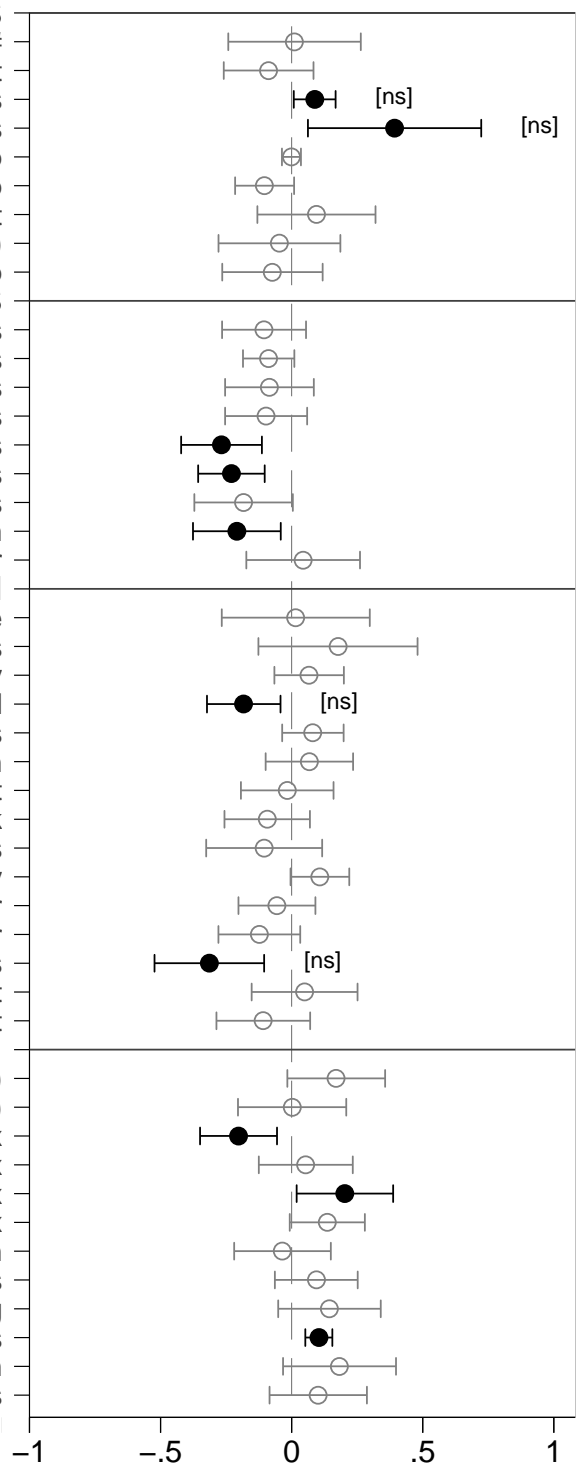

b. No Experience (76.2\%)

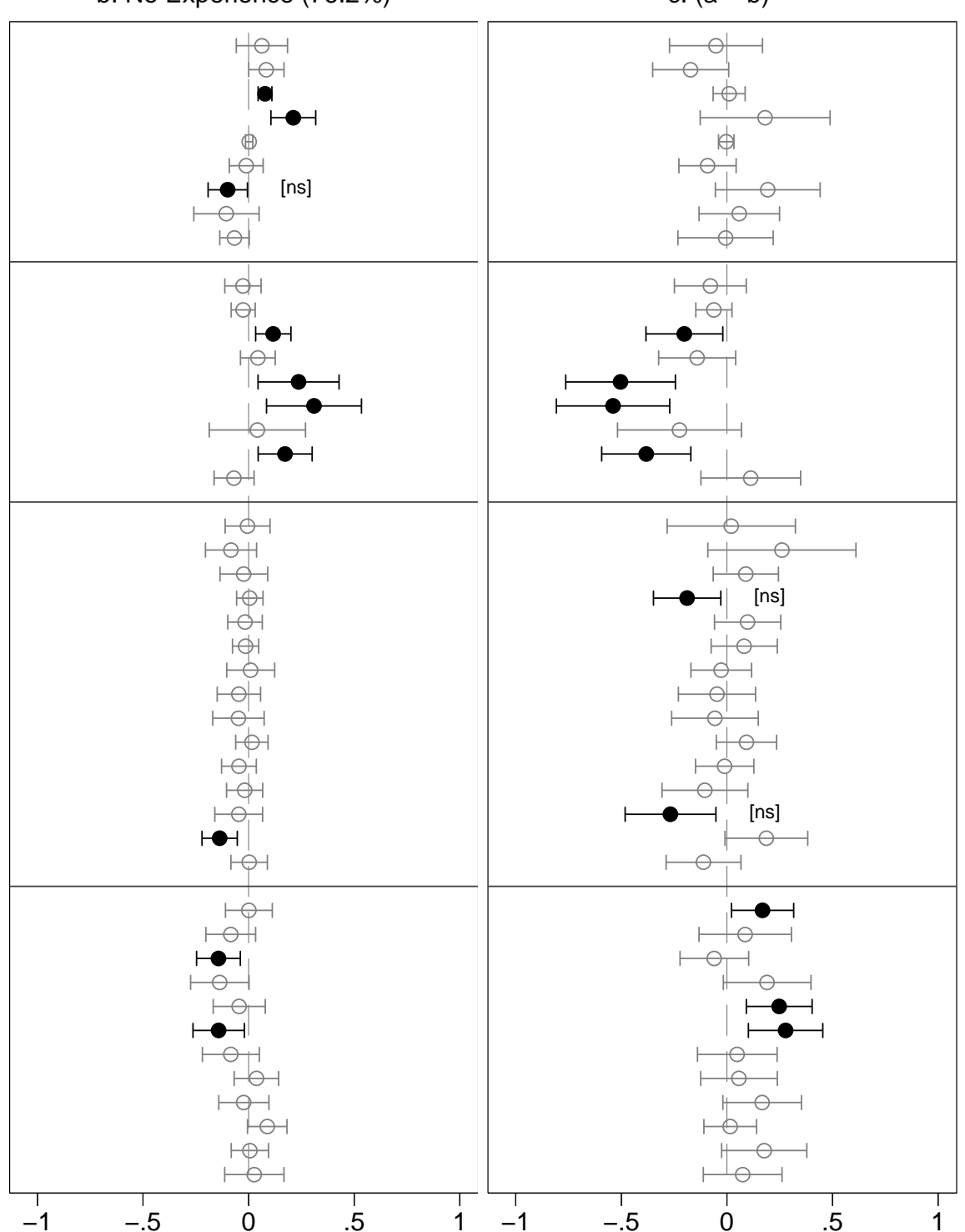

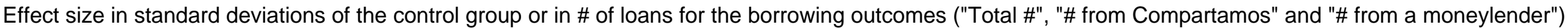

Each line shows the OLS point estimate and $90 \%$ confidence interval for the outcome on the left and group at the top. Panel $\mathrm{C}$ shows the estimate for the difference between the coefficients in panels $\mathrm{A}$ and B. Here treatment effects are presented in standard deviation units or in \# of loans for the borrowing outcomes (Total \#, \# from Compartamos, and \# from a moneylender or pawnshop). Effects that are significant at $p<.10$ are in black. For some outcomes, we adjust the critical level following the Benjamini and Hochberg approach. In brackets, we then indicate whether the treatment effect is not significant [ns] at this level if it is significant at the unadjusted level. 
Figure 14: Heterogeneous Treatment Effects by Risk Tolerance

a. Risk Tolerant $(28.4 \%)$

CREDIT \& OTHER FINANCIAL SERVICES Total \# \# from Compartamos Amount from Compartamos \# from a moneylender or pawnshop Amount from a moneylender or pawnshop Formal credit is 1 st choice for credit Member of informal savings group Has a business Has ever owned a business used a loan to grow a business Number of employees

Revenues in the last 2 weeks xpenditures in the last 2 weeks Profits in the last 2 weeks

Household business income last month No financial problems managing business in the last year Total income

Income from salaried and non-salaried jobs Participated in an economic activity Amount of remittances received Income greater than or equal to expenses
Did not sell an asset to help pay for a loan Used a loan to buy any asset Amount spent on temptation goods in the last week Amount spent on groceries in the last 2 weeks
Nights did not go hungry Nights did not go hungry
Amount spent on school and medical expenses in the last year Amount spent on family events in the last year Asset categories bought item from in the last 2 years Did not sell an asset Made home improvement Depression index (higher $=$ happier) Job stress index (higher $=$ less stress) Locus of control index Trust in institutions index Trust in people index Satisfaction (life and harmony) index Satisfied with economic situation

Fraction of children 4-17 not working Participates in any financial decisions \# of household issues she has a say on \# of household issues in which conflict arises

(ns]

c. $(a-b)$

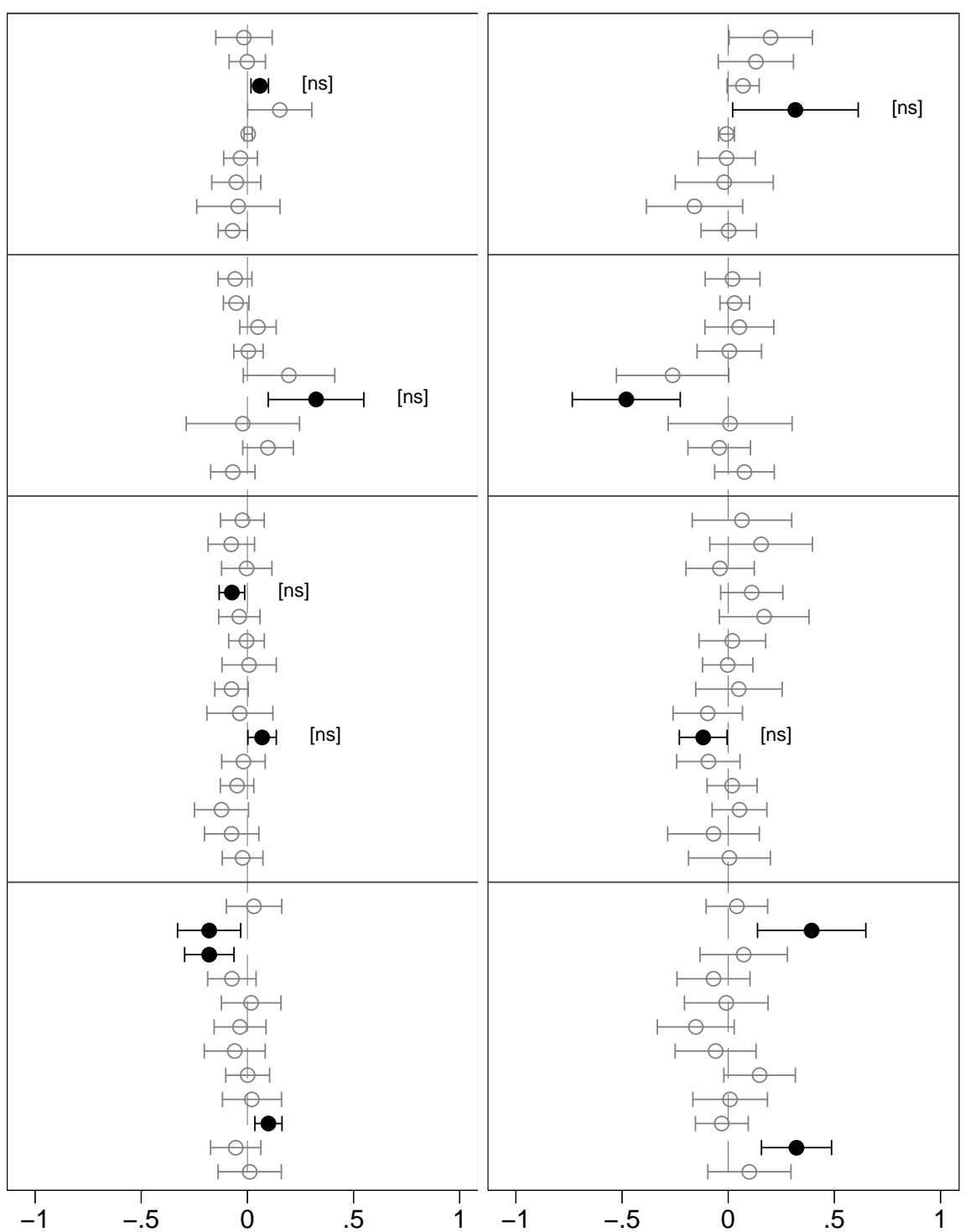

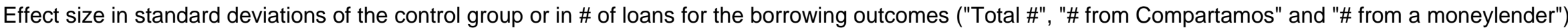

Each line shows the OLS point estimate and $90 \%$ confidence interval for the outcome on the left and group at the top. Panel $\mathrm{C}$ shows the estimate for the difference between the coefficients in panels $\mathrm{A}$ and B. Here treatment effects are presented in standard deviation units or in \# of loans for the borrowing outcomes (Total \#, \# from Compartamos, and \# from a moneylender or pawnshop). Effects that are signicant at $p<.10$ are in black. For some outcomes, we adjust the critical level following the Benjamini and Hochberg approach. In brackets, we then indicate whether the treatment effect is not significant [ns] at this level if it is significant at the unadjusted level. 
Figure 15: Heterogeneous Treatment Effects by Patience

a. Patient (55.5\%)

CREDIT \& OTHER FINANCIAL SERVICES Total \# \# from Compartamos Amount from Compartamos \# from a moneylender or pawnshop Amount from a moneylender or pawnshop Formal credit is 1st choice for colit Member of informal savings group Has a business Has ever owned a business Used a loan to grow a business Number of employees

Revenues in the last 2 weeks renditures in the last 2 weeks Profits in the last 2 weeks

Household business income last month No financial problems managing business in the last year Total income

Income from salaried and non-salaried jobs

Participated in an economic activity
Amount of remittances received Income greater than or equal to expenses Did not sell an asset to help pay for a loan Used a loan to buy any asset Amount spent on temptation goods in the last week Amount spent on groceries in the last 2 weeks
Nights did not go hungry Nights did not go hungry
Amount spent on school and medical expenses in the last year Amount spent on family events in the last year Asset categories bought item from in the last 2 years Did not sell an asset Made home improvement Depression index (higher = happier) Job stress index (higher $=$ less stress) Locus of control index Trust in institutions index Trust in people index Satisfaction (life and harmony) index Satisfied with economic situation

Fraction of children 4-17 not working Participates in any financial decisions \# of household issues she has a say on \# of household issues in which conflict arises

-
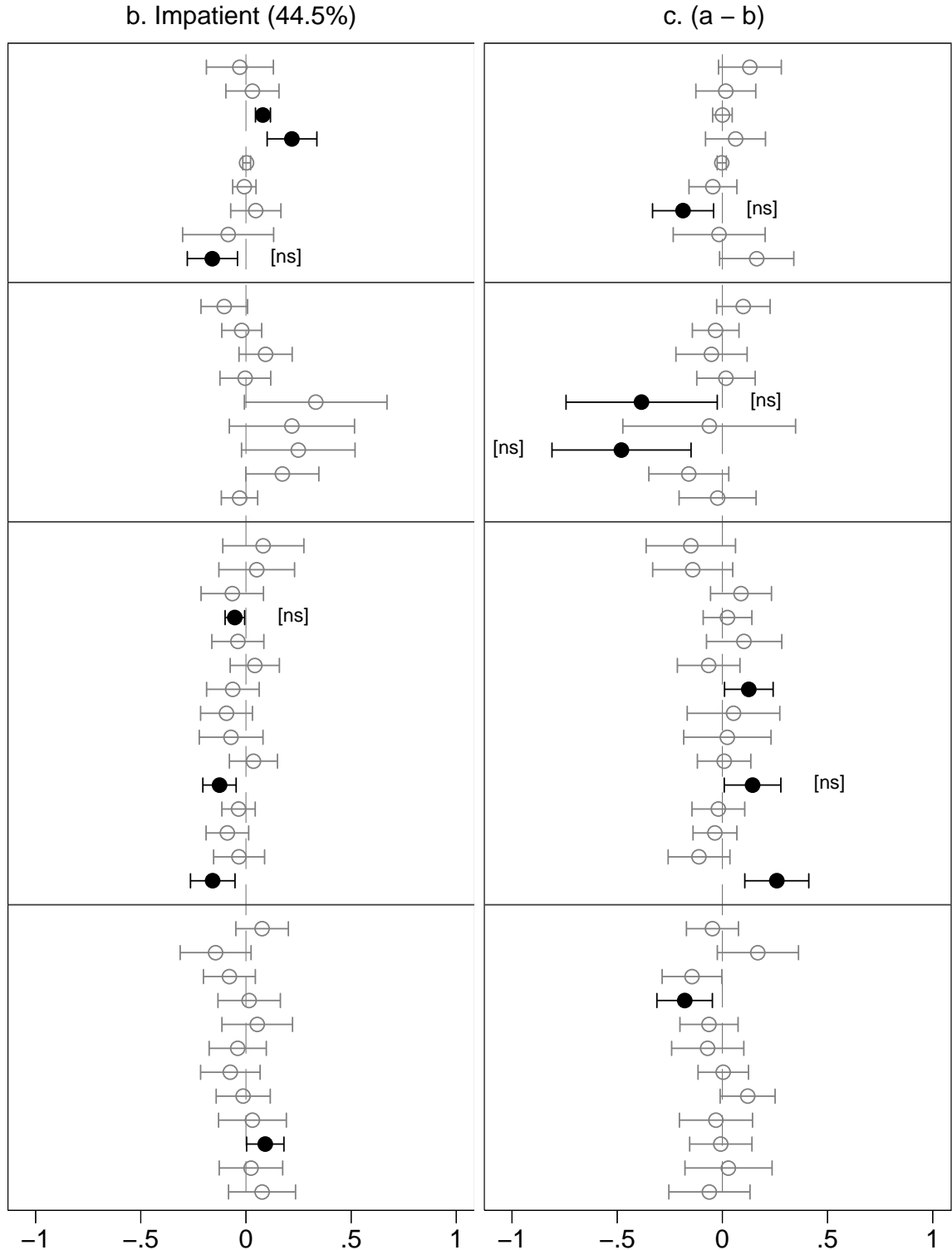

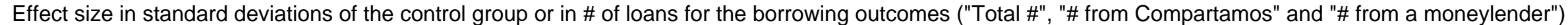

Each line shows the OLS point estimate and 90\% confidence interval for the outcome on the left and group at the top. Panel $\mathrm{C}$ shows the estimate for the difference between the coefficients in panels $\mathrm{A}$ and B. Here treatment effects are presented in standard deviation units or in \# of loans for the borrowing outcomes (Total \#, \# from Compartamos, and \# from a moneylender or pawnshop). Eflects that are significant at $p<.10$ are in black. For some outcomes, we adjust the critical level following the Benjamini and Hochberg approach. In brackets, we then indicate whether the treatment effect is not significant [ns] at this level if it is significant at the unadjusted level. 
Figure 16: Heterogeneous Treatment Effects by Present-biased Preference

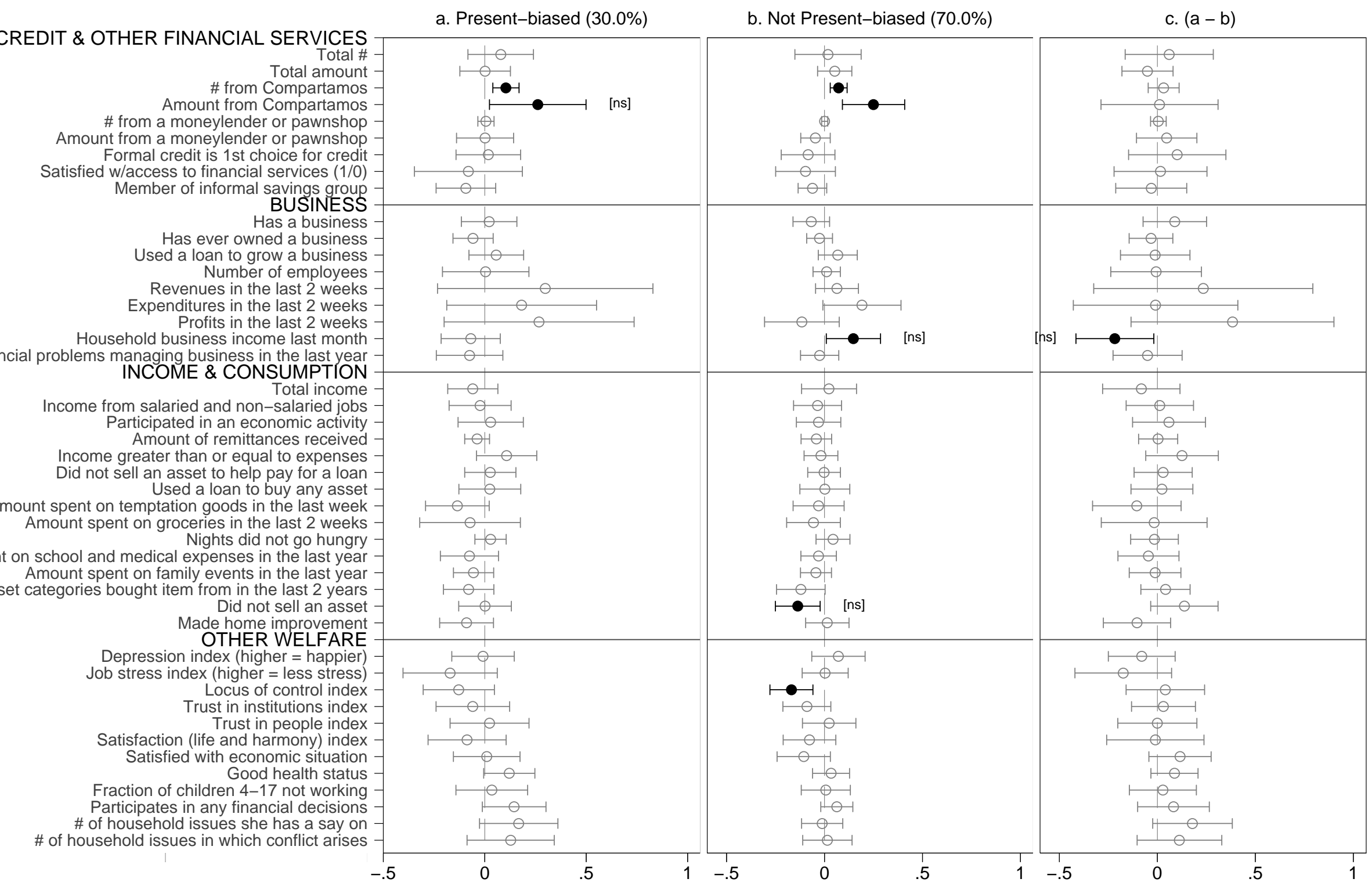

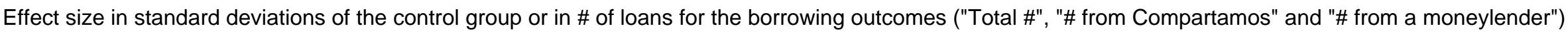

Each line shows the OLS point estimate and $90 \%$ confidence interval for the outcome on the left and group at the top. Panel C shows the estimate for the difference between the coefficients in panels A and B. Here treatment effects are presented in standard deviation units or in \# of loans for the borrowing outcomes (Total \#, \# from Compartamos, and \# from a moneylender or pawnshop). Effects that are significant at $\mathrm{p}<.10$ are in black. For some outcomes, we adjust the critical level following the Benjamini and Hochberg approach. In brackets, we then indicate whether the treatment effect is not significant [ns] at this level if it is significant at the unadjusted level. 
Baseline Sample Targeted for Endline Surveying

Outcome:

Treatment Assignment

Su

Surveyed

Surveyed

Surveyed

$-0.002$

(2)

$-0.012$

(3)

(0.031)

(0.029)

(0.079)

Age

$0.004 * * *$

$0.005 * * *$

$(0.001)$

(0.001)

$0.056^{* *}$

$0.054 * *$

(0.022)

$(0.025)$

$-0.044$

$-0.079$

(0.049)

(0.068)

$0.058 * *$

$0.066 * *$

(0.021)

(0.029)

Household income per adult in the last 30 days (000s)

$-0.020 * * *$

$-0.023 * * *$

(0.003)

(0.003)

$-0.004$

$-0.002$

(0.019)

(0.018)

$-0.002$

0.014

(0.018)

(0.023)

Impatient now

0.014

0.002

(0.022)

(0.029)

$-0.027$

$-0.019$

(0.023)

(0.029)

Has had a formal account

$-0.096 * * *$

$-0.109 * * *$

(0.019)

Has been a member of an

informal savings group

$-0.017$

$-0.009$

(0.018)

(0.021)

Above variables interacted with

Treatment

No

2912

33

Number of clusters

0.626

No

Yes

2853

33

0.627

Outcome mean

2853

0.627

p-value from test that Treatment

and all other variables above

interacted with Treatment are

jointly 0

0.145

Respondents are Mexican women aged 18-60 and all reside in outlying areas of Nogales. Column 1 reports the coefficient on treatment assignment when it is included in a regression with a binary variable for survey response (1=yes, $0=$ no) as the outcome variable. Column 2 reports the coefficient on each variable in the row when they are all included in one regression with survey response as the outcome. Column 3 reports the results of the test for unbalanced attrition between treatment and control groups. The cells show the coefficient for each variable when they are all included in one regression along with each of their interactions with treatment, with survey response as the outcome. The coefficients on the interaction terms (not shown) are each not significant. All regressions include supercluster fixed effects and standard errors are clustered by the unit of randomization. $* \mathrm{p}<0.10, * * \mathrm{p}<0.05, * * * \mathrm{p}<.01$. 
Total \# of household loans

Total amount of household loans

\section{Credit outcomes}

The number of loans taken out by members of the household

Last 2 years

The amount (in pesos) of the 3 most recent loans belonging either to the respondent, or if she has Last 2 years had fewer than 3 loans in the last 2 years, belonging to her and other members of the household.

\# of household loans from Compartamos

The number of loans taken from Compartamos of the 3 most recent loans belonging either to the

Last 2 years respondent, or if she has had fewer than 3 loans in the last 2 years, belonging to her and other members of the household.

Amount of household loans from Compartamos

The amount (in pesos) of loans taken from Compartamos of the 3 most recent loans belonging either to the respondent, or if she has had fewer than 3 loans in the last 2 years, belonging to her and other members of the household.

\# of household loans from a moneylender or pawnshop

Amount of household loans from a moneylender or pawnshop

Formal credit is 1 st choice for credit

either to the respondent, or if she has had fewer than 3 loans in the last 2 years, belonging to her and other members of the household.

The amount (in pesos) of loans taken from a money lender or pawnshop of the 3 most recent loans Last 2 years belonging either to the respondent, or if she has had fewer than 3 loans in the last 2 years, belonging to her and other members of the household.

Binary variable equal to one if the respondent said that a formal source--either a bank or a caja-- $\quad$ At survey would be the first source she would go to if she needed a loan of 6,000 pesos tomorrow

Satisfied w/access to financial services

Binary variable, taken from a question asking respondents to rank their satisfaction with access to financial services on a five point scale. A response of "satisfied" or "very satisfied" was coded as one.

Member of informal savings group Binary variable equal to one if the respondent was a member of an informal savings group

Last 2 years

\section{Business outcomes}

\begin{tabular}{lll}
\hline Has a business & Binary variable equal to one if the respondent has a business & At survey \\
\hline Has ever owned a business & Binary variable equal to one if the respondent has ever owned a business & At survey \\
\hline Used a loan to grow a business & Binary variable equal to one if the respondent has used a loan to grow any of their businesses & Ever \\
\hline Number of employees & The sum of the number of paid and unpaid employees across all of the respondent's businesses & At survey \\
\hline Revenues in the last 2 weeks & Total revenues (pesos) from all of the respondent's businesses & Last 2 weeks \\
\hline Expenditures in the last 2 weeks & Total expenditures (pesos) from all of the respondent's businesses & Last 2 weeks \\
\hline
\end{tabular}




\section{Consumption outcomes}

\begin{tabular}{|c|c|c|}
\hline Did not sell an asset to help pay for a loan & Binary variable equal to one if the respondent sold any asset to help pay off a loan & Last 2 years \\
\hline Used a loan to buy any asset & Binary variable equal to one if the respondent used a loan to buy an asset & Last 2 years \\
\hline Amount spent on temptation goods & Total consumption of sweets, soda, and cigarettes (pesos) & Last week \\
\hline Amount spent on groceries & Total consumption of groceries (pesos) & Last 2 weeks \\
\hline Nights did not go hungry & The number of nights that the respondent did not go hungry & Last 30 days \\
\hline Amount spent on school and medical & Total spent on school or medical expenses by the household (pesos) & Last year \\
\hline
\end{tabular}

expenses

Amount spent on family events Total spent on family events such as weddings, funerals, or birthdays by the household (pesos) Last year

Asset categories bought item from $\quad$ The number of asset categories (of a total of 6) from which the household bought an item from 2 years

Did not sell an asset

Made home improvement

Binary variable equal to one if someone in the household sold an asset

Binary variable equal to one if an improvement was made to the respondent's home

Last 2 years

Last 2 years

\section{Income outcomes}

Total income

Total household income (pesos)

Income from salaried and non-salaried jobs Household income (pesos) from salaried and non-salaried jobs

Last month

Last month

Participated in an economic activity

Binary variable equal to one if the respondent had a business at the time of the survey or worked in the last 30 days

Amount of remittances received

Total remittances (pesos) received

Last 6 months

Income greater than or equal to expenses 

over the last week. The feelings and thoughts include: being bothered by things that do not normally bother you, having a poor appetite, not being able to shake off the blues even with support from friends and family, feeling just as good as other people, having trouble focusing, feeling depressed, feeling like everything required extra effort, being hopeful about the future, thinking your life was a failure, feeling fearful, having restless sleep, feeling happy, talking less than usual, being lonely, thinking people were unfriendly, having crying spells, enjoying life, feeling sad, thinking people dislike you, feeling like you couldn't keep going on. questions were answered on a five point scale. They included: Did you feel stressed by your job or economic activity? Did you find your job or economic activity prevented you from giving time to your partner or family? Did you feel too tired after work to enjoy the things you would like to do at home?

Locus of control index

An index of five questions that ask about the respondent's feelings of control. The first four

At survey questions presented respondents with two phrases and they were asked which one they agree with the most. The choices were: What happens to me is my own doing vs. sometimes I feel that I dont have enough control over the direction my life is taking; when I make plans, I am almost certain that I can make them work vs. it is not always wise to plan too far ahead, because many things turn out to be a matter of good or bad fortune anyhow; in my case, getting what I want has little or nothing to do with luck vs. many times we might just as well decide what to do by flipping a coin; many times I feel that I have little influence over the things that happen to me vs. it is impossible for me to believe that chance or luck plays an important role in my life. The fifth question asked respondents on a five point scale how much they agreed with the following phrase: In the long run, hard work will bring you a better life.

Trust in institutions index

Trust in people index
An index of 3 questions that ask about trust in government workers, financial workers, and banks on a five point scale from "complete distrust" to "complete trust"

An index of trust in family, neighbors, personal acquaintances, people just met, business acquaintances, people who borrow money and strangers on a five point scale from "complete distrust" to "complete trust" and a question about whether people would be generally fair.
At survey

\section{At survey}

An index of one question about satisfaction with life on a five point scale from "very unsatisfied" At survey to "very satisfied" and another about harmony with others on a five point scale from "very unsatisfied" to "very satisfied".

Satisfaction (life and harmony) index A binary variable equal to one with her economic situation on a five point scale. 


\begin{tabular}{|c|c|c|}
\hline Good health status & $\begin{array}{l}\text { A binary variable equal to one if the respondent said she her health was either "very good" or } \\
\text { "good" on a five point scale. }\end{array}$ & At survey \\
\hline Fraction of children 4-17 not working & The fraction of children in the household aged 4-17 who the respondent says are not working. & At survey \\
\hline Participates in any financial decisions & $\begin{array}{l}\text { A binary variable equal to one if the respondent reports participating in any financial decision } \\
\text { making, based on a question that asked for how many financial decisions she participates in the } \\
\text { decision making, allowing answers from "none" to "all" on a five point scale. The variable is only } \\
\text { measured for married respondents living with another adult. }\end{array}$ & At survey \\
\hline \# of household issues she has a say on & $\begin{array}{l}\text { The number of household issues (of } 4 \text { ) in which the respondent reports having some decision } \\
\text { power on, including always making the decision, making the decision for herself, or if she makes } \\
\text { the decision with another person, having some role in deciding disagreements. The variable is only } \\
\text { measured for married respondents living with another adult. }\end{array}$ & At survey \\
\hline \# of household issues in which conflict arises & $\begin{array}{l}\text { The number of household issues (of 4) in which the respondent reports making the decision with } \\
\text { another person and at least sometimes having a disagreement. The variable is only measured for } \\
\text { married respondents living with another adult. }\end{array}$ & At survey \\
\hline
\end{tabular}


Appendix Table 3: Sample Sizes

\begin{tabular}{|c|c|c|c|}
\hline Analysis & Location & Sample & Sample Size* \\
\hline Balance & Table 1, Panel A & Endline & 16,560 \\
\hline Balance & Table 1, Panel B & Panel & 1,823 \\
\hline Takeup & Table 2, Panel A & Endline & 16,560 \\
\hline Takeup & Table 2, Panel B & Panel & 1,823 \\
\hline Average Intent to Treat Effects & Tables 3-7, Panel A & Endline & 16,560 \\
\hline Equality of Standard Deviations and Distributions & Tables 3-7, Panel A & Endline & 16,560 \\
\hline Average Likelihood of Increase/Decrease from Baseline & Tables 3-7, Panels B \& C & Panel & 1,823 \\
\hline Quantile Treatment Effects - Business Outcomes & Figure 3 & Endline business owners & 3,957 \\
\hline Quantile Treatment Effects - All Other Outcomes & Figures 4-6 & Endline & 16,560 \\
\hline $\begin{array}{l}\text { Heterogeneous Treatment Effects by Prior Business Owner } \\
\text { Education, Location }\end{array}$ & Figures 7-9 & Endline & 16,560 \\
\hline Heterogeneous Treatment Effects - All Other Sub-Groups & Figures 10-16 & Panel & 1,823 \\
\hline Attrition & Appendix Table 1 & Baseline & 2,912 \\
\hline Average Intent to Treat Effects for the Panel Sample & Appendix Figure 1 & Endline & 16,560 \\
\hline Loans per client & Appendix Figure 2 & Treatment group in administrative data & 1,565 \\
\hline
\end{tabular}

\section{Sample by Outcome}

Job stress

Endline respondents with a business or job

Fraction of children not working

Endline respondents with children aged 4-17

Intra-household decision power variables

Endline respondents that are married and live

with another adult

12,439

All other outcomes

Endline

16,560

* Sample sizes refer to the maximum possible number of respondents within the sample. In particular parts of the analysis, the sample size will be smaller than shown in this column because respondents may have answered "I don't know" or "No response" for the outcome in question. 
Appendix Figure 1: Average Intent-to-Treat Effects for the Panel Sample (compare to Figure 2)

Credit \& Other Financial Services

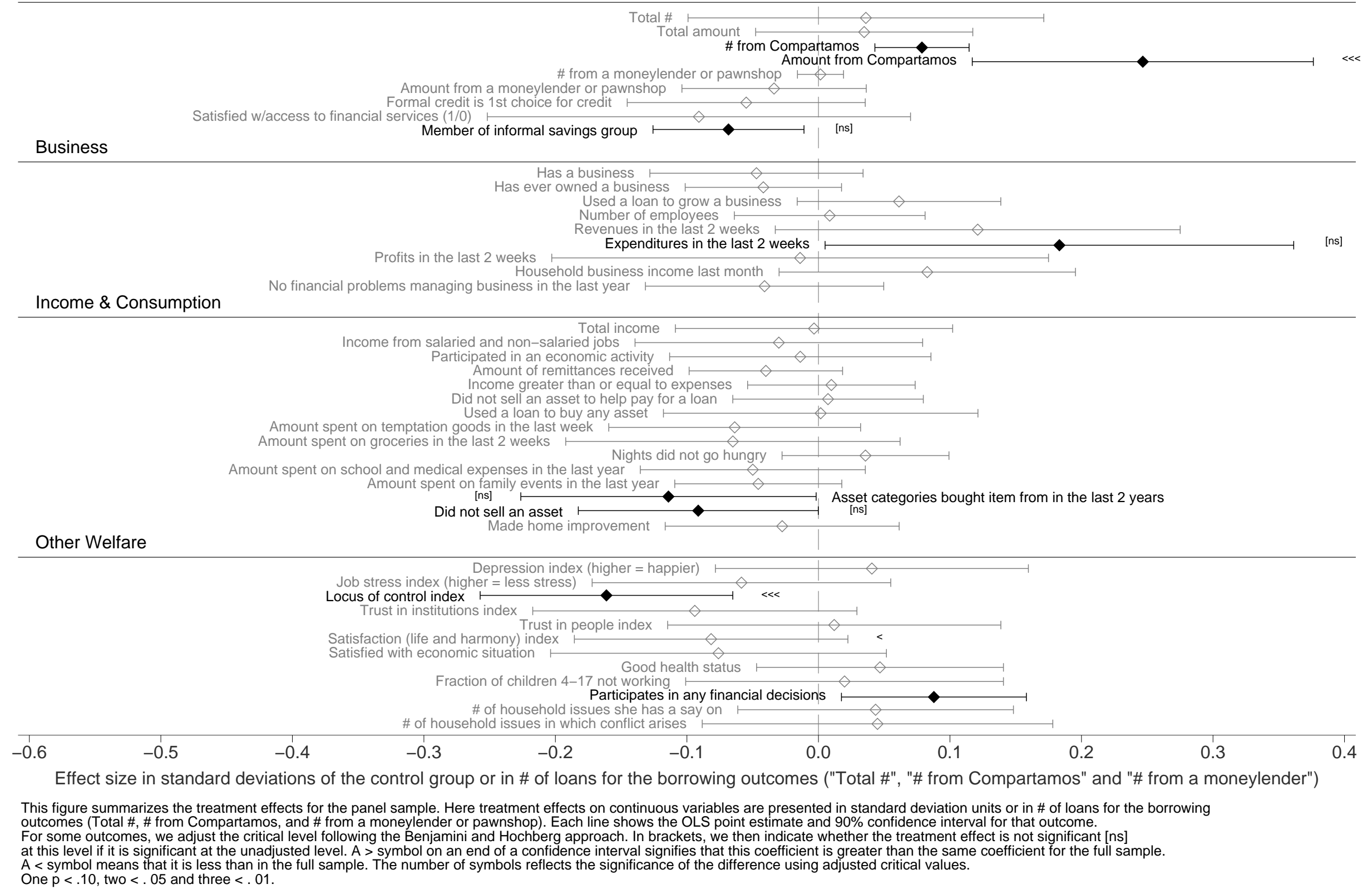




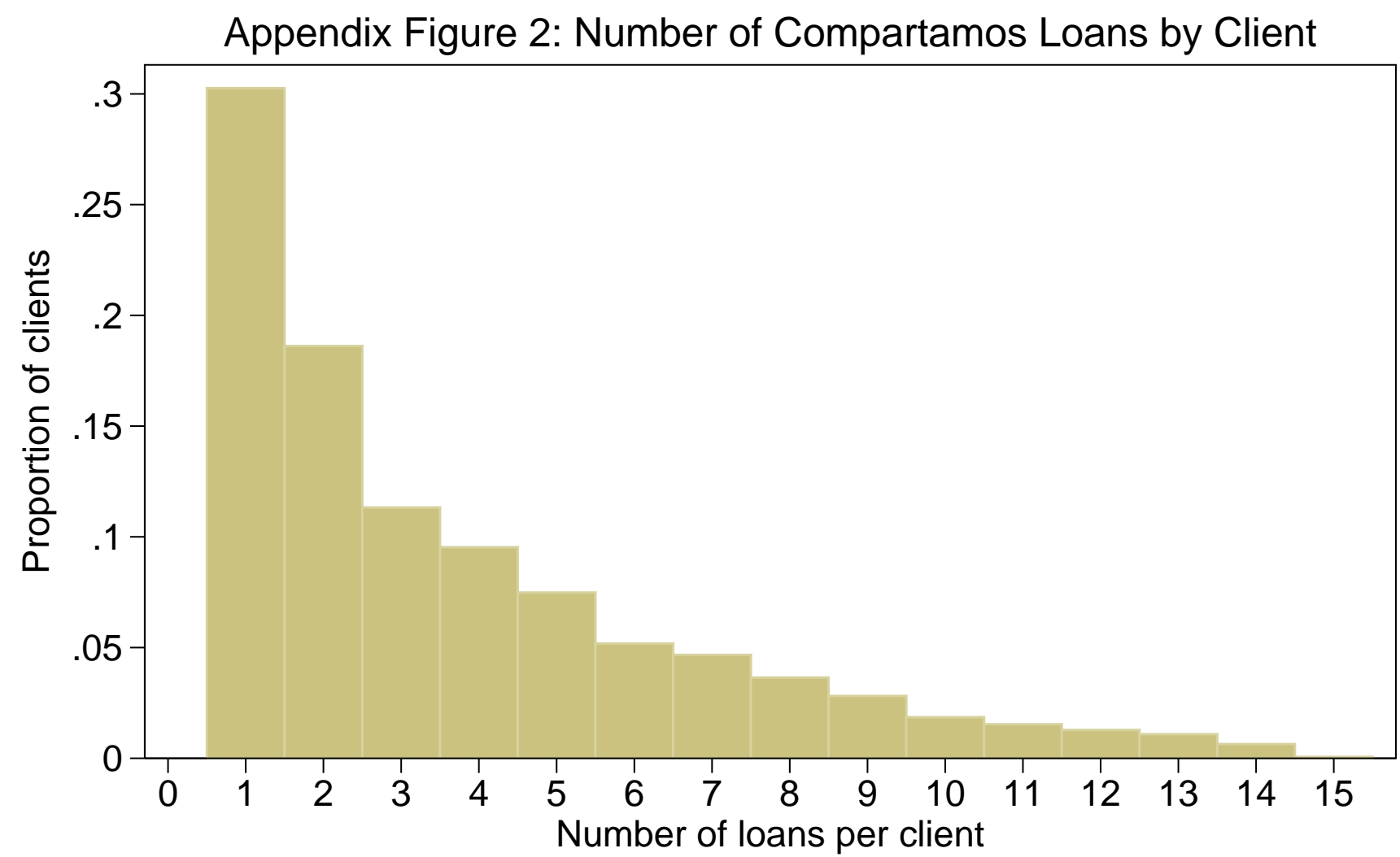

The figure shows the distribution of number of loans per client for all clients in the administrative data and in the treatment group $(1,514)$. The loans are either joint liability loans, or individual liability loans which clients can take out after successful completion of the first joint-liability loan cycle. 